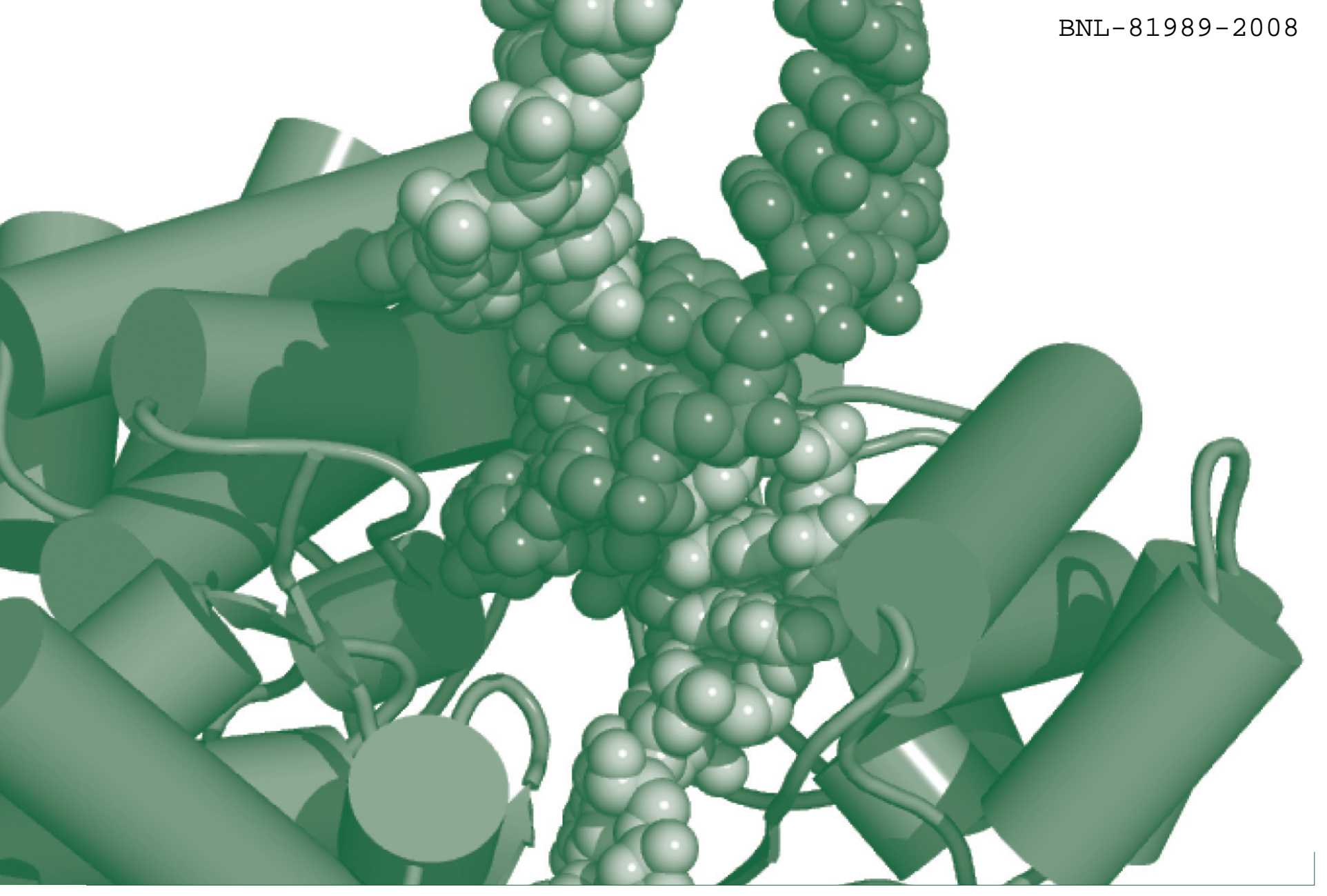

National Synchrotron Light Source 2008 Activity Report 


\title{
National Synchrotron Light Source 2008 Activity Report
}

\author{
Kathleen Nasta \\ Managing Editor \\ Kendra J. Snyder \\ Science Writer \\ Tiffany A. Gagnon \\ Graphic Designer
}

Nancye Wright

Editorial Assistant 
A Beacon for Research

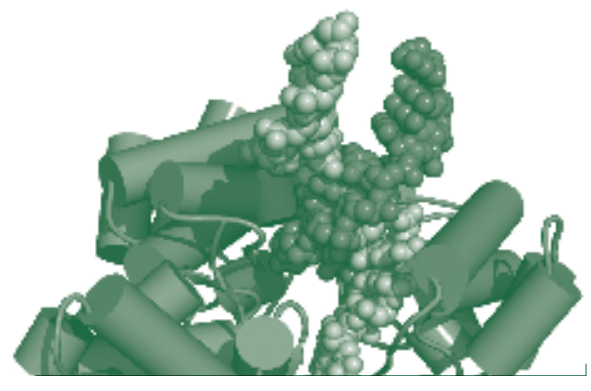

On the Cover

Model of the atomic structure of the enzyme telomerase, which was solved by a group of researchers from the Wistar Institute at NSLS beamline X6A. Telomerase plays a major role in the development of nearly all human cancers and has implications for the creation of therapies to combat aging and other age-related diseases.

The 2008 Activity Report has gone green. This year's book uses 100 percent recycled paper, a move that saves about 120 trees compared to last year's publication. In addition, the paper band wrapped around this book is embedded with wild flower seeds. To use: thoroughly soak the paper with water, plant it one-eighth inch below the surface of your soil, water generously, and watch it bloom!
Science Highlights

Physical and Chemical Sciences Introduction

Condensed Matter Physics

Materials Science

Chemical Sciences

X-Ray Optics and Accelerator Physics

Life and Environmental Sciences Introduction.

Earth and Environmental Sciences

Life Sciences

Soft Condensed Matter and Biophysics

Year in Review

May - August

September - December

Facility Report

Safety

The Accelerator Complex

Experimental Systems

Facility Facts and Figures

\section{Disclaimer}

This report was prepared as an account of work sponsored by an agency of the United States Government. Neither the United States Government nor any agency thereof, nor any of their employees, nor any of their contractors, subcontractors, or their employees, makes any warranty. express or implied, or assumes any legal liability or responsibility for the accuracy, completeness, or usefuiness of any information, apparatus product, process, or service by trade name, trademark, manufacturer or otherwise, does not necessarily constitute or imply its endersementh recommendation, or favoring by the United States Government or any agency contractor, or subcontractor thereof. The views and opinions of authors expressed herein do not necessarily state or reflect those of the United States Government or any agency, contractor, or subcontractor thereof

\section{Printed in the United States of America Available from \\ nical Information Service \\ U.S. Department of Commerce
5285 Port Royal Road}

Springfield, VA 22161

\section{Introduction}

Machine Parameters

2008 Publications

User Statistics

Beamline Status

Beamline Guide

Advisory Committees 


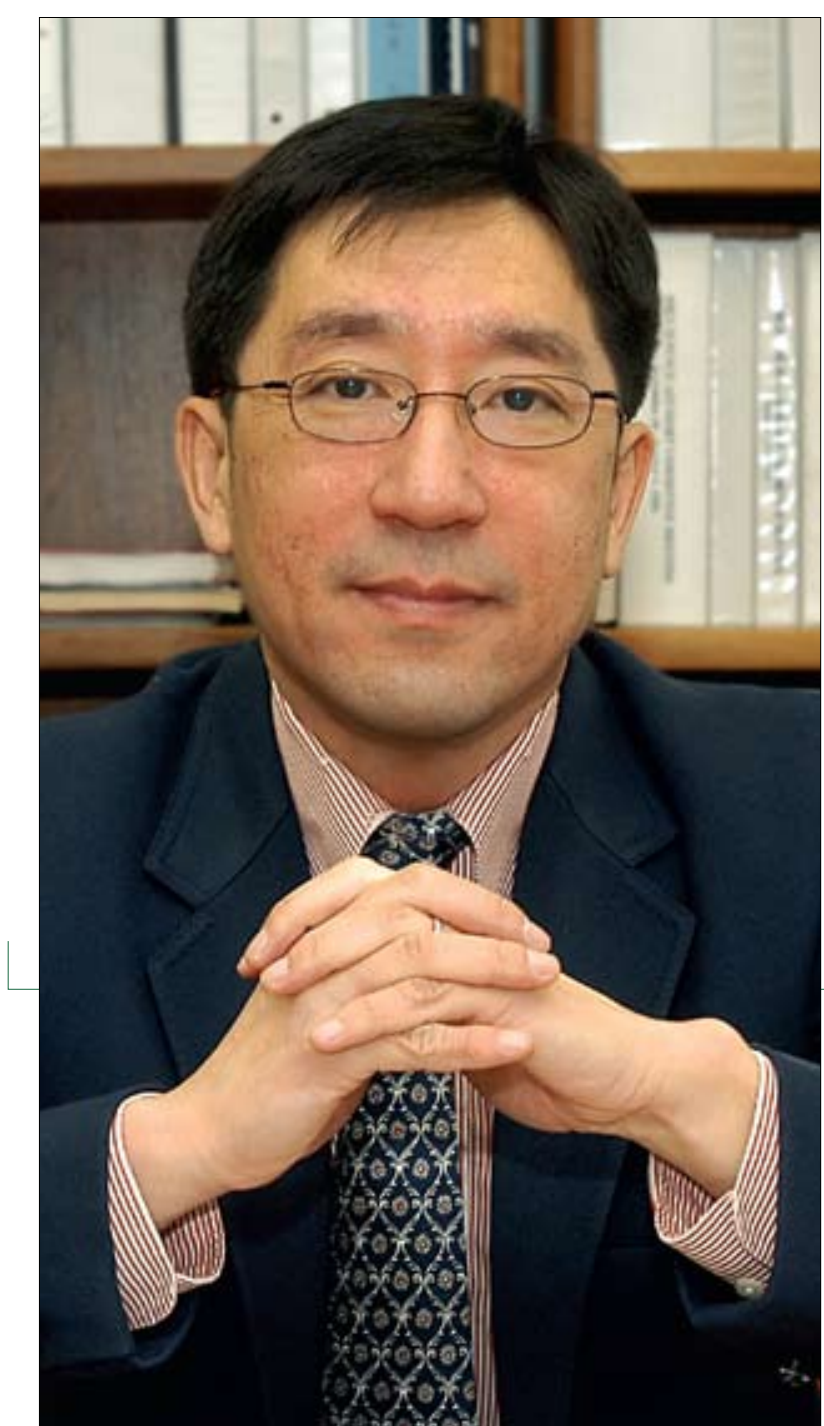

After 20 years at the National Synchrotron Light Source (NSLS), I'm still excited to learn about the wide range of science conducted here and to meet users from around the world. In 2008, even with an additional shutdown due to budgetary constraint, the NSLS attracted almost 2,200 individual users. These researchers produced a collective 964 publications - more than 20 percent of which appeared in premier publications. A few examples of this research, which ranges from exploring the mysteries of high-temperature superconductors to finding an inhibitor of botulinum neurotoxin, can be found in the following pages of this Activity Report.

We will continue to facilitate this world-leading research by providing our users with first-class tools in response to the ever-changing needs of science. One of our major upgrade projects, now near completion, is the construction of beamline $\mathrm{X}$, a new undulator-based beamline jointly developed by the NSLS and the Center for Functional Nanomaterials. $X 9$ will host the small-angle $x$-ray scattering program that $c u$ rently exists at beamline X21 and will provide much-needed beam time for the soft condensed matter physics, life sciences, and nanoscience communities. You can read about all of our recent upgrades in the "Facility Report" at the end of this book.

As we continue to make upgrades to beamlines, their performance must be fully characterized so that users can de sign and plan their experiments bette. With that in mind sign and plan ther experm of NSLS beanines and work wh staff members to solve

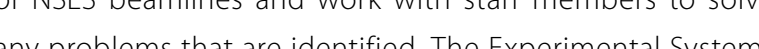
(experimental Systens Division began by comparing the actual flux of the facility's $x$-ray spectroscopy beamlines to theoretical values. Next, we will focus on other types of beamlines as well as develop tools to measure energy resolution and spot size.

We've also made great strides this year to diversify our user base We've launched an initiative to work closely with industrial researchers to identify and exploit new opportunities in industrial applications using synchrotron light. In addition, our second annual NSLS Historically Black Colleges
"After 20 years at the NSLS, I'm still excited to learn about the wide range of science conducted here and to meet users from around the world. nd Universities Workshop was again a success, attracting 17 participants from nine institutions for tutorials about synchrotron science and techniques and a chance to form research collaborations with our staff. I hope we can continue to strengthen their ties to our facility and staff members.

Although basic funding continued to present challenges this year, we also receved some encouraging news: funding ( through the U.S. Department of Energy's (DOE) Office of Basic Energy Sciences. The SCC, which promotes the utilization of synchrotron techniques to perform cutting-edge catalysis research, operates two - and soon, three - beamlines at he NSIS and of operation. We also received grants totaling $\$ 28$ million from DOE's Office of Biological and Environmental Research and the National Institutes of Health's National Center for Research Resources to support the X-ray Crystallography Research Resource (PXRR) at the NSLS. The grants will fund five years of operations and research for the PXRR, which has eceived about 800 vists from 150 university industriat, and Don tion, we were awarded a three-year DOE grant to develop new $x$-ray detectors with unprecedented capabilities. Members of our Detector Group, in collaboration with staff from Brookhaven's Instrumentation Department, will use the funding to explore the use of three-dimensional integration technology, pioneered in the semiconductor industry, to develop $x$-ray detectors with a higher level of functionality than is possible with current technologies.

Finally, as we get closer to the groundbreaking for the National Synchrotron Light Source Il, we are paying a great dea of attention to planning for transition to this new, worldleading facility. Toward that end, one of our major activities this year was a series of planning workshops hosted in collaboration with NSLS-II. The workshops were divided into two types: those that focus on specific scientific communities and those that focus on experimenta techic cor The community inpur collected auring these sessions wi The community mout collected dung these sessions w be used to guide the scientific strategic plans and beamlin development for both facilities.

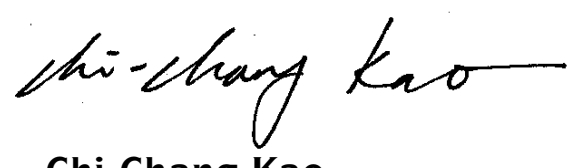

Chi-Chang Kao

Chi-Chang Kation Synchrotron Light Source 


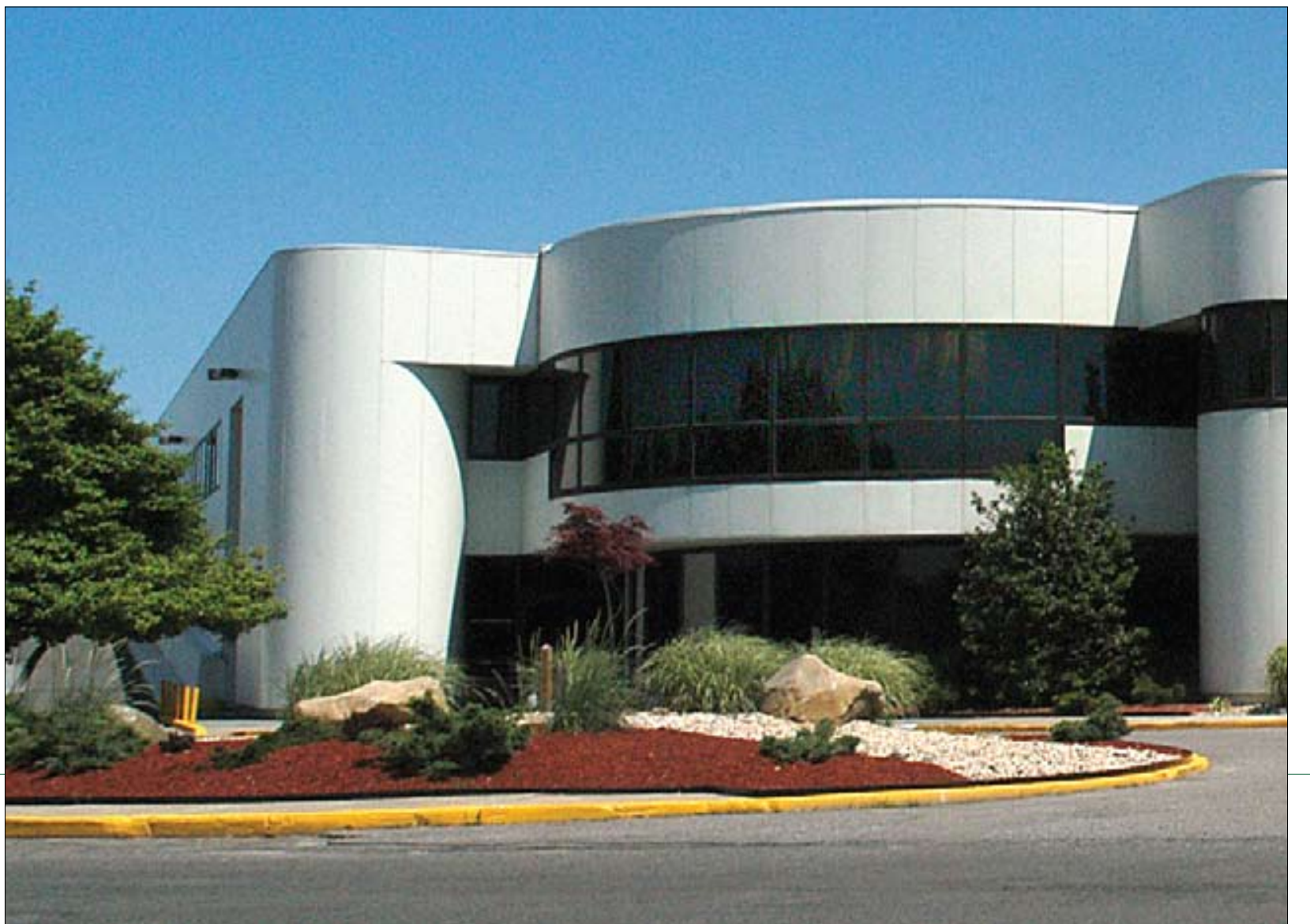

Funded by the U.S. Department of Energy's Office of Basic Energy Sciences, the National Synchrotron Light Source (NSLS) is a national user facility that operates two electron storage rings: X-Ray (2.8 GeV, $300 \mathrm{~mA})$ and Vacuum Ultraviolet (VUV) $(800 \mathrm{mev}, 1.0 \mathrm{~A})$. These two rings provide intense light spanning the electromagnetic spectrum - from very long infrared rays to ultraviolet light and super-short $x$-rays - to analyze very small or highly dilute samples. The properties of this light, and the specially designed experimental stations, called beamlines, allow scientists in many diverse disciplines of research to perform experiments not possible at their own laboratories.

Each year, about 2,200 scientists from more than 400 universities and companies use the NSLS for research in such diverse fields as biology, physics, chemistry, geology, medicine, and environmental and materials sciences. For example, researchers have used the NSLS to examine the minute details of computer chips, decipher the structures of viruses, probe the density of bone, determine the chemical composition of moon rocks, and reveal countless other mysteries of science. The facility has 65 operating beam- lines, with 51 beamlines on the X-Ray Ring and 14 beamlines on the VUV-Infrared Ring. It runs seven days a week, 24 hours a day throughout the year, except during periods of maintenance and studies. Researchers are not charged for beam time, provided that the research results are published in open literature. Proprietary research is conducted on a full-cost-recovery basis.

With close to 1,000 publications per year, the NSLS is one of the most prolific scientific facilities in the world. Amon the many accolades given to its users and staff, the NSLS has won nine R\&D 100 Awards for innovations ranging from a closed orbit feedback system to the first device able to focus a large spread of high-energy $x$-rays. In addition a visiting NSLS researcher shared the 2003 Nobel Prize in Chemistry for work explaining how one class of proteins helps to generate nerve impulses.

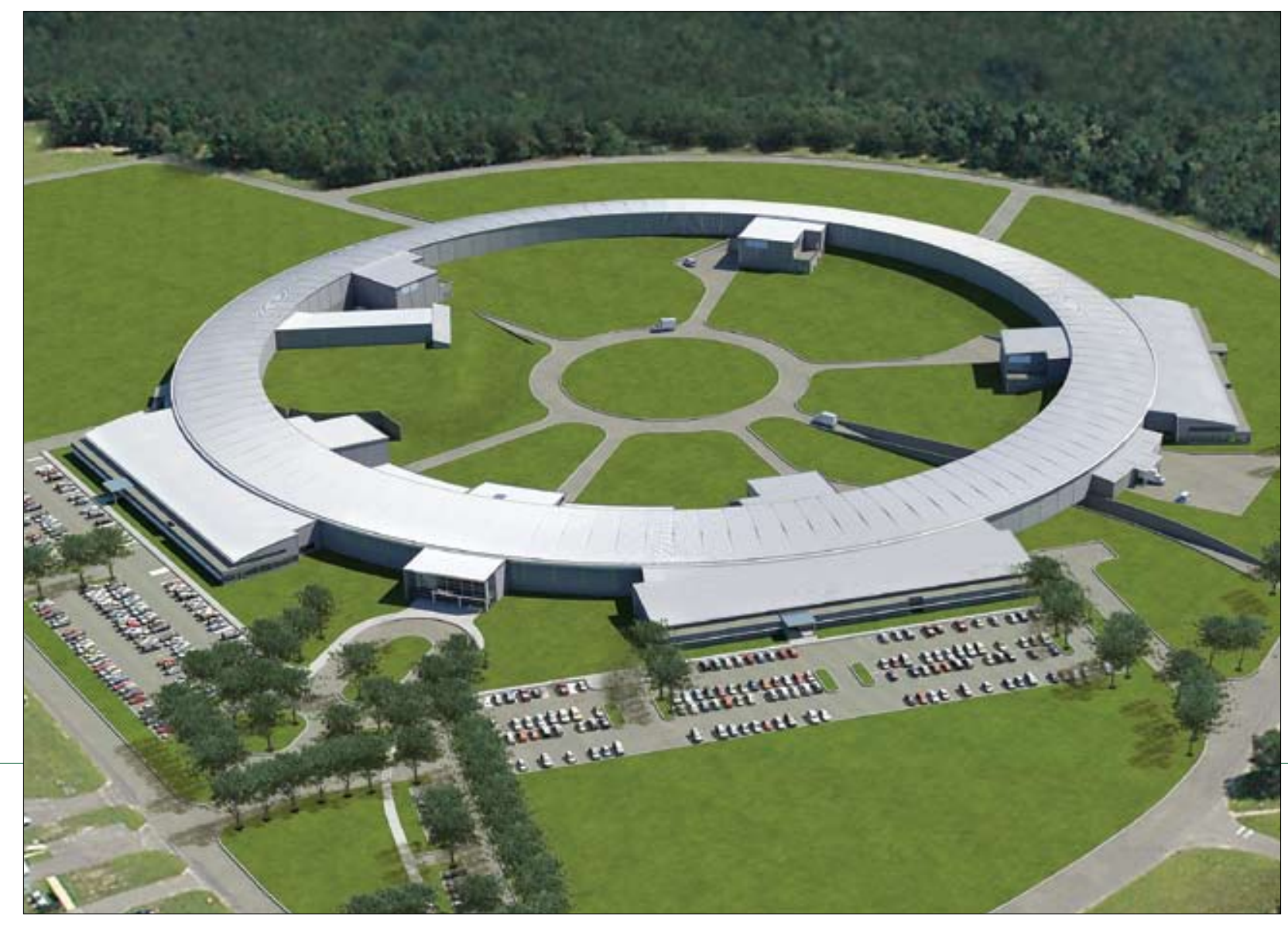

Since its first operations in 1982, the NSLS has continually updated its technology and expanded its scientific capabilities. However, as the boundaries of scientific discovery have been expanded, many researchers are looking for capabilities beyond those provided by the NSLS. And while newer synchrotrons surpass the performance of the present NSLS, no synchrotron anywhere in the world will enable scientists to image and characterize materials down to billionth-ofa meter (nanometer) resolution.

To address this need, Brookhaven is building - the Nationa Synchrotron Light Source II (NSLS-II). The new facility, which will replace the NSLS, will be a medium-energy storage ring designed to deliver world-leading brightness and flux. It will provide advanced tools for discovery-class science in condensed matter and materials physics, chemistryy and biology. or example, major advances in energy technologies - such For the rof rgy carrier, the widespread, economical uses of solar energy, or the development of the next generation of nuclear power systems - will require scientific breakthroughs in developing new materials with advanced properties.
The combination of capabilities at NSLS-II will have broad impact on a wide range of disciplines and scientific inttiatives in the coming decades, including new studies of small crystals in structural biology, the development of probes for nanoscience, coherent imaging of the structure and dynamics of disordered materials, greatly increased applicability of inelastic x-ray scattering, and properties of light source will also foster research in areas sure light source wil a so foster research in areas ies of early disease detection.

The leading-edge ability of NSLS-II to analyze materials wil help guide the development of new materials at Brookhaven's Center for Functional Nanomaterials. The synergy of these two facilities is expected to lead to breakthroughs in the use of renewable energy through improved energy conversion,

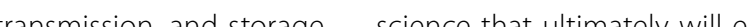
hance national and energy security and help drive abundant, safe, and clean energy technologies. materials under extreme conditions. This high-brightness 


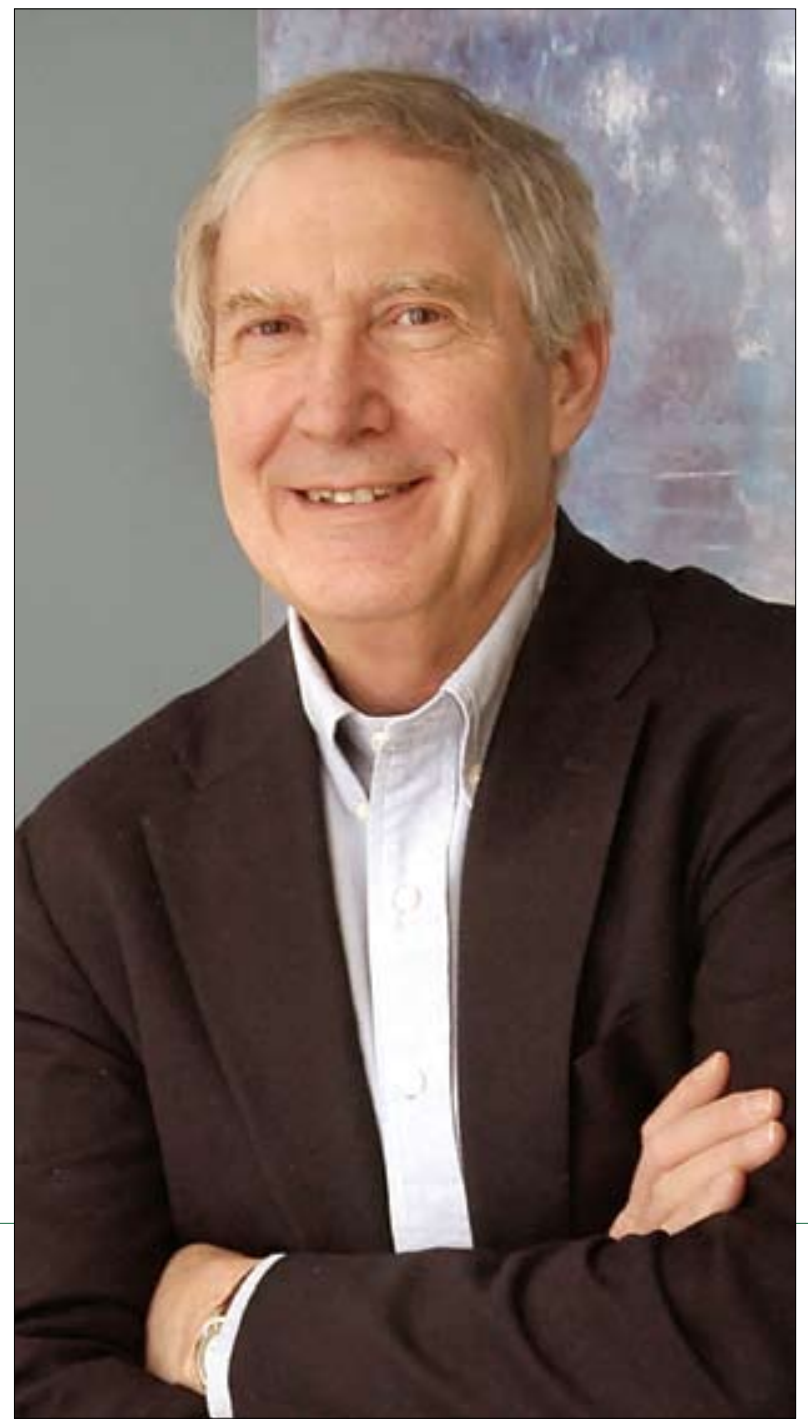

\section{Ron Pindak}

Physical and Chemical Sciences Division Head

While developing future plans for NSLS-II, NSLS staff and users continued to apply existing beamline facilities to advance both new and on-going research programs. In the physical and chemical sciences, dominate research themes were the study of nanoparticles for energy applications, the study of high-temperature superconductivity in copper- and iron-based compounds, and the study of materials under extreme conditions. Key discoveries for each research area are listed below and described more fully in the science highlights that follow.

In hard condensed matter physics, researchers from Brookhaven Lab took a significant step in advancing our understanding of high-temperature superconductors by showing that electron pairs emerge before superconductivity sets in, but only in a particular direction. This observation required the researchers to improve the resolution of their angle-resolved photoemission spectroscopy measurements so they could look at weak signals from above the Fermi level in finer detail. A second important avenue of research conducted this year involved understanding how misfit strains in thin films can modulate their structure and impact their transport properties. A team. from the Max-Planck-Institut demonstrated how Sr-doped lanthanum manganite films have unexpected one-dimensional structural motifs that evolve from a twinning modulation wave in thin films to laterally coherent tilt domains in thicker films.

In materials science, researchers from the University of Minnesota used a gas-condensation technique to fabricate nanoparticles with an iron-cobalt core and gold cladding Using $x$-ray magnetic circular dichroism, the researchers found that the magnetic cicular dichroism the reseachars found that the ron-cobalt core had magnetic moments three to four times higher than traditional iron oxide nanoparticles. These nanoparticles are of potential interest for enhancing contrast in magnetic resonance imaging, for advanced data storage, and further down the road, in spintronic devices. Another active
"In the chemical sciences, a wide range of different synchrotron techniques were applied to advance our

understanding of catalytic activity. area of research in materials science was the study of materiander high pressure. A team led by researchers from the Carnegie Institution of Washington used synchrotron infrared spectroscopy to observe metallic behavior in silane when compressed to over $60 \mathrm{GPa}$. This was the first observation of metallization in a hydrogen-rich IVa hydride and represented a significant step toward ultimately observing metallic behavior in molecular hydrogen which is predicted to occur at significantly higher prestres and is believed to exhibit unique properties that could be useful for methods of energy production. The high pressure created in a diamond-anvil cel was also used to provide new information on the recently discovered iron-based superconductors. Measurements on this new class of superconductors, using angle-dispersive $x$-ray diffraction, revealed that, as pressure was increased, there was an abrupt change in lattice parameters followed by an unusual negative relationship between pressure and the superconducting transition temperature.

In the chemical sciences, a wide range of different synchrotron techniques were applied to advance our understanding of catalyytic activity. Using a combination of $\mathrm{x}$-ray photoemission spectroscopy, scanning tunneling microscopy, and modeling, Brookhaven researchers identified the mechanism underlying the water-gas shift reaction catalyzed by cerium oxide and titanium oxygen nanoparticles on gold. The water-gas-shift reaction is important in preventing carbon monoxide from degrading the performance of the platinum electrode used in fuel cells. Another team of researchers from Utrecht University demonstrated, for the first time, how synchrotron infrared microspectroscopy could be applied to study catalytic reactions olite crystals in a space- and time resolved manie Finaly, a team of reserchers who a menbers of the Syn-

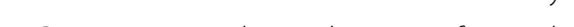
xhay absorpen fonsorium used a combination of extended $x$-ray absorption fine structure, $x$-ray diffraction, and density functional theory to demonstrate how a galvanic replace ment reaction could be used to form palladium-gold nanoparticles from palladium nanowires. The researchers showed that at different stages of the reaction, the palladium-gold in the nanoparticle evolved from being a non-random alloy with gold-rich core to a random alloy. Non-random bimetallic nanoparticles have been shown to have enhanced catalytic activity so this was an important advance. 


\section{Formation and Thickness Evolution of Periodic Twin Domains in Manganite Films}

Since the discovery of colossal magnetoresistance in perovskites containing lanthanides, alkaline earth metals, and magnesium oxide, there has been enormous interest in thei bulk and thin-film forms because of their unusual physical properties that lend to potential applications such as magnetic field sensors, computer read heads, infrared detectors, and microwave active components. Because future applications will extensively exploit thin film geonetries, the associated transport properties will strongly be determined by the strain misfit as caused by the microscopic clamping of the film to the substrate.

Conventional film material adjusts its lattice parameters to the substrate by stretching or compressing its bond lengths. But a perovskite film may use tilting of its oxygen octahedral for strain accommodation at relatively low energy costs. Single crystals are naturally microtwinned indicating a low energy cost for domain boundaries. Exploiting both aspects, manganite films are able to grow epitaxially on a perovskite substrate even for large lattice misfits. Thus, by a microscop-

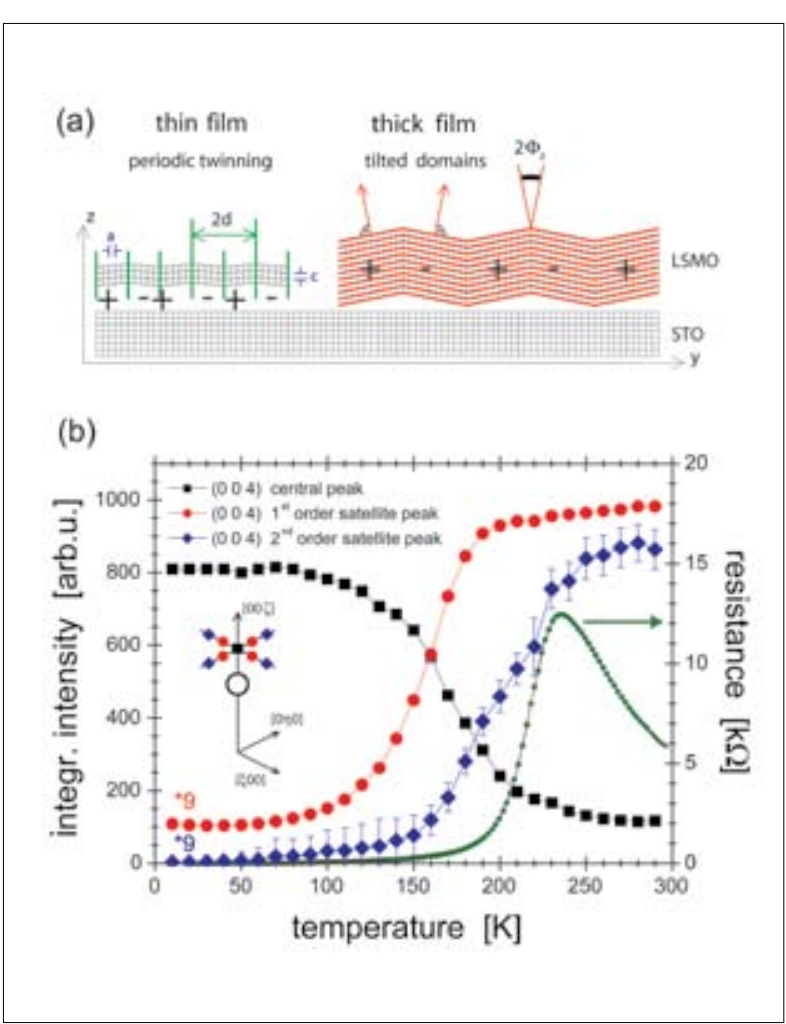
ties of manganite films. c understanding of this misfit strain relaxation mechanism. one may get a tool at hand for tuning the electronic proper-

At NSLS beamline X22A, researchers from the Max-PlanckInstitut conducted a systematic $x$-ray diffraction study of the strain relaxation behavior of a strontium-doped lanthanum mangarite film on a strontium titanate substrate. They reveled a new kind of misfir stan reaxaton process the ocess that emerges as unexpected one-dimensional structural motif that evolve from a twinning modulation wave in thin films to laterally coherent tilt domains in thicker films.

U. Gebhardt, N.V. Kasper, A. Vigliante, P. Wochner, H. Dosch, F.S. Razav.

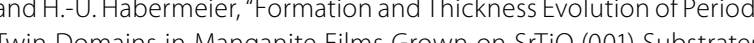
Phys. Rev. Lett., 98, 096101 (2007)

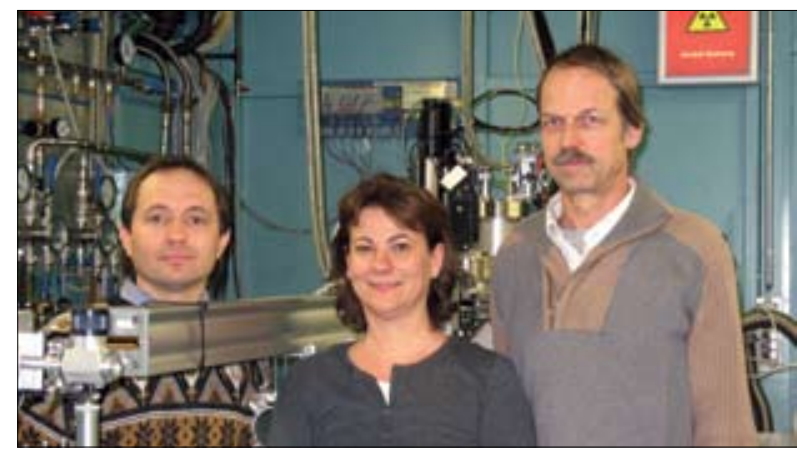

From left. Nikolai Kasper, Assunta Vigliante, and Peter Wochner

(a) Real-space sketch to show which motifs of the film structure, grown on average pseudomorphically on top of a rigid cubic substrate (left) and a thick manganite film (right) The difference tin variance of the TD length for the two cases is not ill lustrated in the picture. (b) Temperature dependence of the structure (integrated intensity of the central peak and the 1 st and 2 nd port of the $26 \mathrm{~nm}$ (SMO film. The inset shows the (tons) associated film (solid symbols) and substrate (open circle peak positions.

\section{Electron Pairs Precede High-Temperature Superconductivity}

Brookhaven physicists have found ways to sharpen images of the energy spectra in high-temperature superconductors materials that carry electrical current effortlessly when cooled below a certain temperature. These new imaging methods confirm that the electron pairs needed to carry current emerge above the transition temperature, before superconductivity sets in, but only in a particular direction.

To search for pre-formed electron pairs, the Brookhaven team bombarded a copper-oxide material, held at temperatures above and below the transition temperature, with beams of light from NSLS beamline U13UB, and analyzed the energy spectrum of electrons emitted from the sample. This method, known as angle-resolved photoemission spectroscopy, ordinarily gives a clear picture of only half of the energy spectrum - all the levels electrons can occupy below the so-called Fermi level olimpse the ohe hat, above the Fermi level, he scientsts devised ways to sharpen the resolution of their images.

Seeing both sides of the Fermi level is important because, when a material becomes a superconductor, there is an en-

ergy gap surrounding the Fermi level. A perfectly symmetrcal gap is a strong indication that electrons are paired up. But scientists had previously observed a second gap, or pseudogap, in some high-temperature materials, well above the transition temperature. If this pseudogap exhibited the same symmetry around the Fermi level, the researchers reasoned, it would be definitive evidence of paired electrons above the transition temperature. Using their new image-enhancing techniques, the Brookhaven team demonstrated that the pseudogap does indeed exhibit this same symmetry.

Another interesting observation: The pairing occurs only along certain directions in the crystalline lattice of atoms making up the material - along those in which copper atoms are bonded with oxygen atoms. H. Yang, J. Rameau, P. Johnson, T. Valla, A. Tsvelik, and G. Gu, "Emer-
gence of Preformed Cooper Pairs from the Doped Mott Insulating State in $\mathrm{Bi}_{2} \mathrm{Sr}_{2} \mathrm{CaCu}_{2} \mathrm{O}_{8}+\delta_{0}$, Nature, 456, 77-80 (2008).

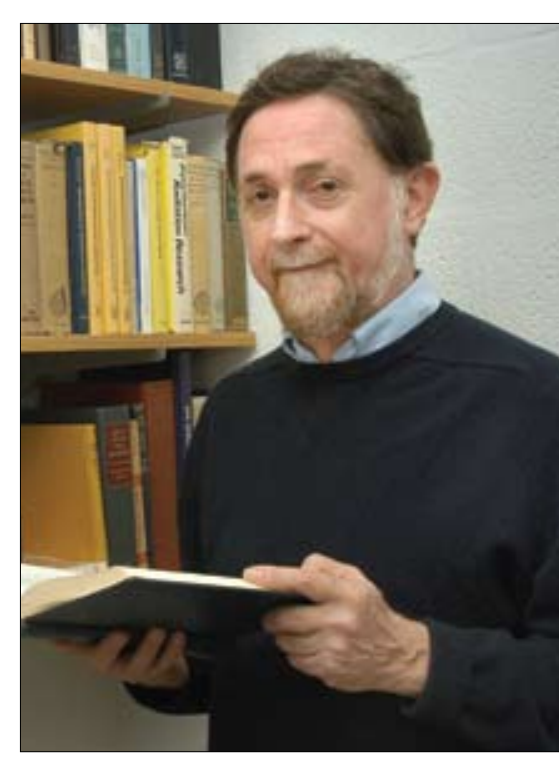

Peter Johnson

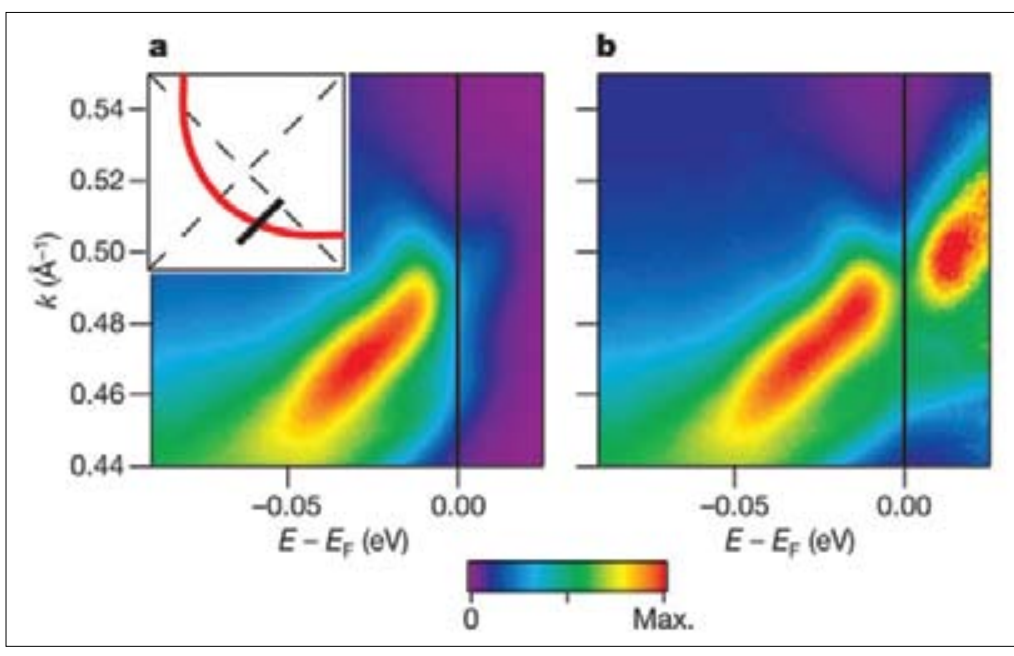

Map of the spectral intensity of photoelectrons emitted from a high-Tc superconductor in the superconducting state as a function of energy and momentum. a) The spectral intensity as measured and b) the spectral intensity after
analysis showing states both above and below the Fermi level (vertical line). 
Determining the Dislocation Sense of Closed-Core Screw Dislocations

Defects existing in semiconductor single-crystal materials adversely affect the device performance fabricated on them. Understanding the defect characters plays a critical role in designing strategies to eliminate or reduce their negative effect. At the NSLS, researchers from Stony Brook University used $x$-rays to reveal details about a particular defect in silicon carbide, an abrasive material used in everything from grinding wheels to semiconductor equipment.

Single-crystal materials have pre-existing boundaries between regions that are displaced relative to one another These boundaries, called dislocations, come in several forms. One form, called a screw dislocation, features planes that are rently, no technique is able to reveal the dislocation sense (left- or right-handed) of closed-core screw dislocations in commercial silicon carbide wafers in a simple, unambiguous, and non-destructive way But the researchers demonstrated two new techniques that might be able to do just that.

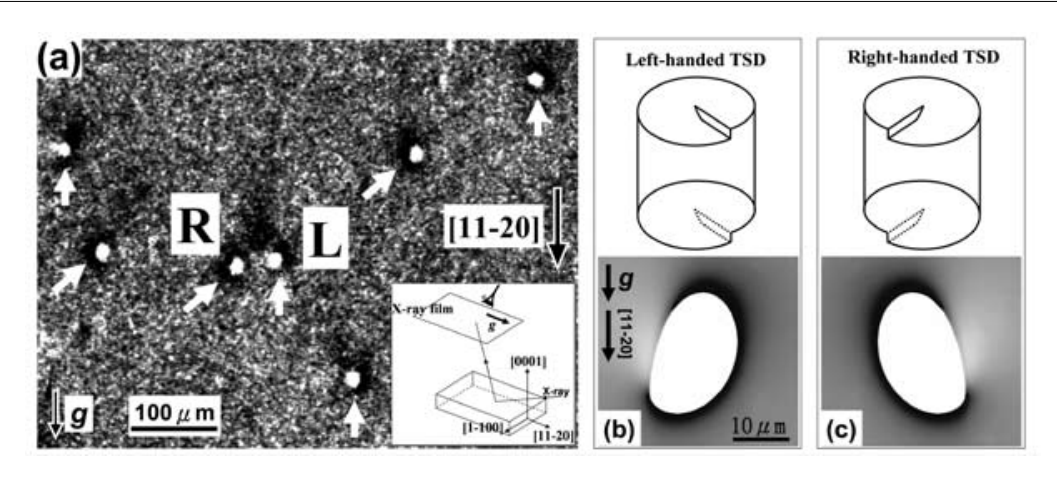

(a) A highly magnified $\mathrm{x}$-ray topograph showing the images of 1C TSDs in 4 handed IC TSD. (c) Ray-tracing simulaconnected in a manner similar to a spiral parking ramp. Cur-

\section{Response of Pyrochlore to Extreme Conditions}

At the NSLS, a team of researchers from the University of Michigan and Rensselaer Polytechnic Institute demonstrated the effect of composition on the stability and response of the pyrochlore structure under high pressure and high radiation. This study lays the foundation for understanding how complex ceramics will respond to the extreme environments, such as hose in advanced nuclear reactors.

Pyrochlore has a flexible structure, which can exist in more than 500 compositions that have a wide variety of chemical and electronic properties with many technological applications. Some pyrochlores can also incorporate actinides, such as plutonium, so there is great interest in their use as nuclear waste forms or as inert matrix fuels.

In order to investigate the effects of high pressures and irradiation on pyrochlore, two closely related compositions - a gadolinium titanate oxide and a gadolinium zirconate oxide - were compressed with up to 45 gigapascals (GPa) of pressure, roughly more than six million pounds per square inch. That, by comparison, is almost 200,000 times the pressure in a car tire and more than the weight of a space shuttle on one's fingertip.

X-ray diffraction images for $\mathrm{Cd}_{2} \mathrm{Ti}_{2} \mathrm{O}_{7}$ at (a) 22.2 $\mathrm{GPa}$, (b) $45.0 \mathrm{GPa}$, (c) $0 \mathrm{GPa}$ (recovered sample and measured immediately), (d) $1 \mathrm{bar}, 5 \mathrm{~h}$ after (g) $0 \mathrm{CPa}$ (recovered sample and measured impressure.
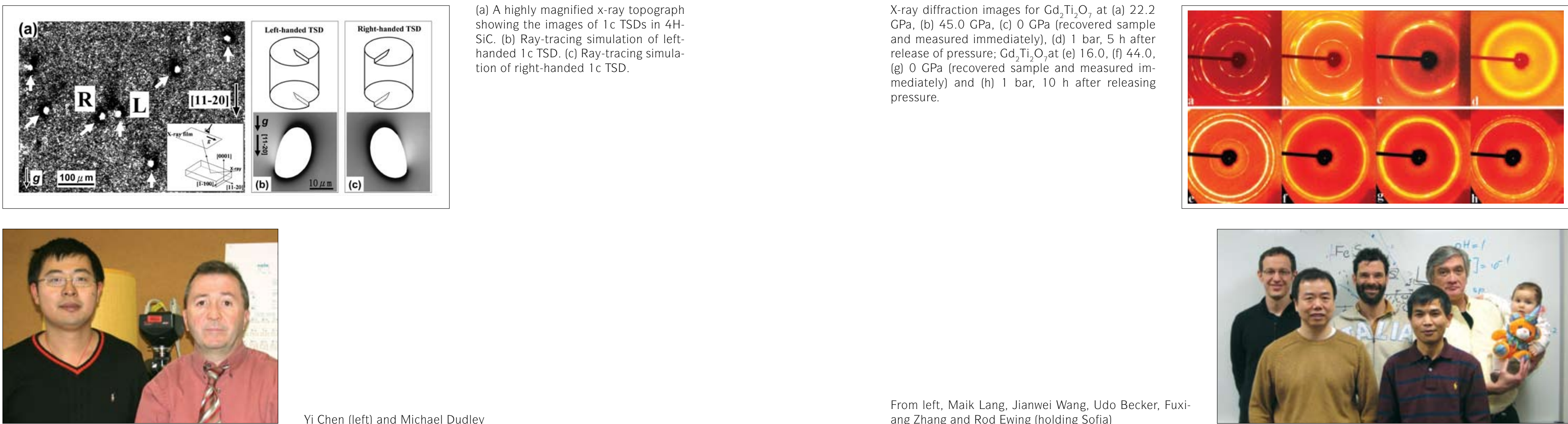

The structure of gadolinium titanate oxide remained relatively stable under the highest pressures tested $(45 \mathrm{GPa})$, but the gadolinium zirconate oxide only maintained stability up to 23 GPa, above which it structurally distorted. When the pressure was released, the zirconate pyrochlore further disordered into a very stable defect-fluorite structure.

Under ion-beam radiation, however, the behaviors of the two pyrochlores changed The zirconium pyrochlore was more resistant to radiation damage, and therefore remained crystalline. In contrast, the titanate pyrochlore transformed into disordered structure at low doses and finally became stable at higher doses.

After using Raman scattering, calculations, and angle dispersive $x$-ray diffraction at NSLS beamline X17C, the researchers concluded that the performance of these materials in extreme environments is directly related to the energetics of the disordering process.

F. X. Zhang, J. W. Wang, J. Lian, M. K. Lang, U. Becker, and R. C. Ewing "Phase stability and pressure dependence of defect formation in $G$

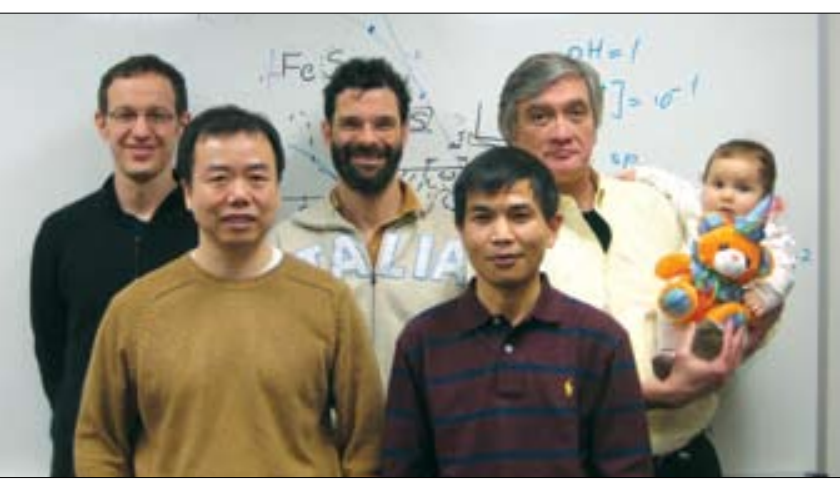




\section{Through the Wire: A New Nanocatalyst Synthesis Technique}

Materials containing bimetallic nanoparticles are attractive in vast technological fields because of their unique catalytic, electronic, and magnetic properties. One of the most promising of the bunch is made from palladium and gold, an alloy that could be used in a wide variety of catalytic activities including the water-gas shift reaction and the oxidation of carbon dioxide - both important steps in alternative energy applications like fuel cells. This alloy has the highest catalytic activity when its structure is "non-random," with a core made predominantly of gold nanoparticles and a shell made mostly of palladium. However, creating the material with traditional chemistry techniques is tricky and difficult to control.

Recently, though, a team of researchers from Brookhaven, Yeshiva University, and the University of Delaware demonstrated an alternative, highly efficient method based on galvanic replacement - the principle behind the technology of batteries. The driving force for galvanic replacement is the electrical potential difference between two metals, with one metal acting principally as the cathode and the other metal as the anode. The reaction was set up between palladium

nanowires just about 2.5 nanometers thick - one of the thinnest wires reported in the scientific community - and a solution of gold chloride in toluene. The researchers then "watched" the reaction take place through multiple techniques, including electron microscopy and UV-vis absorption at Brookhaven's Center for Functional Nanomaterials, $x$-ray diffraction at NSLS beamline X7B, and extended $x$-ray absorption fine structure at beamline $\mathrm{X} 18 \mathrm{~B}$

In the early stages of the reaction, the alloy was, indeed, non-random, with a gold-rich core and palladium-rich shell. The subsequent addition of the ampound alkylamine stabilized palladium to the of the compound alky non-random form intact. However, if the reaction was allowed to continue, a random alloy was formed, with uniformly mixed gold and palladium atoms inside the particles.

X. Teng, Q. Wang, P. Liu, W. Han, A. Frenkel, W. Wen, N. Marinkovic, J. Nanowires via Galvanic Replacement Reaction," I. Am. Chem. So

\section{Putting the Pressure on Iron-Based Superconductors}

Traditionally, magnetism and superconductivity don't mix. For more than 20 years, the only known superconductors that worked at so-called "high" temperatures (above $30 \mathrm{~K}$, or about -406 degrees Fahrenheit) were almost all based on copper. Materials with strong magnetism, scientists thought, would disrupt the pairing of electrons that is key to achieving the frictionless flow of superconductivity. So when a group of researchers recently found high-temperature superconductivity present in a class of iron-based materials their discovery shocked and excited the scientific community.

Made from conducting layers of iron, arsenic, and various other elements, this new class of materials could lead to applications such as more-efficient power transmission However, iron-based superconductors are still in the early stages of experimentation and implementation. That's why researchers from the Harbin Institute of Technology, the Chinese Academy of Sciences, and the NSLS set out to study the characteristics of a specific iron-and-arsenic-based, neodymium-containing superconductor.

The main objective for scientists in the field is to find superconductors with the highest transition temperature (TC). To find out how Tc is affected by high pressure in the iron-based neodymium arsenide superconductor system, the research team subjected their samples to more than 30 GPa with NSLS beamline X1733's diamond-anvil cell. High pressure can compress the crystalline structure of the material and force its layers closer

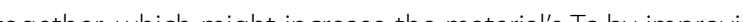
researchers used angle-dispersive $x$-ray diffraction.

Their results didn't turn out exactly as expected: As pressure increases from 0 to $15 \mathrm{GPa}$, the spacing decreases and $\mathrm{Tc}$ increases marginally. But as the pressure increases further, one of the other lattice parameters abruptly increases and the Tc drops. These new findings could offer insight on how to design and create other superconducting systems.

J. Zhao, L. Wang, D. Dong, Z. Liu, H. Liu, G. Chen, D. Wu, J. Luo, N Wility of Iron-Based $S$. G. Guo, "Structure Stability and Compress-

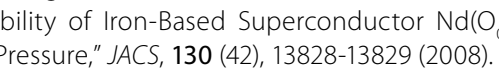

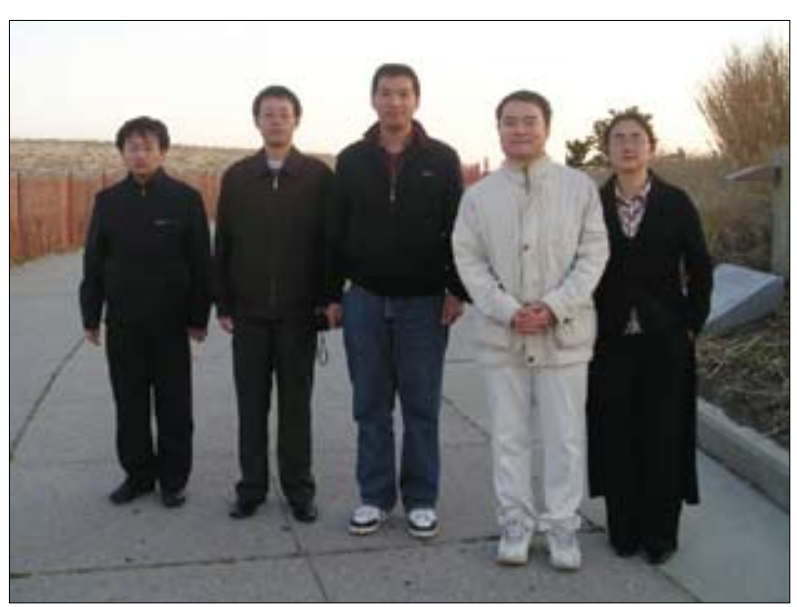

From left, Jinggeng Zhao, Dawei Dong, Zhiguo Liu, Haozhe Liu, and Luhong Wang
Schematic side view (top) and cross sec$\mathrm{Pd}_{45} \mathrm{Au}_{55}$, and $\mathrm{Au}$ nanomaterial during the galvanic replacement reaction.
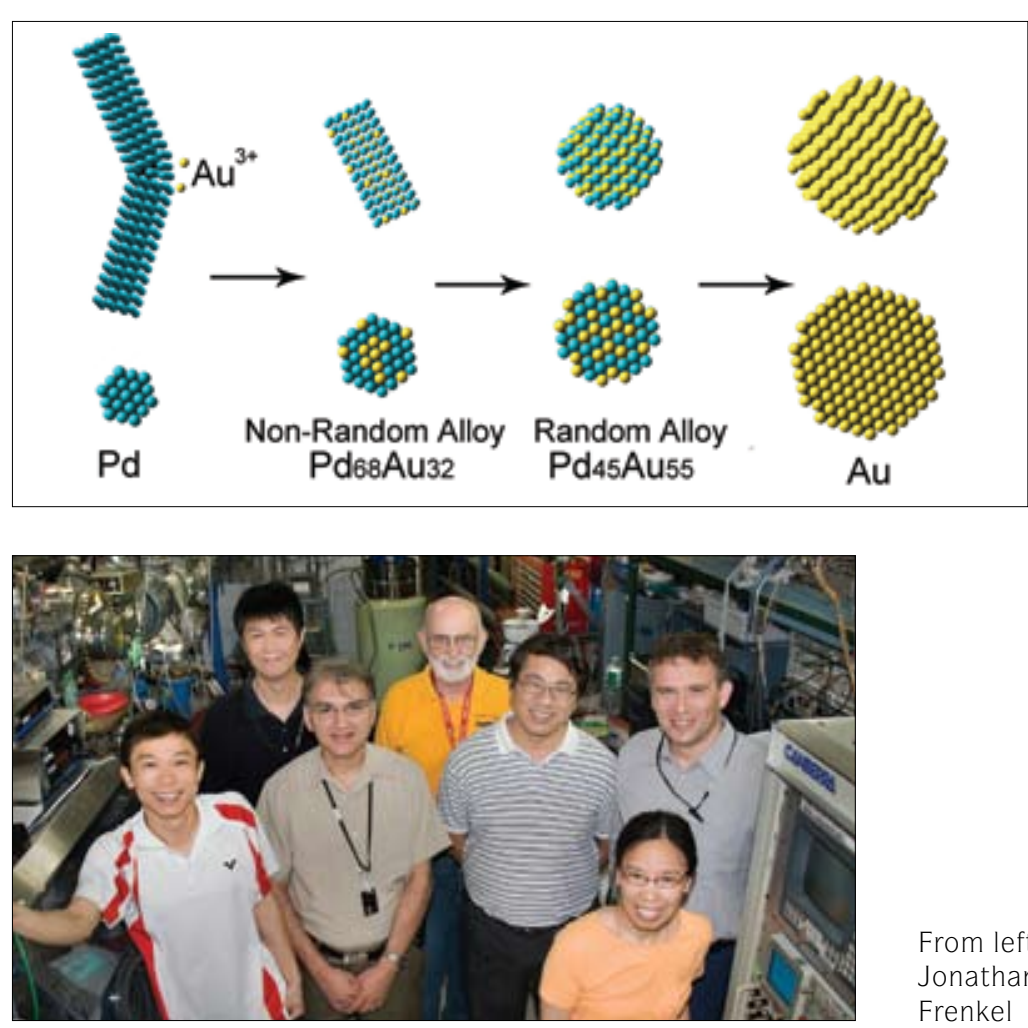

From left, Wen Wen, Xiaowei Teng, Nebojsa Marinkovic Jonathan Hanson, Weiqiaing Han, Qi Wang, and Anatoly

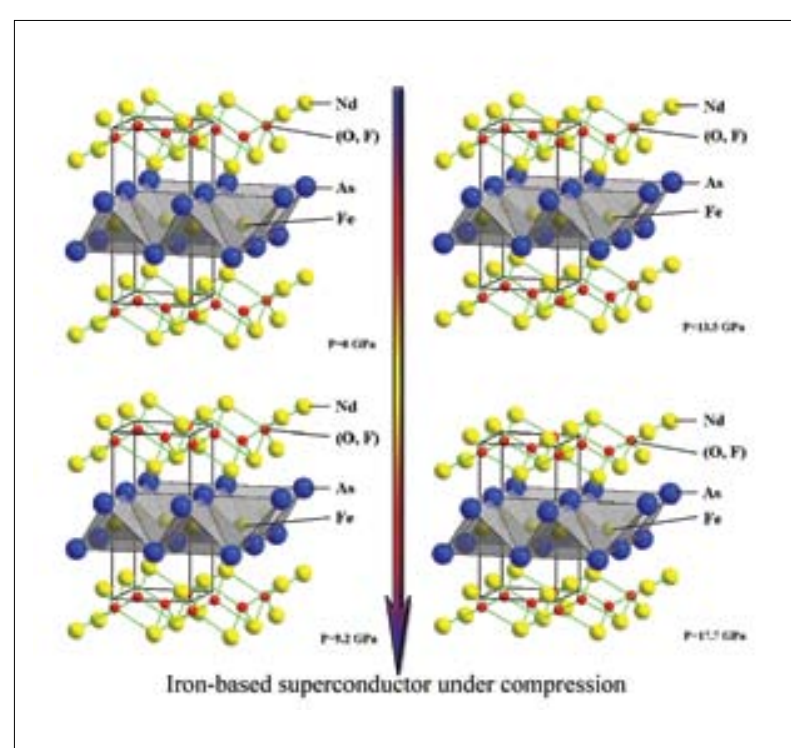

An iron-based superconductor under pressure. 


\section{Squashing Silane into Metal}

Squeeze it hard enough and hydrogen, the most abundant and lightest element in our Universe, strangely takes on a metallic nature. During this state, as it loses hold of its electrons, hydrogen is believed to display unique characteristics including high-temperature superconductivity and properties that could be useful in developing new methods of energy production using nuclear fusion and alternative fuels. Creating this drastic phase change, however, is extremely difficult. As a result, efforts to form and detect solid metallic hydrogen have been elusive. Recently, though, a team of researchers from the Carnegie Institution of Washington, South China University of Technology, and the University of Western Ontario, used the NSLS to study silane, a hydrogen-rich compound, to learn more about the leader of the period tab

Most scientists believe that the recipe for creating metallic hydrogen involves heating it to 3,000 degrees Kelvin (a little hotter than 2,700 degrees (elsius) and exposing it to about 1.4 million atmospheres of pressure (140 GPa). By comparison, the pressure inside the core of the Earth is $380 \mathrm{GPa}$
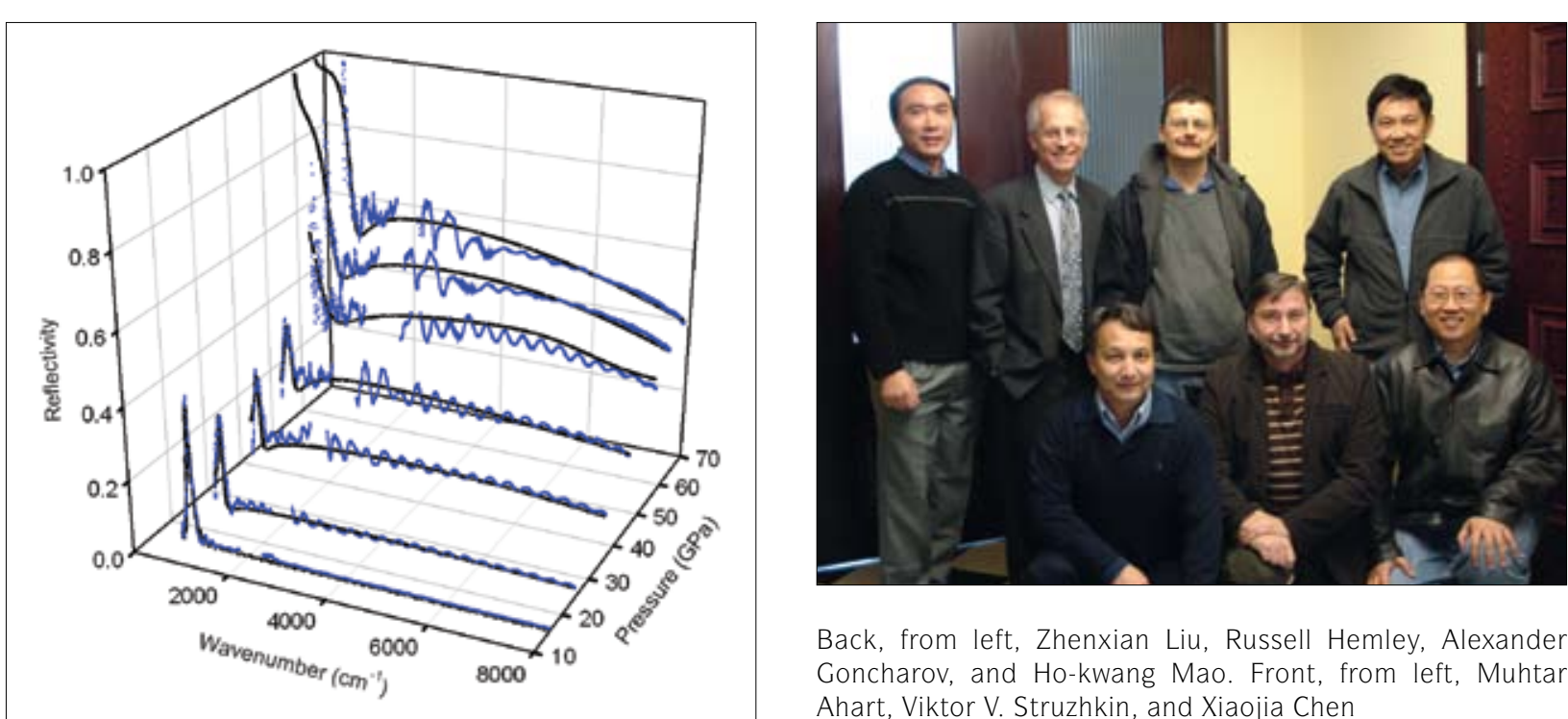

Back, from left, Zhenxian Liu, Russell Hemley, Alexander
Goncharov, and Ho-kwang Mao. Front, from left, Muhtar
Ahart, Viktor $V$ Struzhkin, and Xiaojia Chen

Room-temperature infrared reflectivity spectra of $\mathrm{SiH}_{4}$ at selected pressures up to $67.2 \mathrm{CPa}$. The blue squares are the measurement results. The solid lines represent model fits to
the data. The small gap in the spectrum near $2000 \mathrm{~cm}^{-1}$ is the siamond anvil absorption.
However, these conditions are very difficult to reach and record in a laboratory.

Using two silane samples, the researchers found far less demanaing pressure requirements for metallization: about 60 GPa. Their experiment offers the first example for the metal-

In order to conduct the experiment, the researchers placed their silane samples in a diamond anvil cell, a device that uses the polished faces of two diamonds to apply extremely high pressure. By applying a range of pressures and measuring the results through infrared reflectivity experiments at beamline U2A, the group found that silane undergoes three Above $606 P_{0}$ indicating pressure-induced metallization.

X. Chen, V. Struzhkin, Y. Song, A. Goncharov, M. Ahart, Z. Liu, H. Mac

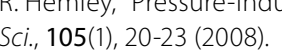

\section{Creating Highly Sought Magnetic Nanoparticles in One Step}

Researchers from the University of Minnesota demonstrated a one-step technique for producing a class of magnetic nanoparticles that could be used in everything from biomedical applications to data storage.

In the medical realm, single magnetic nanoparticles might someday be used to deliver anticancer drugs to a targeted area of the body or to enhance the contrast anance imaging ( development of reacin sphition ticle's magnetic moment - the measure of a material's magnetic strength - the more valuable it is for these applications.

The research group studied nanoparticles made of iron-cobalt (the core) and gold (shell), which have a magnetic moment three to four nanoparticles. Their study is the first to show how these particles can be created in a simpler and more efficient manner than conventional chemical methods, which are limited by the solvent's extremely high boiling temperature and the risk of corrosion due to air exposure. In their one-step, gas-condensation technique, a sputter gun bombards a solid metall. target made of iron, cobalt, and gold with energetic ions. This all happens within a heat bath of high-pressure gas, which transforms the high-energy atoms into the desired nanoparticles.

The resulting nanocrystals were analyzed with high-resolution transmission electron microscopy and energy-dispersive $x$-ray spectroscopy, as well as with x-ray magnetic circular dichroism at NSLS beamline U4B. Their findings suggest that the nanoparticles are very promising for biomedical applications: the resulting cubic crystals are very pure; the shell is thick enough to prevent oxidation of the iron-cobalt core for more than four months of air exposure: and the nanoparticles' magnetic moments are close to the values in bulk iron-cobalt alloy.

Y. Xu, J. Wang, "FeCCo-Au Core-shell Nanocrystals," Appl. Phys. Lett, 91

(Right): Structure of FeCo-Au nanocrystals. (a) CBED of the nanocrysating two perpendicularted hexagons (dot and dot-dash line) inda nanocrystal. (c) illustration of the epitaxial relationship between the bcc FeCo (dotted line) and fcc Au (solid line) (smaller atom, fe the two Au (110)s (indicated by arrows) at two netghboring facets of FeCo $\{100\}$, with a twinning at the rim. (e) a 3D illustration of a corner of the FeCo-Au nanocrystal. (f) HRTEM image of a corner of a nanocrystal w
neighboring Au.
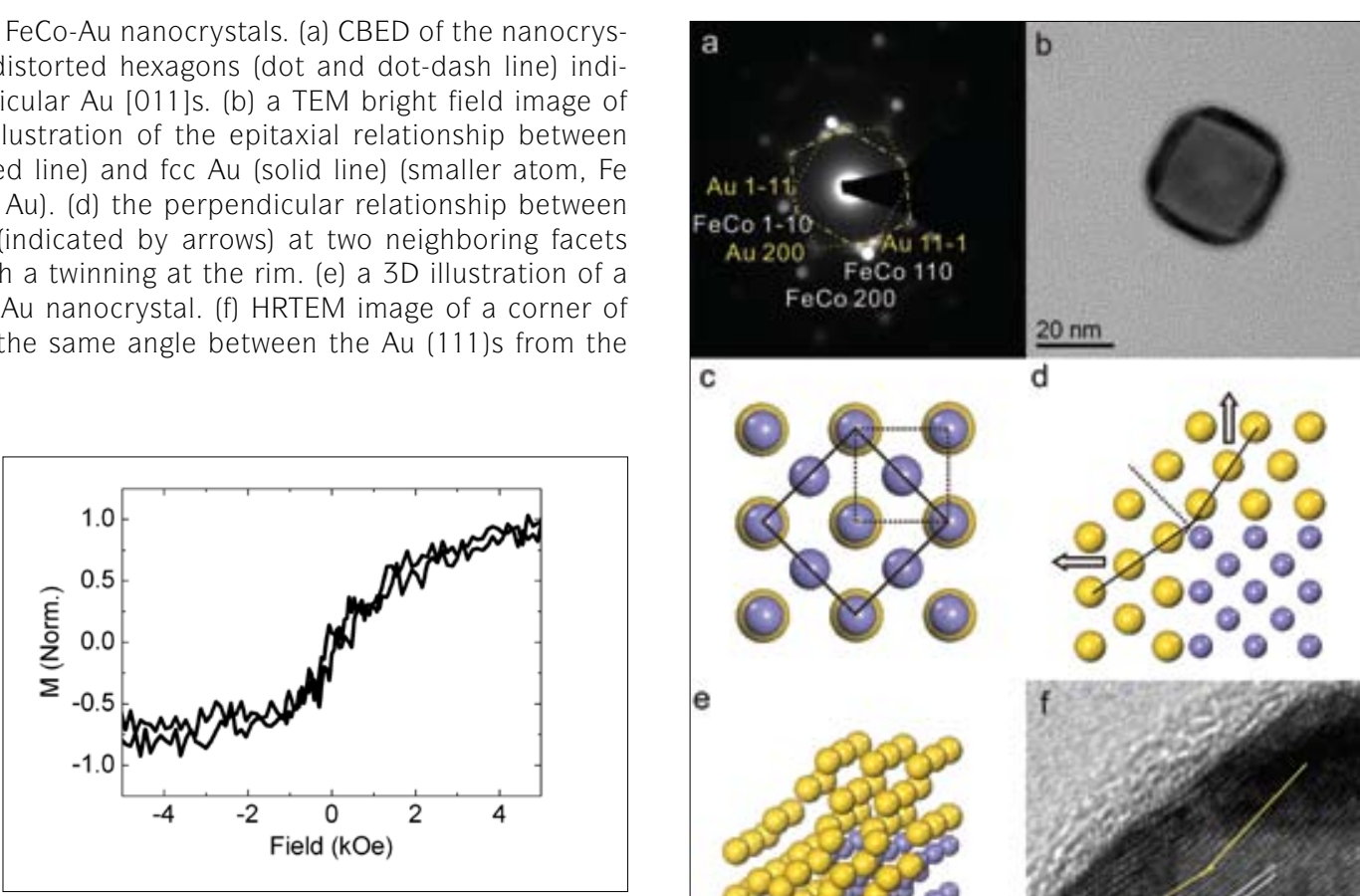

(-) 9 \&os.

\section{(}

(Above): Hysteresis loop of Fe in FeCo-Au nano-
crystals (measured at Fe-L edge by XMCD).

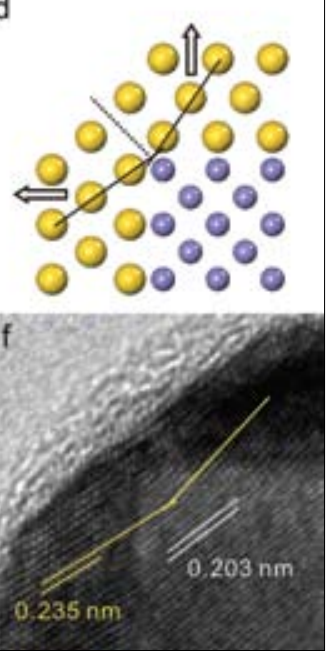

(1)




\section{Experiments Reveal Unexpected Activity of Purifying Catalysts}

A group of Brookhaven-led researchers unveiled important details about a class of catalysts that could help improve the performance of fuel cells. With the goal of producing "clean" hydrogen for fuel cell reactions in mind, the researchers determined why two next-generation catalysts including gold, cerium, titanium, and oxygen nanomaterials exhibit very high activity.

A major problem facing fuel cell technology is that the hydrogen-rich materials feeding the reaction often contain carbon monoxide (CO), which deteriorates the expensive platinum-based catalysts that convert hydrogen into electricity. That's where the "water-gas shift" (WGS) reaction comes in, combining $\mathrm{CO}$ with water to produce additional hydrogen gas and carbon dioxide. The ultimate goal is to find the catalysts that will help convert nealy 100 percent of the $\mathrm{CO}$ into carbon dioxide, an important step toward achieving a hydrogen-based economy.
Toward this effort, the researchers, from Brookhaven's chemistry department, the Center for Functional Nanomaterials, and the Central University of Venezuela, examined the nanoscale catalysts gold-cerium oxide and gold-titanium oxide. Thes catalysts usually consist of gold nanoparticles dispersed on catalysts work, the researchers studied the "inverse modek," ceria or titania nanoparticles on gold.

Using $x$-ray photoelectron spectroscopy at NSLS beamline UTA, in addition to scanning tunneling microscopy and calculations, the group found that although pure gold is inert for the WGS reaction, it becomes extremely active when combined with ceria or titanium. This high activity is due to the catalysts' nanosized oxides, which are able to break apart water molecules J.A. Rodriguez, S. Ma, P. Liu, J. Hrbek, J. Evans, and M. Pérez, "Activity
of CeOx and TiOx Nanoparticles Grown on Au(111) in the Water-Gas Shift Reaction," Science, 318: 1757-1760 (2007) a ceria or titania surface. But to get a better idea of how the

\section{Watching Catalytic Reactions from Within}

Researchers from Utrecht University, in The Netherlands, have demonstrated a new way to get a real-time, microscopic view of the inner workings of catalytic reactions.

Catalysis, a natural and manmade way to accelerate and direct chemical reactions, is a common process used in everything from the production of gasoline, electronic devices, and the cen echnologies. Tradtionally, catalysts are studied using a synchrotron technique called $x$-ray absorption spectroscopy (XAFS), during which samples are bombarded with beams of high-energy $x$-rays.

But XAFS is not always capable of giving clear details about the chemical transformation that reactant molecules undergo on the catalyst's surface To get a better idea of the inner haph team used a unique setup at NSLS beamline U10B, where an infrared spectrometer is coupled with an optical microscope to create a powerful technique called infrared microspectroscopy.
IR microspectroscopy offers unprecedented chemical sensitivity and spatial resolution and gives researchers direct insight into the chemical nature of the reactant molecules, the potential intermediates, and the resulting products as the caalytic reaction occurs. The method is one of just a few techniques capable of analyzing the internal surfaces of catalyst materials during the course of a reaction, and it's the first to be done using infrared light.

The researchers tested the technique on a zeolite - a powerful catalyst used in the petrochemical industry that contains aluminum, silicon, and oxygen. Specifically, the researchers looked at the transformation of the organic compound, sty rene, within the zeolite crystals. They were able to determine the principal reaction intermediate and identify important structure-function relationships within the materia.

E. Stavitski, M.H. Kox, I. Swart, F.M.F. de Groot, B.M. Weckhuysen, " "In Situ Sychrotron-Based IR Microspectroscopy To Study Catalytic Re-
actions in Zeolite Cryystals" Angew Chem. 47(19) 3543-3547, (2008). etions in Zeolite Crystals," Angew. Chem., 47(19) 3543-3547, (2008)
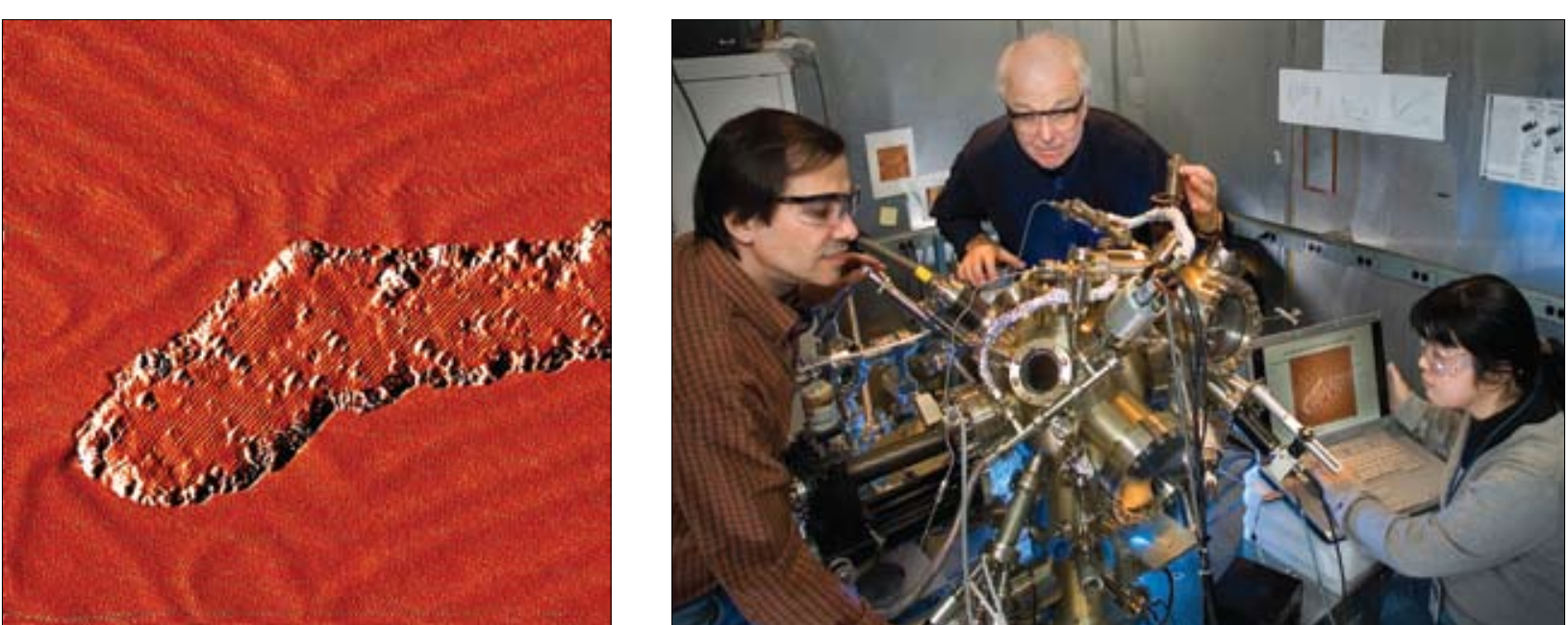

A scanning tunneling microscopy (STM) image
taken of ceria nanoparticles on a gold surface. taken of ceria nanoparticles
From left, Jose Rodriguez, Jan Hrbek, and Ping Liu

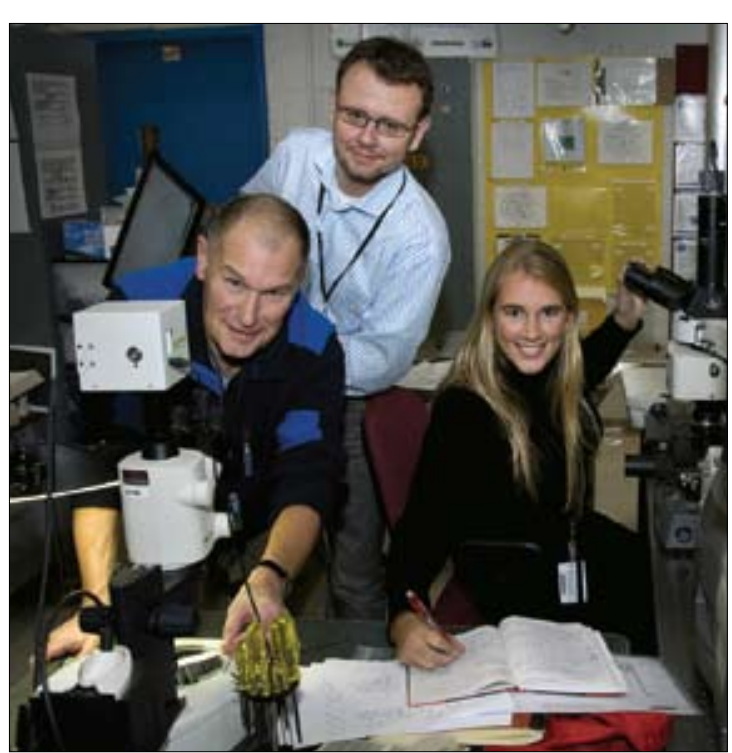

From left, Tom Visser, Eli Stavitski, and Marianne Kox

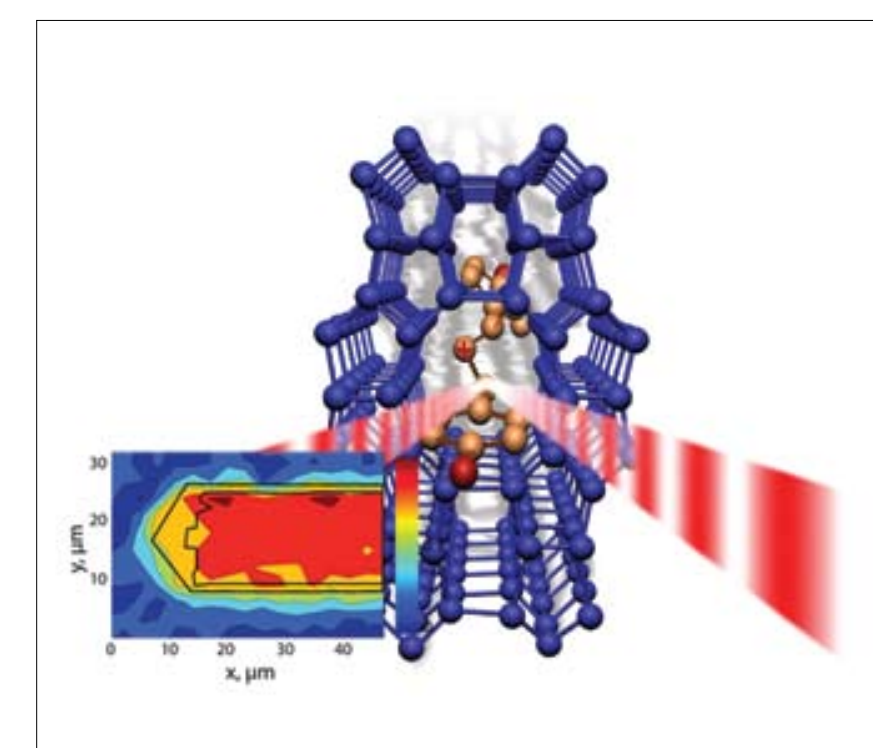

Molecules formed during a catalytic reaction in the zeolite Molecules formed during a catalytic reaction in the 


\section{Creating an Electron Avalanche without Electronics}

Dilute elements - those with low concentrations in a material - are extremely hard to pinpoint using synchrotron radiation. However, a team of scientists from the NSLS and Southern University is testing a way to amplify these small signals, creating a signal stronger than those produced by traditionally used detectors.

Extended $x$-ray absorption fluorescence spectroscopy (EXAFS) is a powerful technique used often in the environmental and geological sciences for measuring trace element concentrations in a sample. Conventional devices such as passivated implanted planar silicon (PIPS) and Lytle detectors are generally used in EXAFS experiments to pinpoint weak signals. Neither is perfect: Lytle detectors produce noise that can further hide the already weak dilute element signals, and PIPS detectors are sensitive to light and temperature changes.

That's why the research group explored the use of a detec tor based on a gas electron multiplier (GEM), which amplifies

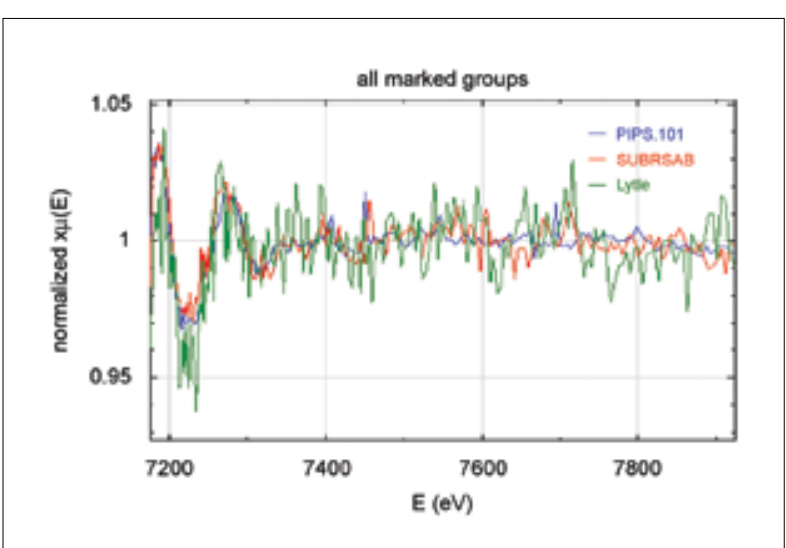

$\mu(E)$ for the detectors SUBRSAB, PIPS, and Lytle a signal without electronics, and therefore, virtually with out noise. Like a single chunk of snow that grows into an avalanche, the amplification technique accelerates a small group of electrons in a field, which hits and excites other atoms until the signal is very strong.

Using an arbitrary tree leaf as a sample on NSLS beamline $\mathrm{X} 19$, the research team tested its GEM detector in the search for the dilute element iron. They found that the GEM resulted in an improvement in signal amplitude by a factor of 20 and a factor of 2 when compared to the Lytle and PIPS detectors respectively.

E.H. Shaban, D.P. Siddons, A. Kuczewski, "Gas Electron Multiplier (GEM) Enhanced lonization Chamber for Fluorescence Detector," Nucl
struments and Methods in Physics Research, 582, $185-186$ (2007).

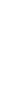

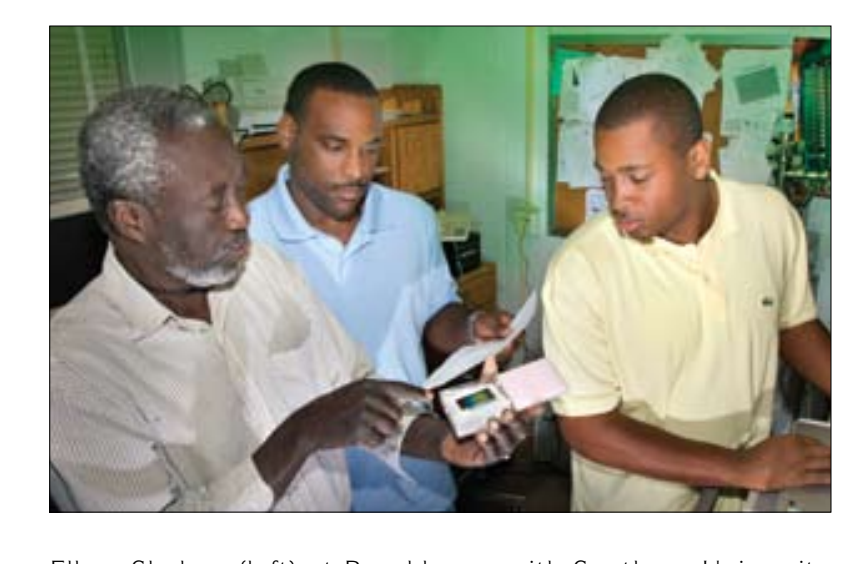
Elhag Shaban (left) at Brookhaven with Southern University

\section{Efficiency Doubling in a Laser-Seeded Free Electron Laser Amplifier}

As scientific research continues to explore the limits of smaller (nanometer and sub nanometer) and faster (femtosecond and attosecond) phenomena, light pulses are commonly used as probing tools. Free electron lasers (FELs) are capable of generating light levels that exceed those of conventional synchrotron sources by many orders of magnitude. However, by simply relying on the FEL instability, x-ray FEL emisson can have good transverse (spatial) coher-ence but lacks sion can have good ans is seeded FEL emission, in which the instability is initiated by a coherent seed laser pulse. Recently, researchers from Brookhaven and Science Applications International Corp. used the NSLS Source Development Laboratory to demonstrate the doubling of FEL efficiency without degradation of its quality. This is the first direct experimental demonstration of the FEL spectral stability in a laser-seeded FEL.

In the detuning experiment, a $800 \mathrm{~nm}$ Ti:sapphire laser was used as the seed, and the FEL output energy and spectrum were measured as the electron beam energy was scanned.

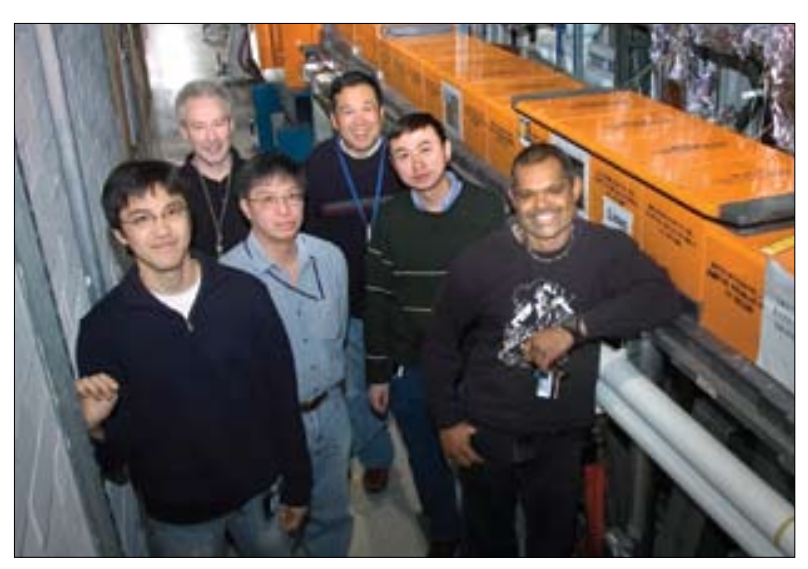

From left, Takahiro Watanabe, James Murphy, Thomas Tsang. jie Wang, Yuzhen Shen and Boyzie Singh at the Source De velopment Lab
When the electron beam energy was tuned to about 07 percent higher than resonance, the FEL energy more than doubled. Instead of the 1.4 percent spectral shift predicted by the resonance condition, no FEL spectral shift was observed within the spectrometer resolution (0.05 percent) as the electron beam energy was scanned. An increase in the FEL gain length was also observed with energy detuning.

The experiment not only demonstrated for the first time a simple technique to improve the FEL efficiency, but also showed that the coherent seed laser determines FEL central wavelength, hence FEL spectral is insensitive to the electron beam energy jitter.

X.J. Wang, T. Watanabe, Y. Shen, R.K. Li, J.B. Murphy, T. Tsang, and H.P.

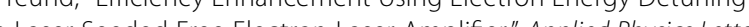
a Laser Seeded Free 


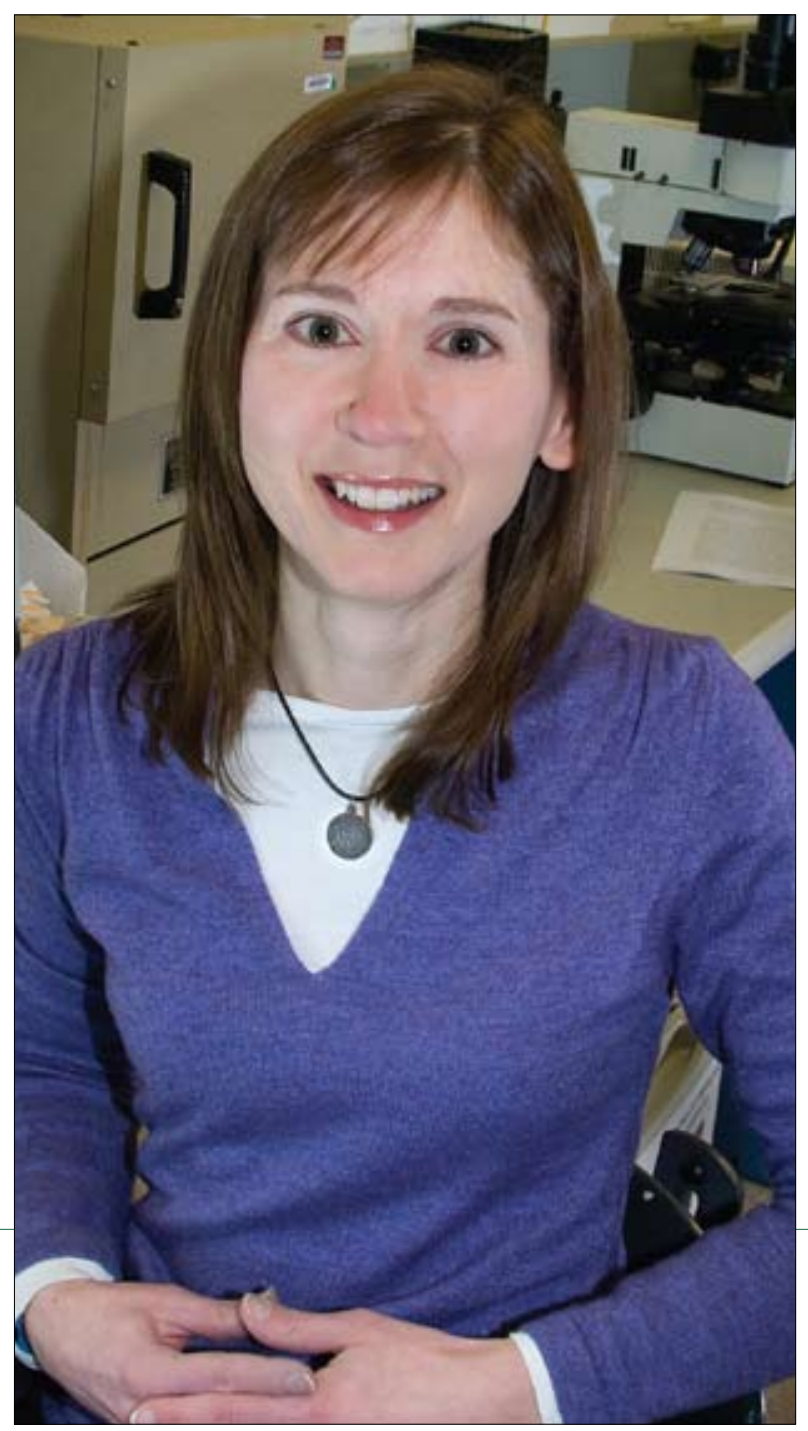

\section{Lisa Miller}

life and Environmental Sciences Division Head

2008 was another exciting and productive year for NSLS users and staff research in the fields of structural biology, biomedical imaging, geological and environmental sciences, and soft condensed matter and biophysics. The community represents more than 60 percent of the NSLS users and its publications continue to be of high impact in premier scientific journals like Science, Nature, Physical Review Letters, and PNAS. This year's Activity Report briefly describes some of the highlights of 2008, while many more highlights can be found on the NSLS website.

In the fields of soft condensed matter and biophysics, the mechanisms behind the ordering and self-assembly of materials were studied in a wide range of systems in 2008 . Selected as an
"Editors' Favorite" in Nature in 2008, a team of Brookhaven Lab researchers used DNA to guide the creation of three-dimensional, ordered, crystalline structures of nanoparticles (Nykypanchuk, et al.) The ability to engineer such 3-D structures is essential to producing functional materials that take advantage of the unique properties that may exist at the nanoscale - for example, enhanced magnetism, improved catalytic activity, or new optica

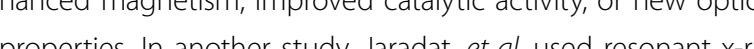
properties in anoher sudy Jardat, at al used resonant $x$-rá phases. Depending on how the direction of the in-plane polarization varies between layers, an applied electric field can induce changes in orientation, which can be utilized in application from high-resolution camera viewfinders to large-area monitors.

In earth and geosciences, the high brightness of synchrotron light shined in 2008 when Lehmann, etal. used $x$-rays to illustrate. for the first time, the nanoscale heterogeneity of organic carbon soils from countries around the world including the United States, Panama, Brazil, Kenya, and New Zealand. Since the presence of natural organic matter in soils is a sensitive indicator of environmental stresses such as climate change, it is important to under-

"The life and environmental science community represents more than 60 percent of the NSLS users and its publications continue to be of high impact in premier scientific journals."

Sand the fate of natural organic matter worldwide. A further understanding of this process in nutrient-poor lakes was gleaned by Schafer, et al. when they used transmission electron microscopy (TEM), scanning transmission $x$-ray microscopy (STXM), and Fourier transform infrared micro-spectroscopy ( $\mu$ FTIR) to show that natural organic matter adsorbs to inorganic particles in the lakes, reducing their bioavailability.

Synchrotron applications yielded further progress toward improved environmental remediation in 2008 when $x$-ray fluorescence microprobe studies of plutonium (Kaplan, et al.) and uranium (Tokunaga, et al.) showed how the mobility of these contaminants in the environment is heavily dependent upon their oxidation state. These findings have important implications for the disposal and remediation scenarios for long-lived radiosotopes In addition, Ndiba, etal used exten ded x-ray absorption De immobled in ded sed sedments though phosphe thermal treatment, making them safer and reusable for things ke road-based construction
Finally. it was another impressive year for the structural biologists in the field of macromolecular crystallography. As an example this year's Activity Report highlights work by Kumaran, etal tha dentifies a highly efficient inhibitor of the botulinum neurotoxin. which is a promising drug target for the most deadly neurotoxin known to humans. We also feature four important crystal struc tures published in Nature this year that provide atomic resolution images that describe enzyme functions including how the 300 et al) how AMP-activa intracellular ratio of AMP:ATP (Amodeo, et al); how telomerase works to replicate the ends of chromosomes - a process critica to both tumor development and the aging process (Gillis, et al.). and how calpastatin can inhibit calcium-bound calpain without being cut and destroyed in the process (Hanna, et al). But this selection of highlights barely touches the sufrce of the hundeds of cis of structurs solved at he NSLS in 2008 and lencoura of crystal structures solved at the NSLS In 2008 and I encourage you to visit then 


\section{Heating Up Dredged Sediment}

Historically, dredged materials - often contaminated with heavy metals and toxins from industrial and urban activities - were dumped in open waters, rivers, estuaries, or wetlands. But heightened environmental regulations and increasing costs for land deposition have presented a major challenge for dredging projects. As an alternative, attention has turned to the treatment and reuse of sediments, a move that would reduce costs a a c conserve resources Most of these aternative technologies involve heating the sediment to extreme temperatures in order to eliminate its toxic nature and make it environmentally safe for products such as cement, lightweight bricks, and ceramic and glass tiles. However, few ex isting technologies are actually commercially used, stressing the need for further development.

Toward that effort, a group of researchers from the New Jersey Institute of Technology investigated a specific thermal technique that incorporates the addition of phosphate.

After obtaining sediment from waterways in Belgium, the group added phosphoric acid to their samples and then
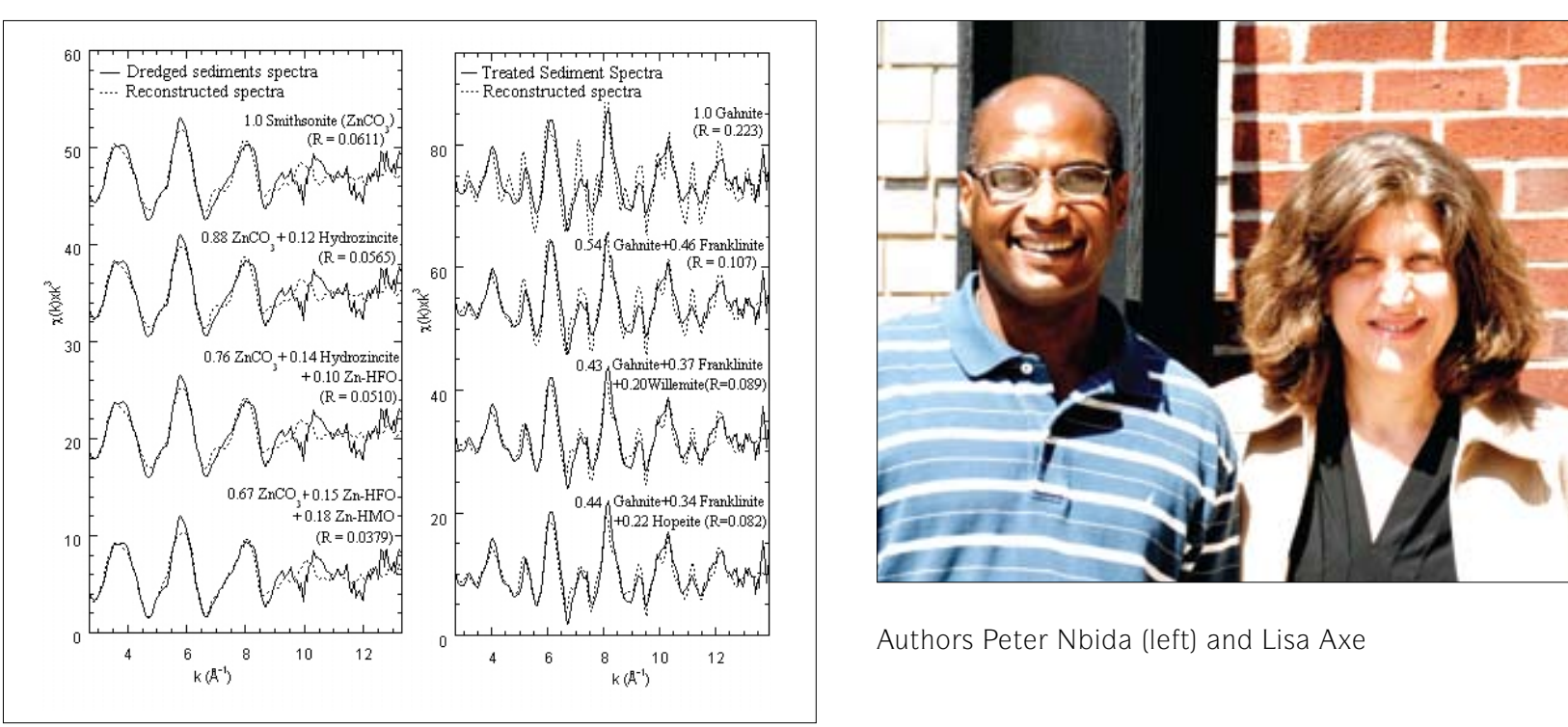

Lake Brienz $1 \mathrm{~m}$ depth left to right: absorption image at $280 \mathrm{eV}$, distridistribution of organics. Shades of bright grey indicate high concentra tions of organic function
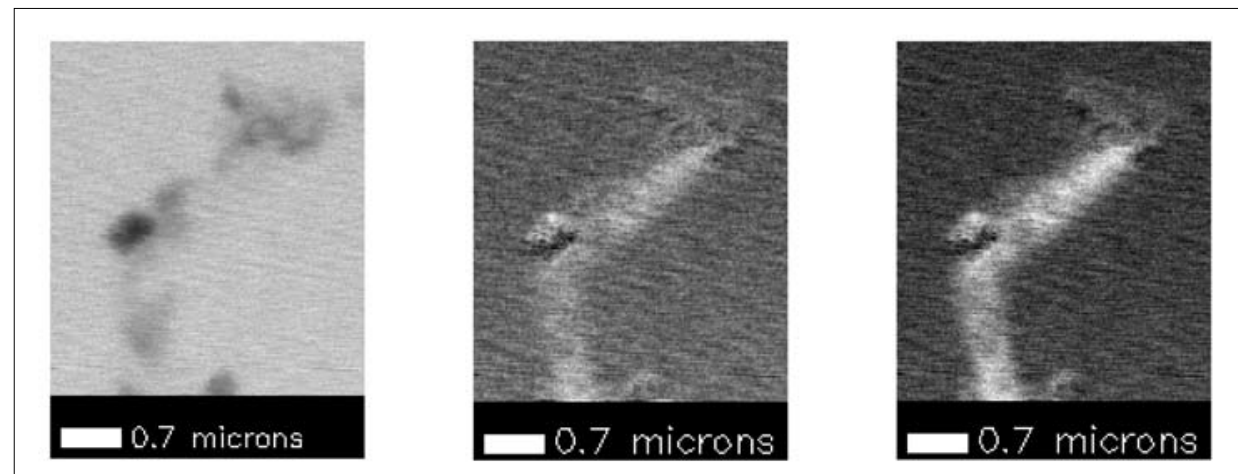

Authors Peter Nbida (left) and Lisa Axe
The group found that NOM concentrations remained extremely low throughout the year, melting snow was responsible for about 32 percent of the lake's annual refractory organic matter inpu $(\mathrm{ROM})$, and about 25 percent of ROM was lost within the lake that is not accounted for by lake flushing.

In particular, all organics in a Lake Brienz sample taken at a 100-meter depth showed an association to potassium-rich minerals and very comparable organic functionality to the mineral-associated organic matter of the surface waters. This suggests that sedimentation of organic material is one of the major organic removal processes in the lake, thus supporting conclusions that NOM sorption onto inorganic settling particles mainly causes the elimination of NOM in the lake. Their results prove that STXM and FTIR are suitable to characterize colloidal and particulate organic material and its functionality in very low organic carbon systems.

T. Schäfer, V. Chanudet, F. Claret, and M. Filella, "Spectromicroscopy Mapping of Colloidal/Particulate Organic Matter in Lake Brienz, S S
zerland," Environmental Science \& Technology, 41, 7864-7869 (2007)

v. Chanudet and M. Filella, "Submicron Organic Matter in a Peri-Alpine, (1146-1160 (2007)

Experimental and linear combination fitting reconstructed $\chi(k) \cdot k^{k}$ spectra for dredged and treated sediments. Only spectra with
more than $10 \%$ contributions are included. The fitting factor R $=\sum\left[\left(k^{3} \chi_{\text {exp }}-k^{3} \chi_{\text {moded }}\right) / k^{3} x_{\text {exp }}\right]^{2}$ where $\chi$ model refers to spectra re construction $\mathrm{z}$.

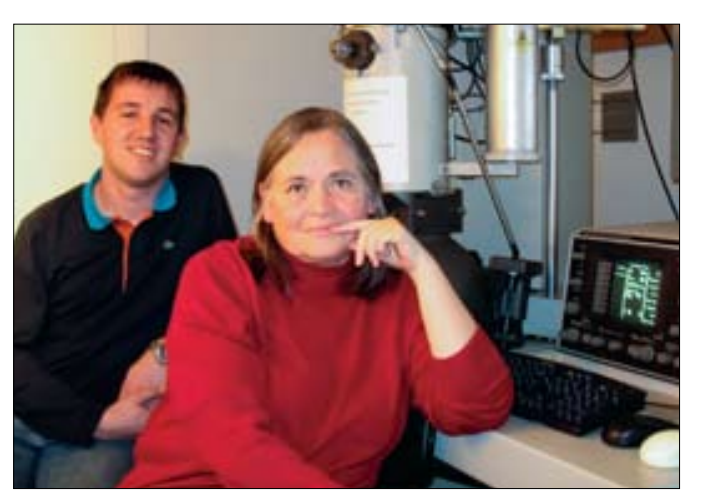




\section{Investigating Plutonium Oxidation State Transformations}

Plutonium (Pu) is an element of concern in disposal and remediation scenarios because of its radiotoxicity and very long half-lives for several isotopes. Once released into the environment, the movement of Pu is strongly related to its oxidation state. In aqueous solutions, Pu can exist in oxidation states III, IV, V, and VI, with two or three of these oxidation states commonly present at equilibrium. Pu(V) and Pu(VII) are typically two orders of magnitude more mobile than Pu(III) or Pu(IV). To further investigate Pu oxidation state transformations in its natural environment, a team of researchers from the Savannah River National Laboratory and Clemson University used $\mathrm{x}$-ray techniques at the NSLS.

First, the researchers established a series of lysimeters on the Savannah River Site located in Aiken, South Carolina, to evaluate the long-term transport of $\mathrm{Pu}$ through vadose zone sediments - the region below the root zone and above the sedments - the reglon below the root zone and above the underlying water table where radioactive waste in the U.S. Is disposed. Five lysimeters, planted for 11 years, were evaluated for this study: an unamended control and four lysimeters amended with varying oxidation states of $\mathrm{Pu}$

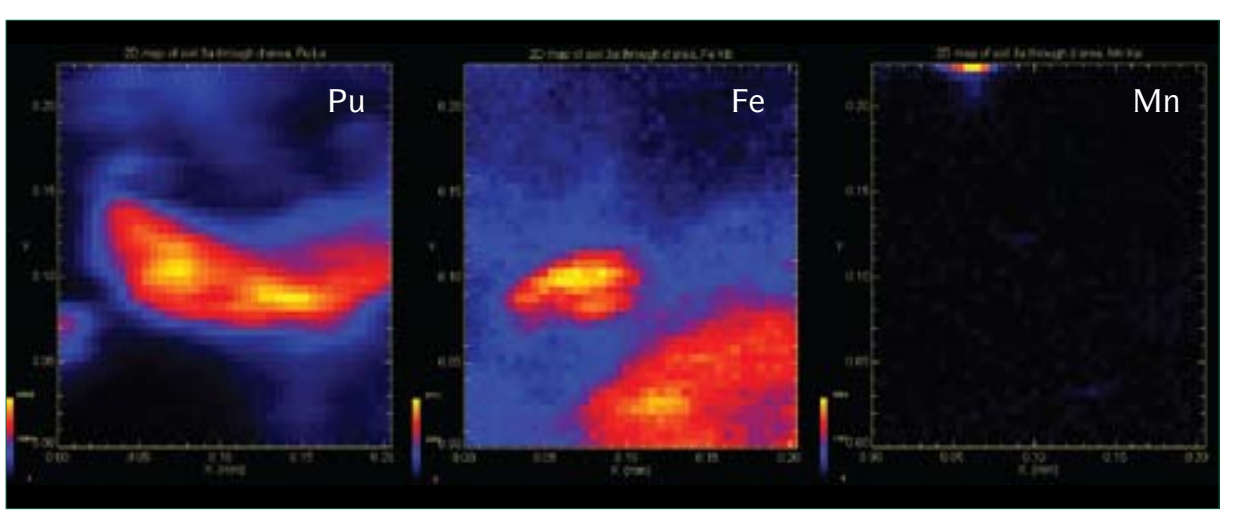

Micro-SXRF elemental map mages of sediment next
to the $\mathrm{Pu}^{\mathrm{v}}\left(\mathrm{NO}_{3}\right)_{4}$-amended filter disc. Relative concentrations on these maps concentrated), bluck (least and yellow (most concentrated.

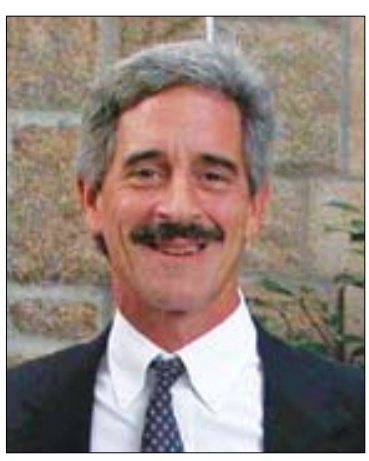

Daniel Kaplan

Micro- $x$-ray fluorescence studies at NSLS beamline X26 vealed that Pu was very unevenly distributed on the sed ment and manganese concentrations were too low and perhaps of the wrong mineralogy to influence Pu distribufion. X-ray absorption near-edge structure of the Pu(III) and Pu distributions, suggesting steady state had been achieved This is likely the first observation of steady state Pu(III) in as-

DI. Kaplan, B.A. Powell, M.C. Duff, D.I. Demirkanli, M.E. Denham, R.A. Dield, and F.J. Molz, "Plutonium Source Solubilities and Oxidation
state Transformans hol, 41(21): 7417-7423 (2007)

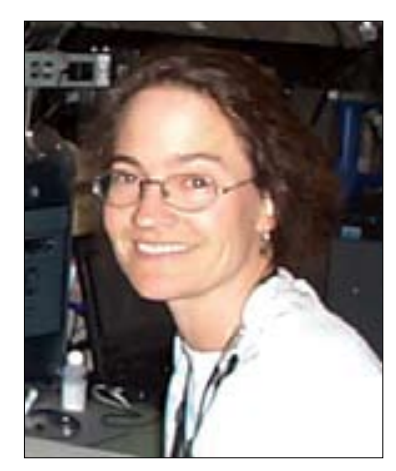

Martine Duff

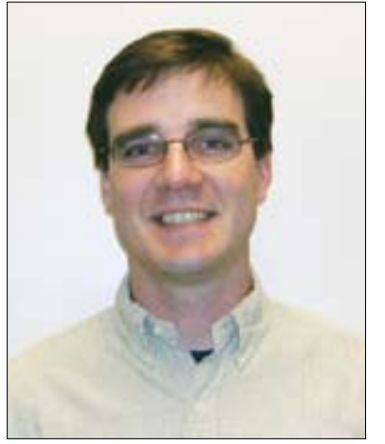

Brian Powell

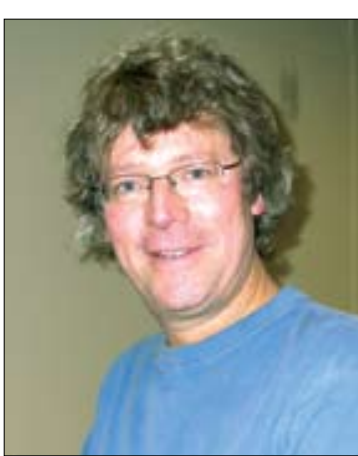

Miles Denham

\section{First Nanoscale Image of Soil Reveals an 'Incredible' Variety}

A handful of soil is a lot like a banana, strawberry, and apple smoothie: Blended all together, it is hard to tell what's in there especially if you have never tasted the fruits before.

But when you look at soil's organic carbon closely, it has an incredible variety of known compounds. And looking closely is exactly what Cornell researchers did for the first time - at a scale of 50 nanometers 1 nanometer equals the widh of soil humus (or the organic component of soil, formed by the decomposition of leaves and other plant material by soil microorganisms looked remarkably similar.

Knowing the structure and detailed composition of soil carbon could provide a better understanding of the chemical processes that cycle organic matter in soil. For example, the processes that cycle organic mater in sol. For exa research may help scientists understand what happens when materials in the soil get wet, warm or cool and how soils se-
quester carbon, which has implications for climate change.

The soil measurements were made at NSLS beamline XIA1 using near-edge $x$-ray fine structure spectroscopy coupled scan-

ning transmission $x$-ray microscopy - a method developed by physicists at Stony Brook University. Using this technique, the researchers found that while the composition of organic carbon in soils from North America, Panama, Brazil, Kenya or New Zealand proved remarkably similar within each sample, within spaces separated by mere micrometers, soils from any of these locations showed striking variation in their compositions.

The researchers were also able to identify the origins of some of the nano-sized compounds, determining that some of them, for example, were microbe excretions and decomposed leaves

This method can now be used to break soil down, separate compounds, conduct experiments on individual compounds and better understand the interactions.

- Krishna Ramanujan. NSF

J. Lehmann, D. Solomon, J. Kinyangi, L. Dathe, S. Wirick, C. Jacobs Scales," Nature Geosci, 1: 238-242 (2008).

Distribution of carbon conin a soil microassemblase from Nandi Forest (Kenya) combination with STXM. a) Total carbon. b) Aromatic carbon. c) Aliphatic carbon. d) Carboxyl carbon. e) Phenofic carbon. ff Cluster map
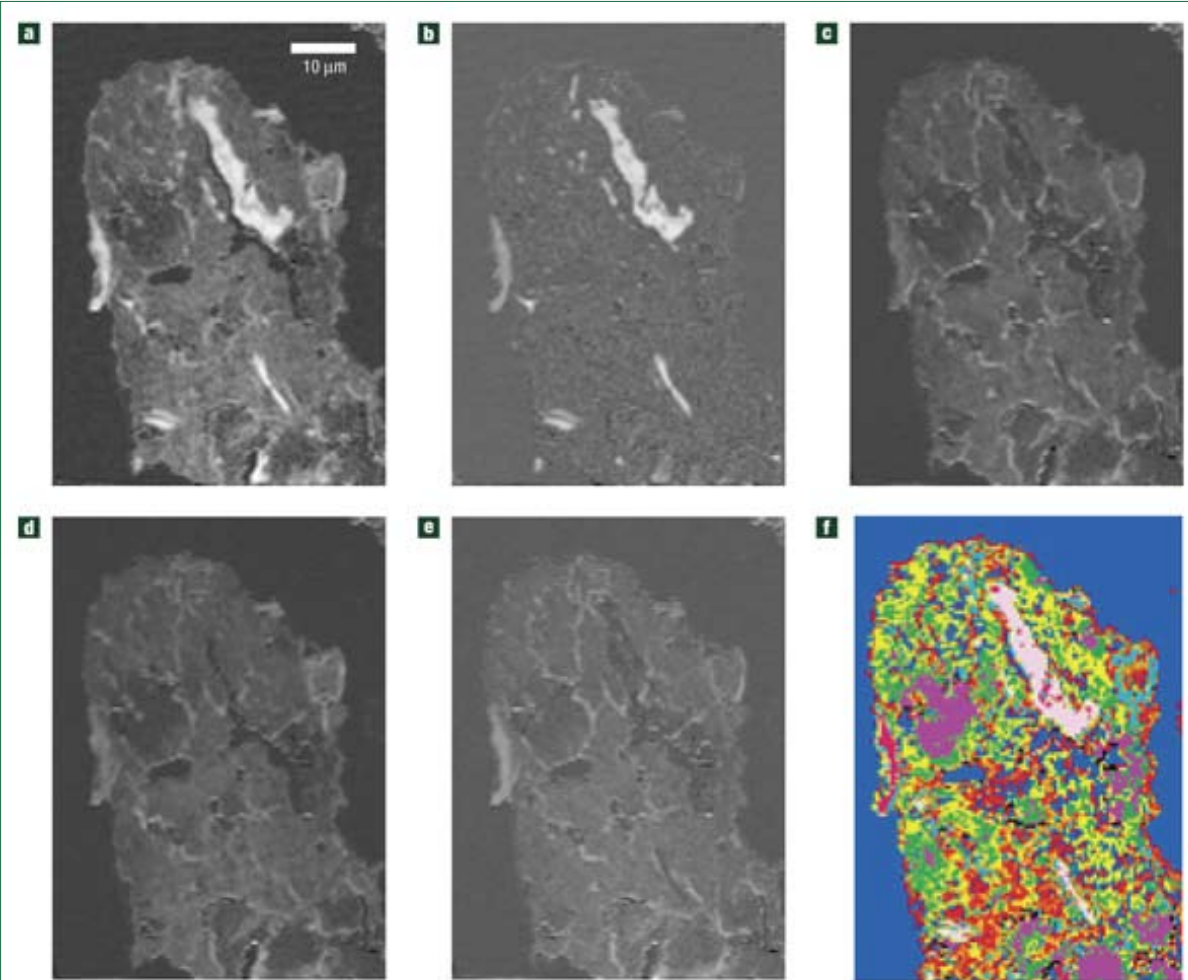


\section{Researchers Identify Problems in the Uranium Bioremediation Avenue}

Uranium found in soil and groundwater takes billions of years to decay radioactively. In addition, traditional clean-up methods involving pumping of contaminated water are useless against uranium because it sticks to soil, making it tricky to find a treatment option that is both efficient and cost-effective. To help narrow the search, a team of researchers from Lawrence Berkeley National Laboratory the University of California, the ratory set out to question a popular potential bioremediation method involving the infusion of organic carbon.

The overall mobility of uranium in the environment is determined by its oxidation state, which is either hexavalent - $U(V)$, soluble and travels with water - or tetravalent - U(IV), insoluble and practically immobile. The goal for researchers is to reduce uranium and keep it stabilized in its tetravalent state.

Using uranium-contaminated sediments from Oak Ridge National Laboratory, the research team previously studied the effect of adding various levels of organic carbon to samples, which encourages the reduction of uranium.
Their results were surprising: Rapid reduction of U(VI) to U(IV) was shortly followed by the reoxidation of uraniuam. The researchers guessed that this reoxidation could be due to one of the other predominant elements coexisting in the contaminated samples - iron or manganese. The challenge for the team in the most recent study was to determine the true culprit.

While treating sediment samples with varying amounts of organic carbon, scientists used micro-x-ray absorption nearedge spectroscopy at NSLS beamline X26A to determine the oxidation states of uranium, iron, and manganese in real time The data showed that as the uranium switched to its tetravalent state under the influence of organic carbon, manganese also reduced while most of the iron remained in its $\mathrm{Fe}$ (III) state - evidence that it's the likely reoxidizing agent.

T.K. Tokunaga, J. Wan, Y. Kim, S.R. Sutton, M. Newville, A. Lanzirott,
W. Rao "Real-Time X-ray Absorption Spectroscopy of U. Whanganese in Contaminated Sediments During Bioreduction: (1) Manganese in Contaminated Sediments

\section{Enzyme Discovery May Lead to Better Heart and Stroke Treatments}

A Queen's University study sheds new light on the way a specific cell enzyme, implicated in causing tissue damage after heart attacks and strokes, is normally kept under control. The research team's discovery will be useful in developing new drug treatments that can aid recovery in stroke and heart disease, as well as lessen the effects of Alzheimer's and other neurologically degenerative diseases.

In remodeling proteins needed for cell growth and movement, cells use the enzyme calpain to break off pieces from other proteins. Calpain is activated when the cell releases short bursts of calcium. During heart attacks or strokes, however, blood supply to cells is interrupted. When the blockage is re-opened, the influx of blood causes calcium levels in the cell to become dangerously high, and the calpain activity to increase. The result is significant damage to tissues.

The researchers' study shows how another protein, calpastatin, binds and blocks calpain once it has been activated by calcium. Because the crystals grown in the lab at Queen's

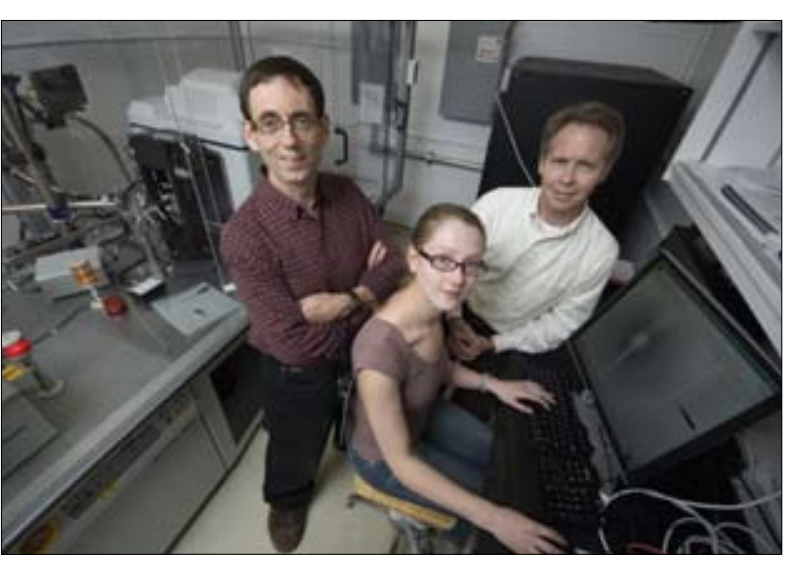

Queen’s University Biochemistry Ph.D. student Rachel Hanna checks data from one of the university's diffractometers

Tetsu Tokunaga (left) and Tony Lanzirotti

Uranium contaminated sediment column during micro-XAS data collection at beamline X-26A. Examples of XANES
spectra for determining oxidation states of (a.) manganese. (b.) iron, and (c.) uranium

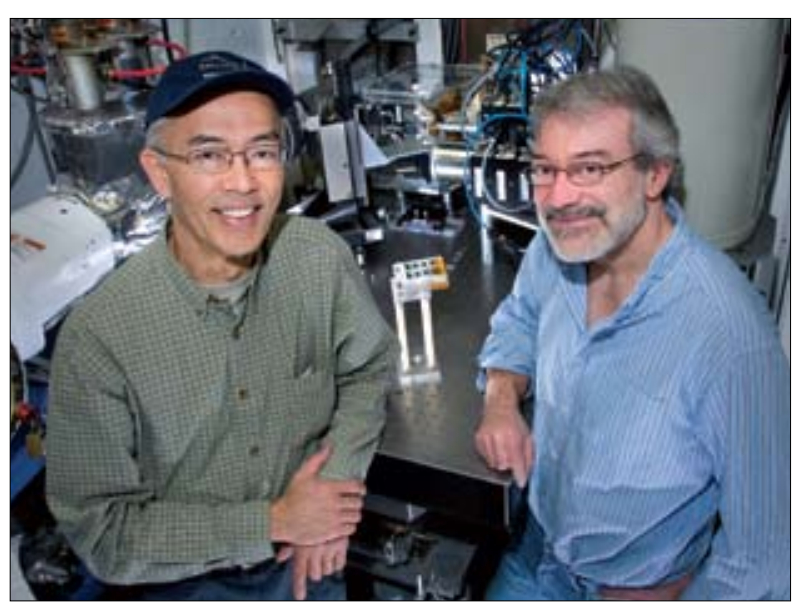

were too small to be used for $x$-ray diffraction data collection on the university's diffractometer the group booked time at NSLS beamline X6A. Using $x$-ray crystallography, the 列 政 Cand calpain and discover how calpastatin can inhibIt calpain without being cut and destroyed in the process. Thainst the damage caused by overactivation of colpon.

— Nancy Dorrance, Queen's University

R. Hanna, R. Campbell, and P. Davies, "Calcium-Bound Structure of

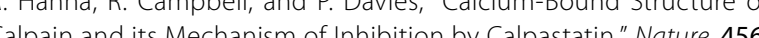
409-412 (2008)

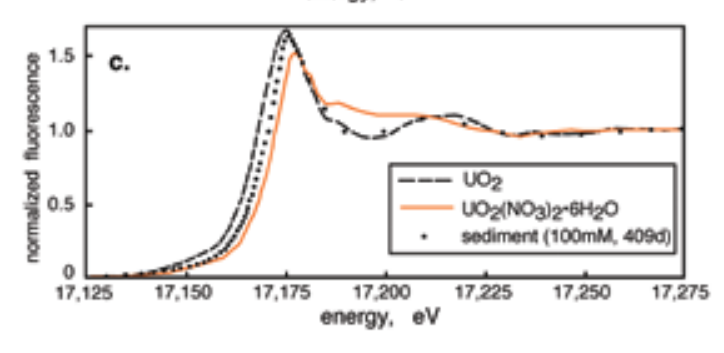

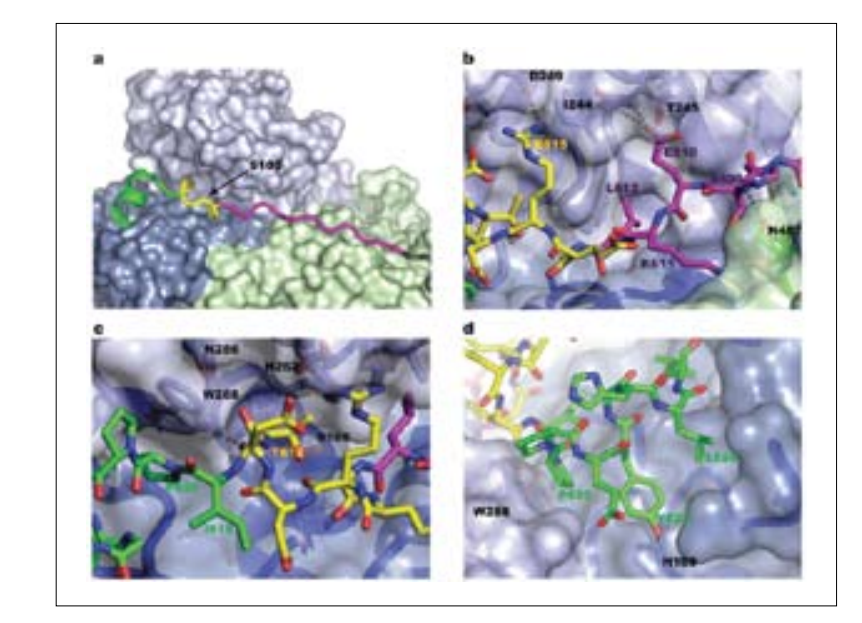

The 27-residue B-peptide is colored as follows: the residues that make the loop out of the active site are yellow, the resi dues $\mathrm{N}$-terminal to the loop are purple, and the residues $\mathrm{C}$ are dark grey. Hydrogen-bond interactions of calpastatin with calpain are shown by black dashed lines. $\mathrm{O}$ and $\mathrm{N}$ atoms are red and blue, respectively. a) Overview of calpain binding tin at the unprimed side of the active site. c) Close-up view calpastatin looping away from the catalytic residue d) Close up view of calpastatin at the primed side of the active site. 


\section{Cracking the Structure of a Key Cancer-Related Protein}

A team of researchers from The Wistar Institute, the University of Pennsylvania, and Johns Hopkins University used Xray crystallography at NSLS beamline X6A to solve the threeimensional structure of a an enzyme whose mutations are linked to a variety of deadly human cancers, including pancreatic, colon, and lung cancer.

The protein, p300/CBP, belongs to a family of enzymes known as histone acetyltransferases (HATs) that activate genes by attaching chemicals called acetyl groups to chromosomes, altering gene function. A substance that selectively inhibits the protein might be the basis for an anticancer drug.

After 10 years of work, the researchers cracked the structure of p300/CBP bound to a small molecule that inhibits its acivity. They found that although other HATs are built quite differently than $\mathrm{p} 300 / \mathrm{CBP}$, the central region of the protein is very similar. The study also shows how the binding site and chemical mechanism of the enzyme enable it to regulate a range of genes: p300/CBP has a binding pocket that is able

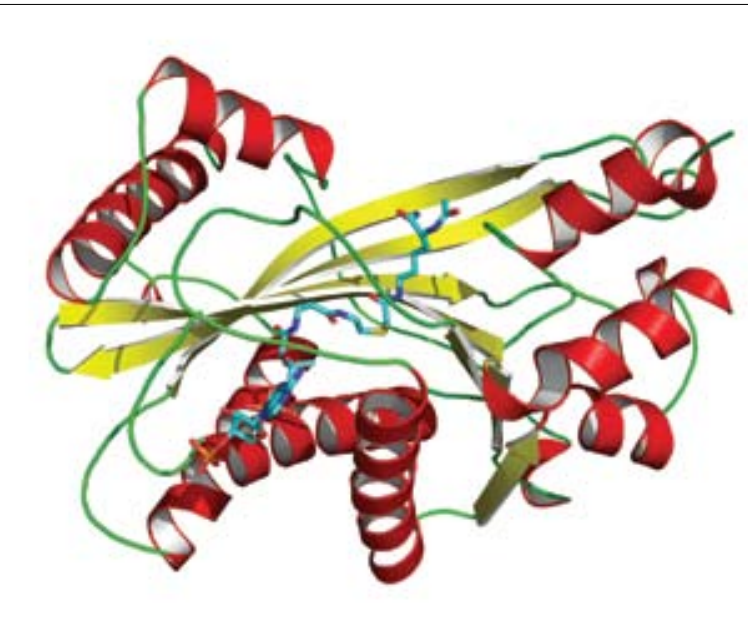

Structure of the histone acetyltransferase domain of $p 300$ bound to the Lys-CoA bisubstrate inhibitor. The propein is
shown as a cartoon with a-helices $\beta$-strands and loops show shown as a cartoon with a-helices, $\beta$-strands and loops shown is shown in CPK coloring (carbon in blue) as a stick figure. to link with a wide variety of substrates: and the protein uses a "hit-and-run" mechanism to attach acetyl groups to chromosomes. Other HATs tend to hang on to both the acety group and chromosome until the transfer is made. These characteristics are well suited for designing cancer drug capable of targeting p300/CBP without causing unwanted side effects.

X. Liu, L. Wang, K. Zhao, P.R. Thompson, Y. Hwang, R. Marmorstein,
P.A. Cole, "The Structural Basis of Protein Acetylyation by the p300/CB Transcriptional Coactivator," Nature, $451,846-850$ (2008).

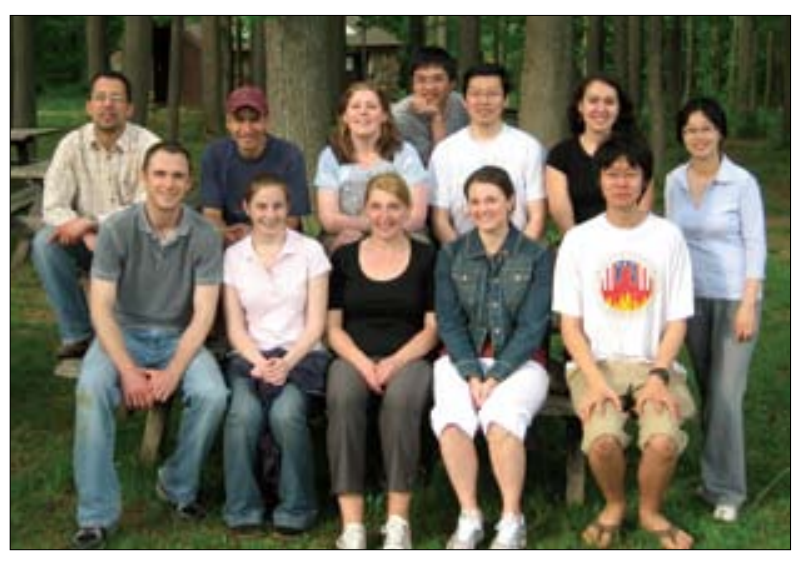

The Marmorstein laboratory. Bottom, from left, Michaa Brent, Kimberly Malecka, Jasna Maksimoska, Brandi San ers, Zhenyu Zhao; midale, from left, Dario Segura Pena,
Ronen Marmorstein, Katie Meeth, Peng Xie, Daniela Fera, Manqing Hong; top, Yong Tang

\section{Landmark Study Opens Door to New Cancer, Aging Treatments}

Researchers at The Wistar Institute deciphered the structure of the active region of telomerase, an enzyme that plays a major role in the development of nearly all human cancers. The achievement opens the door to the creation of new, broadly effective cancer drugs, as well as anti-aging therapies.

Telomerase is a complex structure made up of multiple proin domains and a stetch of RMA, which contains the temein domains and plate the enzyme uses to synthesize telomeres. Last year, the Wistar team solved the structure of a key segment of the molecule - the so-called TRBD domain, where RNA binding occurs. However, the complexity of telomerase has proved a roadblock to determining the enzyme's overall architecture - a goal pursued by researchers worldwide for more than 15 years.

First, the researchers needed to find sufficient quantities of the enzyme for the study. They looked beyond commonly relied-on sources such as humans and yeast and discovered that a gene from the red flour beetle could produce telomerase in copious amounts, and in a stable form. The researchers then used $x$-ray crystallography at NSLS beamline $X 6 A$ a a technique that analyzes the diffraction patterns

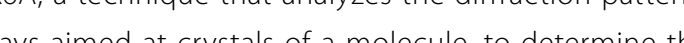
first three-dimensional structure of the enzyme's active region - the catalytic component called telomerase reverse transcriptase protein, or TERT.

The study revealed surprising details, at the atomic level, including the fact that the molecule's three domains are of ganized into a doughnut shape. Knowledge of the structure allowed the researchers to create a model of the enzyme's function, in particular, how it works to replicate the ends of chromosomes - a process critical to both tumor development and the aging process.

— Abbey J. Porter, The Wistar Institute A Gillis, A Schuller, E Ekordalakes, "Structure of the Tribolium castane-
um Telomerase Catalytyic Subunit TERT," Nature, 455, 633-637 (2008).
Model of the atomic structure of telomerase, solved by Emmanuel Skordalakes. a researcher at The Wistar Institute. Shown are the molecule's protein comin beige) and DNA (in red).

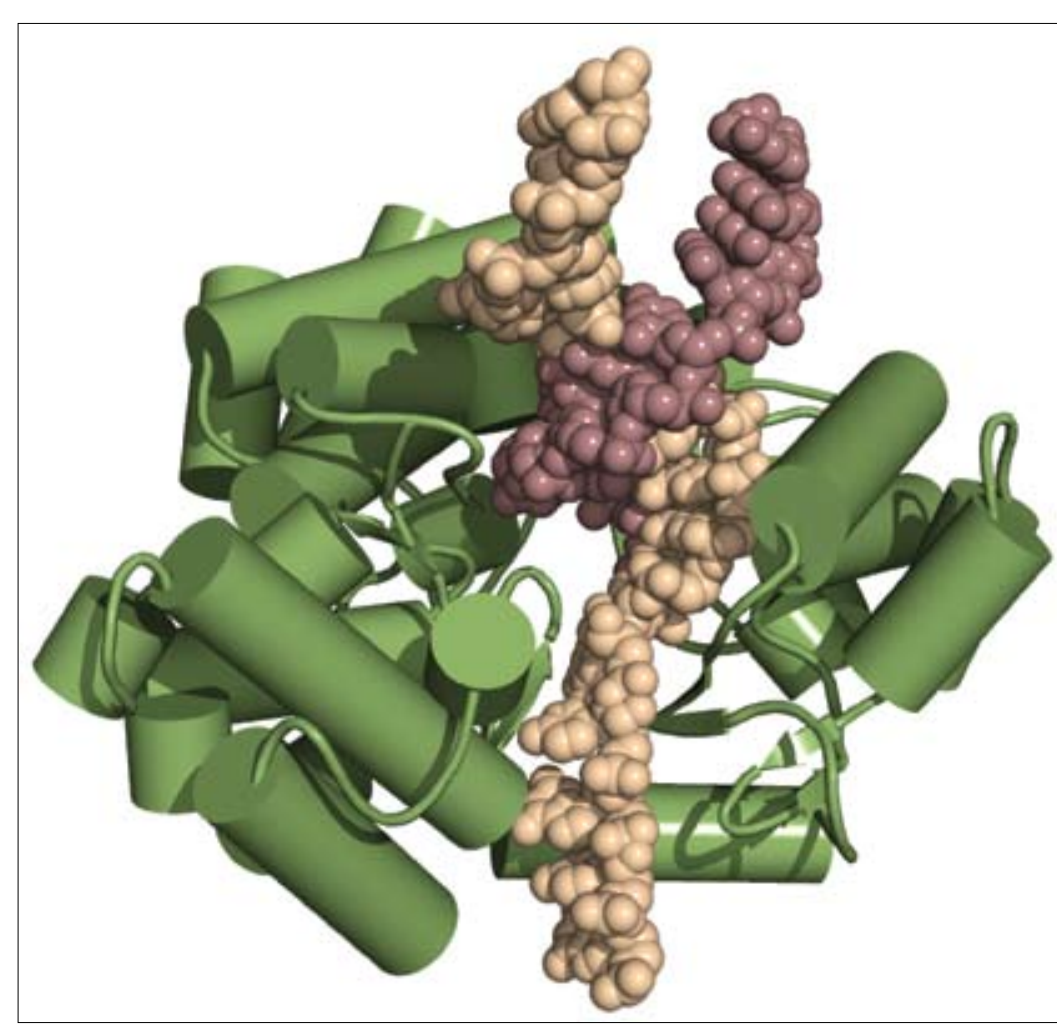




\section{Scientists Determine Drug Target for the Most Potent Botulinum Neurotoxin}

Botulinum neurotoxin - responsible for the deadly food poisoning disease botulism and for the beneficial effects of smoothing out facial wrinkles - can also be used as a dreaded biological weapon. Although experimental vaccines administered prior to exposure can inhibit the destructive action of this neurotoxin - the most deadly protein known to humans - no effective pharmacological treatment exists.

However, scientists at Brookhaven National Laboratory and the U.S. Army Medical Research Institute of Infectious Diseases have taken the first step toward designing an effective antidote to the most potent form of the toxin.

To cause its deadly effects, the botulinum neurotoxin first binds to a nerve cell membrane and eventually cleaves specific proteins, thereby blocking the release of neurotransmitters - Chemicals ner is communication paralyzes muscles, including those that enable breathing.
To block the toxin's action, the researchers designed four "decoy" protein fragments that mimic the structure of the protein to which the toxin ordinarily binds. The toxin attaches itself to the decoy fragments instead of to the cell's protein, which allows neurotransmitters to keep functioning.

The scientists used $x$-ray diffraction at NSLS beamline X29 to in's binding to the cer

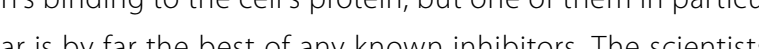
lar is by far the best of any known inhibitors. The scientist' next step in this process is to transform the most effective of the four protein fragments into a drug-like molecule before clinical testing is done. than, "Structure and Substrate Based Inhibitor Design for Clostridium see how the toxin binds to the protein inhibitors They found

D. Kumaran, R. Rawat, M.L. Ludivico, S.A. Ahmed, and S. Swamina-
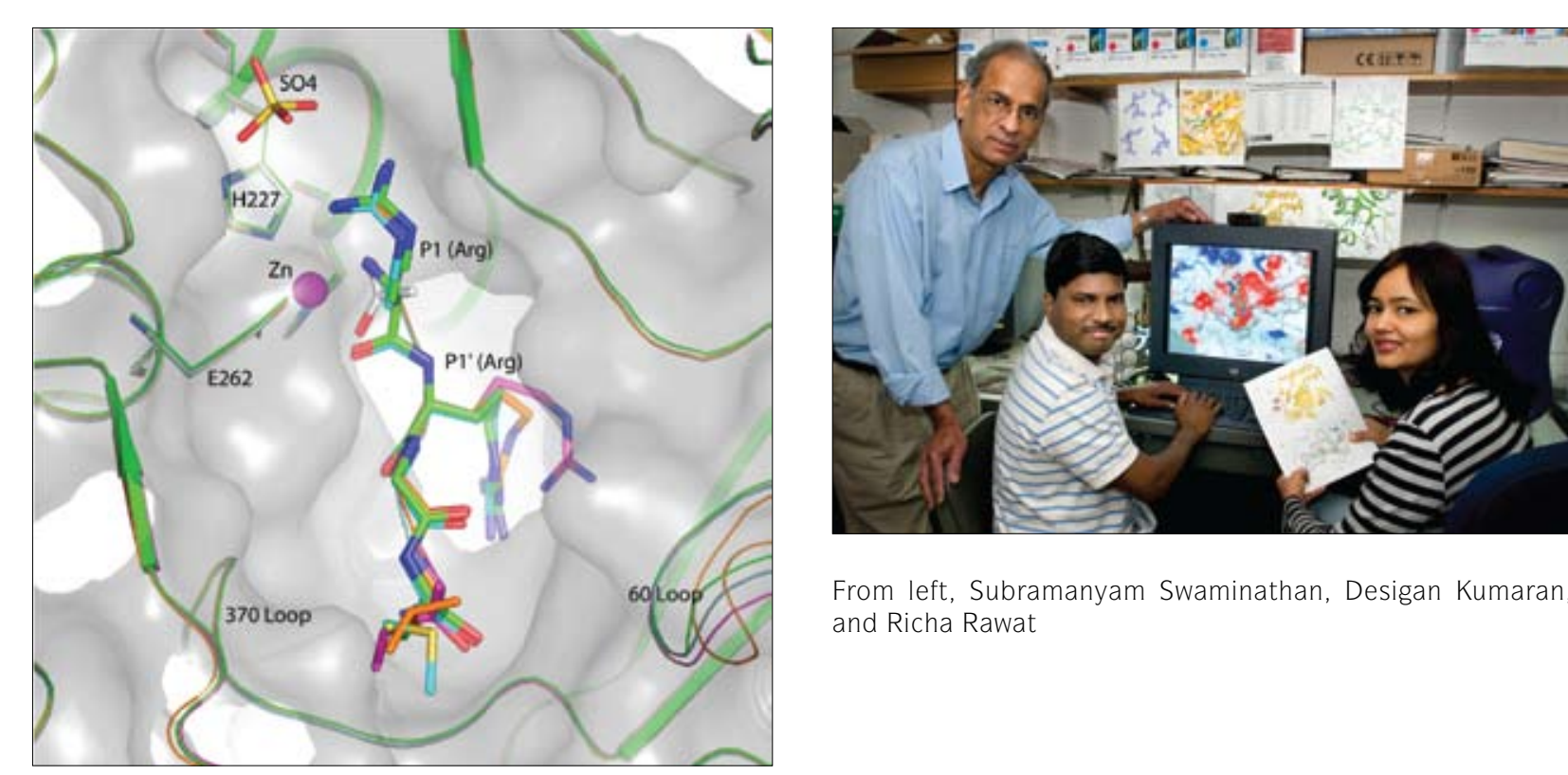

From left, Subramanyam Swaminathan, Desigan Kumaran,

\section{Revealing the Crystal Structure of an AMPK Homologue Core}

Adenosine monophosphate-activated protein kinase (AMPK) is a crucial enzyme for maintaining energy homeostasis in eukaryotes (nucleus-containing organisms ranging from yeast to humans). It is regulated by the intracellular ratio of AMP: adenosine triphosphate (ATP). When this ratio is high, indicating a low-energy state, AMPK is activated, whereas, it is inhibited when the ratio is low. Upon activation. AMPK up-regulates a Wumber of catabolic processes while simutaneouly down-

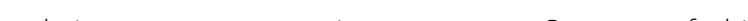
egulating energy-consuming processes. Because of this, AMPK is an attractive drug discovery tanget for obesity and type II diabetes, among other diseases. Using the NSLS, a group of Columbia University researchers were able to determine the structure of the core of the AMPK homologue SNF1 from $\mathrm{S}$. cerevisiae, a species of budding yeast.

AMPK consists of three proteins (subunits $\alpha, \beta$, and $\gamma$ ) that together make a functional enzyme by taking on specific roles related to stability and activity. To find out more about the interactions between these subunits, researchers used $x$-ray diffraction at NSLS beamlines X29A and X4C on samples of SNF1.

Their findings confirm biochemical and genetic data indicating a direct subunit interaction that probably regulates the kinase domain, which plays an important role in numerous cellular processes, including division, proliferation, apoptosis, and differentiation.

Specifically, they discovered that the a-subunit has a regulatory sequence that might control both the inhibition and the activation of SNF1: inhibition could be caused by the regulatory sequence binding to the active site or interacting with lobe of the kinase domain. Once SNF1 is activated, this inhibition is removed by sequestration of the regulatory sequence by the $Y$-subunit, which might represent the activated core of S. cerevisiae SNF1. The authors propose that mammalian AMPK might use a similar regulatory mechanism.

G.A. Amodeo, M.J. Rudolph, and L. Tong, "Crystal Structure of the G.A. Amodeo, M.J. Rudolph, and L. Tong, "Crystal Structure of the
Heterotrimer Core of Saccharomyces cerevisiae AMPK Homologue
SNF1" Noture $449,492(2007)$.

Substrate analogs binding to the active site of Balc424. Suerposed models of RRGC, RRGM, RRGL, and RRCl are shown represented in ribbons embedded on the surface model.

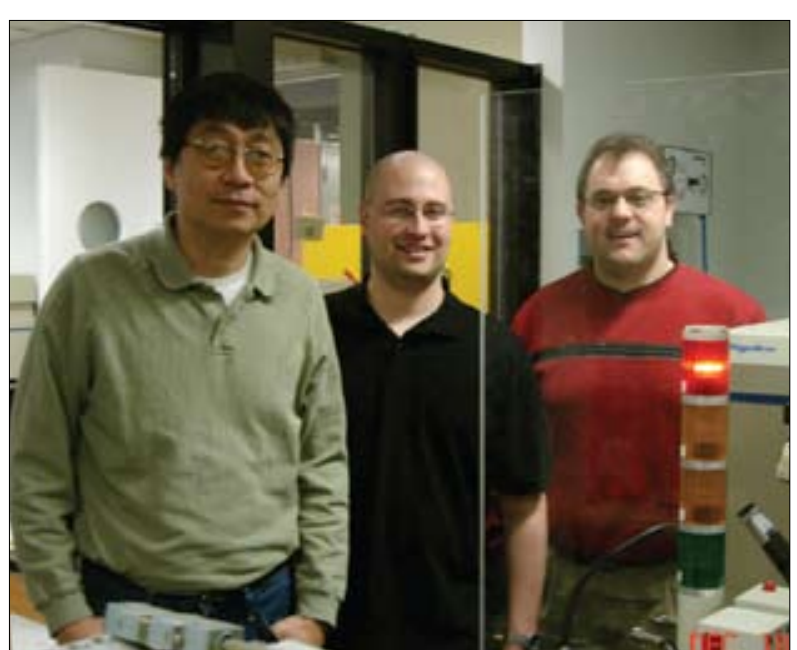

From left, Liang Tong, Gabriele A. Amodeo, and Michael J. Rudolph

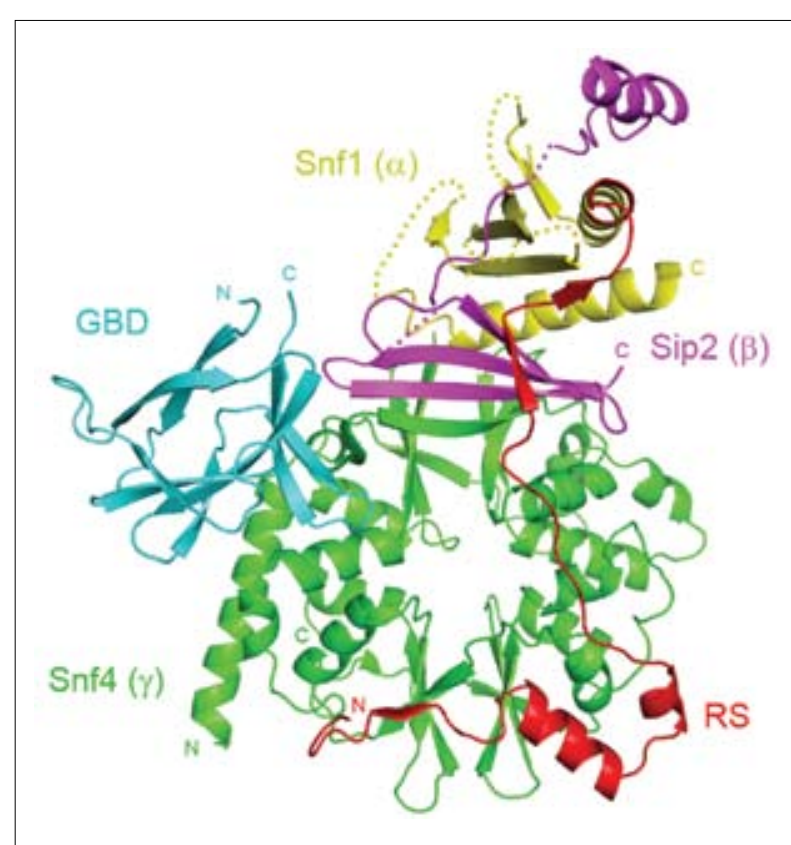

Structure of the SNF1 heterotrimer core 
DNA Technique Yields 3-D Crystalline Organization of Nanoparticles

An interdisciplinary team of Brookhaven researchers, for the first time, used DNA to guide the creation of three-dimension$\mathrm{a}$, ordered, crystalline structures of nanoparticles (particles with dimensions measured in billionths of a meter). The ability to engineer such structures is essential take advantage of the unique properties that may exist at the nanoscale - for example, enhanced magnetism, improved catalytic activity, or new optical properties.

The new assembly method relies on the attractive forces between complementary strands of DNA - the molecule made of pairing bases known by the letters $A, T, G$, and $C$ that carries the genetic code of living things. First, the scientists attach to nanoparticles hair-like extensions of DNA with specific "rec ognition sequences" of complementary bases. Then they mix the DNA covered particles in solution, during which the recognition sequences bind together to link the nanoparticles.

To achieve ordered crystals, the scientists heat the samples of DNA-linked particles and then cool them back to room tem-

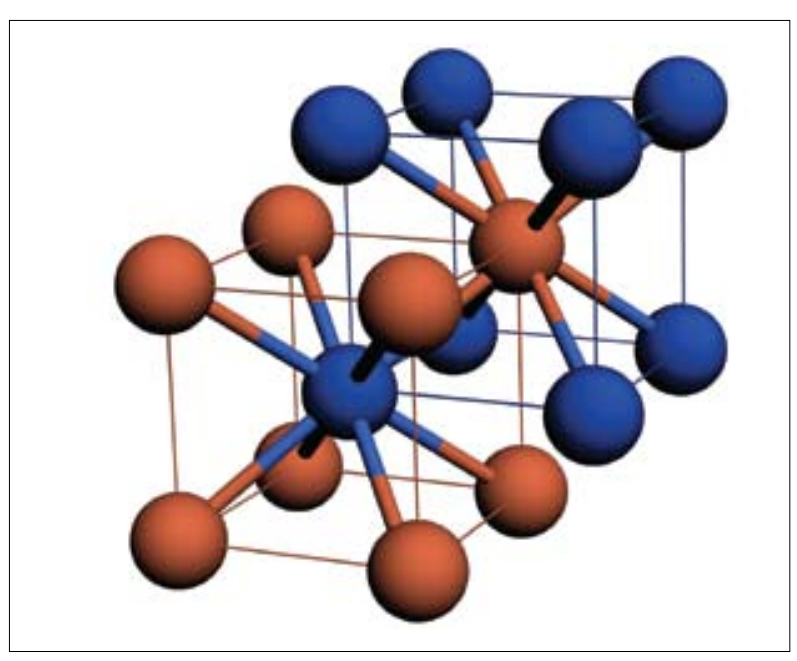

"Body-centered-cubic" unit cells of the 3-D nanoparticle crystals. One type of nanoparticle occupies each corner of the cube and a second type of nanoparticle is located cen form a repeating lattice that extends more than a micron (1.000 nanometers) in three dimensions. perature This allows the nanoparticles to unbind, reshuffle, and find more stable binding arrangements. The team also alters the properties of DNA in order to find a "sweet spot" where a stable, crystalline form would appear.

Small angle x-ray scattering at NSLS beamline X21 and dynamic light scattering and different types of optical spectroscopies and electron microscopy at the Center for Function copies and electron microscopy at the $C$ dered structures and the underlying formation processes.

The resulting crystals are extraordinarily sensitive to therma expansion and remarkably open, which leaves room for future modifications that would enhance nanoscale properties and reveal new classes of applications.

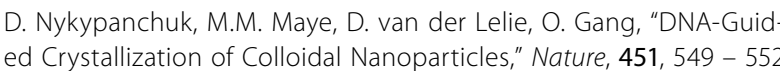
(2008)

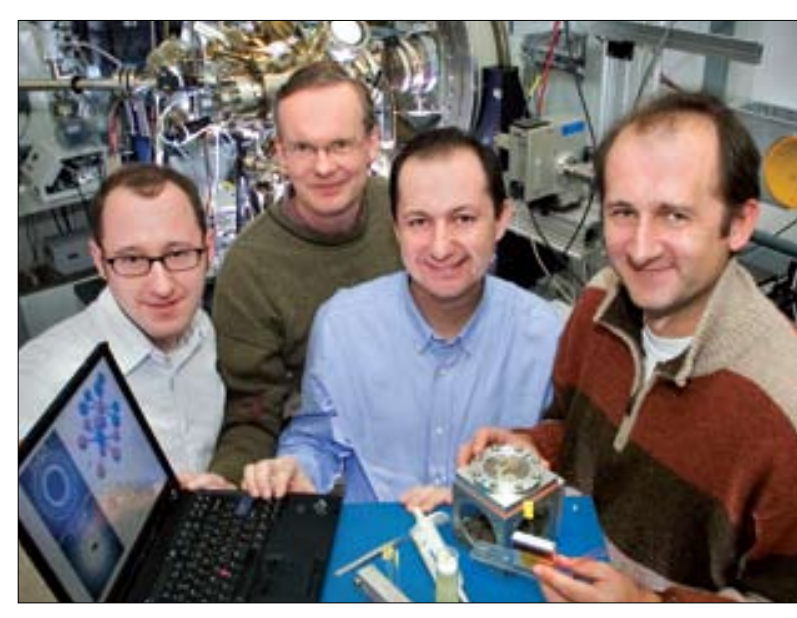

Erom left, Mathew Maye, Niels van der Lelie, Oleg Gang, and Dmytro Nykypanchuk

\section{Investigating Orientational Order of Liquid Crystals}

Orientational order enables technological applications for liauid crystals as positional order does for crystals. Electric-fieldinduced reorientation of the large optical anisotropy of the molecules has been utilized in applications from high-resolution camera viewfinders to large-area monitors. In order to learn more about the behavior of these intriguing phases, three groups, headed by the University of Minnesota, The University of Manchester, and Bordeaux University, collaborted with NSLS scientists to use resonant $x$-ray scattering to measure orientational order in various layered liquid crystal phases.

Because of the chirality or banana-shape of the molecules, the tilted, layered, liquid-crystal phases lack a mirror symmetry, which allows the existence of an in-plane polarization. Depending on how the direction of the in-plane polarization varies, the phases can be ferro- ferri-, heli- or antiferioelectic and an applied electric field can induce changes in orientation or phase.

Each research group made significant discoveries in this field using NSLS beamlines X6B and X19A: while using chiral additives to extend the temperature range of the rod-shaped molecule

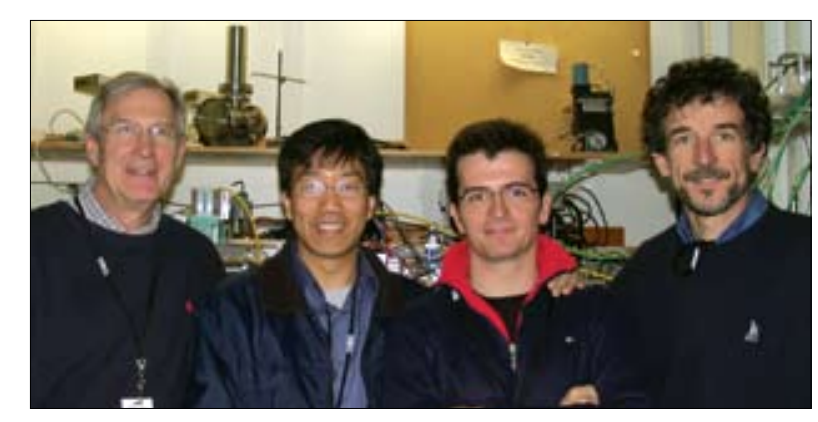

From left, Ron Pindak, Suntao Wang, Paulo Fernandes, and

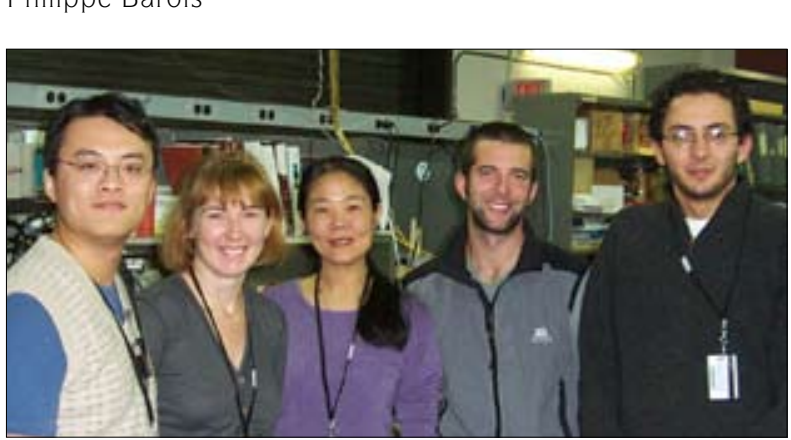
From left, Zengqiang Liu, Helen Cleeson, Winnie Wang, Nich-
olas Roberts, and Shaden Jaradat phases, the Manchester group made an unexpected discovery of a five-state switching sequence for one of the phases under applied fields; the Minnesota group showed a continuous evolution of the incommensurate helical pitch (NHP) through the fourlayer lock-in region in agreement with theory, but also showed a significant change in curvature at INHP=four layers, which is no explained by any theory; and the Bordeaux group made progress determining the structure of the non helical Bz liquid crysta phase that is comprised of fluid layers of achiral banana-shaped molecules stacked in an antiferro-electric sequence.

S. Jaradat, P. Brimicombe, C. Southern, S. Siemianowski, E. DiMasi, Phase Transitions Betwe and F. Gerieelectric and Antiferroelectric Liqu Crystal Structures," Phys. Rev. E, 77: 010701, (2008).

Z.Q. Liu, B.K. McCoy, S.T. Wang, R. Pindak, W. Caliebe, P. Barois, P. Fer-

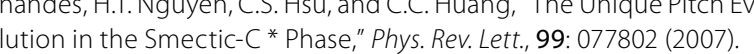

P. Fernandes, P. Barois, S.T. Wang, Z.Q. Liu, B.K. McCoy, C.C. Huang, R. Forbidden Reflections in Liquide, Crystals", Phys Rever Lett. 99: 22780 (2007)

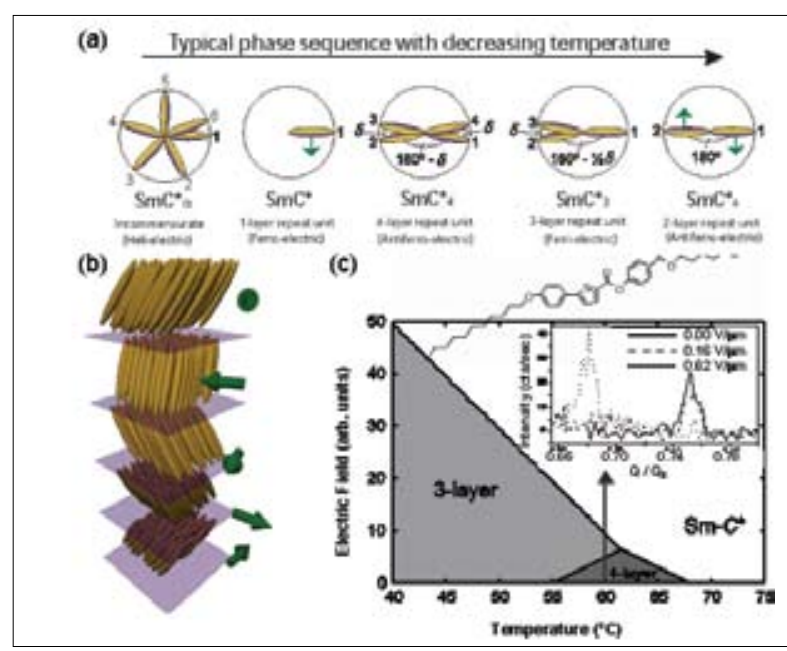

(a) View of the $\mathrm{SmC}^{*}$ phases along their layer normal showing the molecular projections in sequential layers labelled $1,2,3, \ldots$ The in-plane polanization direction is shown by the of the $S \mathrm{SC}^{*}$ phase, the green arrows indicate the helietec tric polarization. (c) Schematic showing the dependence of the induced SmC* phases on applied electric field and temperature. Insert shows the change in resonant $x$-ray scatter- 


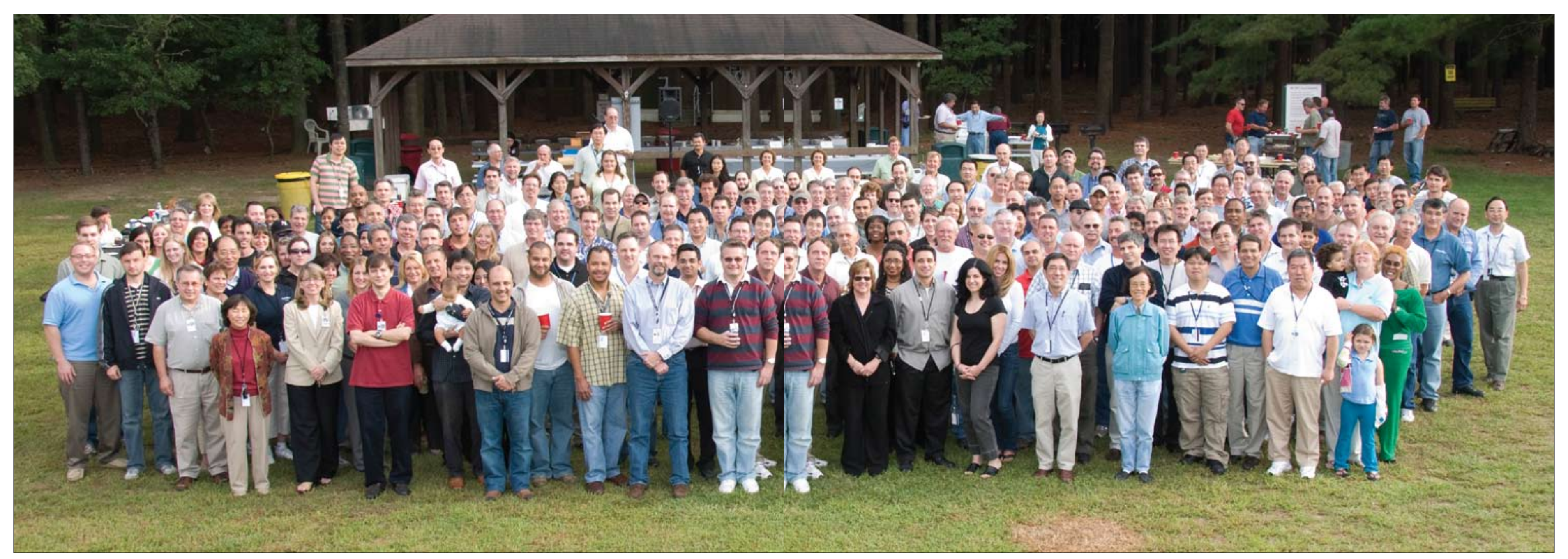

NSLS and NSLS-II staff gather at the Light Sources Directorate 
NSLS Sons, Daughters Become

Materials Science Detectives

"The series of Light Source Directorate planning workshops hosted by the NSLS and NSLS-II were very well attended and received. The users and organizers l've talked to were pleased with the quality of the talks given and the resulting input from current and new users."

\section{2nd Brookhaven Lecture: Jim Murphy}

NSLS Deputy Chairman for Accelerators \& Operations Jim Murphy
gives the 432nd Brookhaven Lecture, "At the Cutting Edge of Bright Beams: The NSLS Source Development Laboratory," focusing on

\section{NSLS Black Diamond Research}

Among Discover Magazine's 2007 Tops

The discovery of the origin of Earth's so-called black diamonds at the Discover Megozine The article, which details "the trends and eve th that most changed our understanding of our world" appears in the magazine's January 2008 issue.

January$$
\text { February }
$$

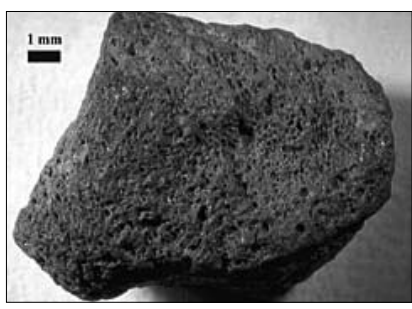

(Above) A black, or carbonado

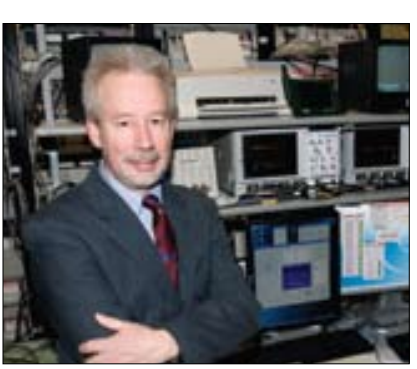

Materials Science and Engineering group at the NSLS and NSLS-II Strategic Planning Materials S
Workshop

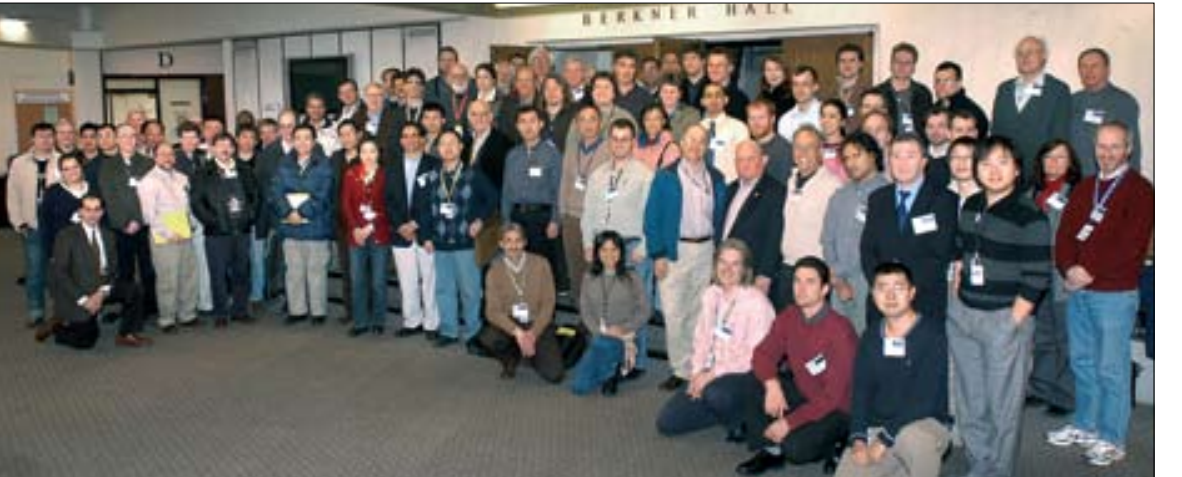

(left) Jim Murphy
NSLS, NSLS-II Strategic Planning Workshops Draw User Input from Hundreds

About 330 current and prospective users from around the world attend a series of Sclentific Strategic Planning Workshops sponsore by NSLS and NSLS-ll meant to help guide the future of light sources and engineering, earth and environmental sciences, chemical and energy sciences, hard condensed matter and materials physics, and soft and biomolecular materials - the workshops were coordinated with a related sthy of seven NsLS-1 workshops based on experment for both facilities. the group developed the framework for a National Science Founda-
NSLS Users Earn Prestigious Honors

Four users are honored for scientific achievement, including: Univery of Delaware professor Jing guang Chen, wint if he 2008 AwaNew York; Florida State University researcher Linda Hirst, recipient of a National Science Foundation Faculty Early Career Developmen grant for research involving cell membranes; Camegie Institution of can Geophysical Union's Inge Lehmann Medal; and Brookhave chemist José Rodriguez, who received HENAAC's Outstanding Technical Achievement Award.

Historically Black Colleges and Universities Faculty, Curriculum

Professors from the NSLS Historically Black Colleges and Universities
(HBCSU User Consortium meet to further the involvem ent of $H B C U$ (HBCU) User Consortium meet to further the involvement of $\mathrm{HBCU}$ students and faculty at the NSLS. In addition to planning for the sec-
ond annual HBCU-NSLS workshop and touring the experiment floor tion proposal to create a new curriculum that emphasizes synchrotron research and instrumentation for $\mathrm{HBCUs}$.

March

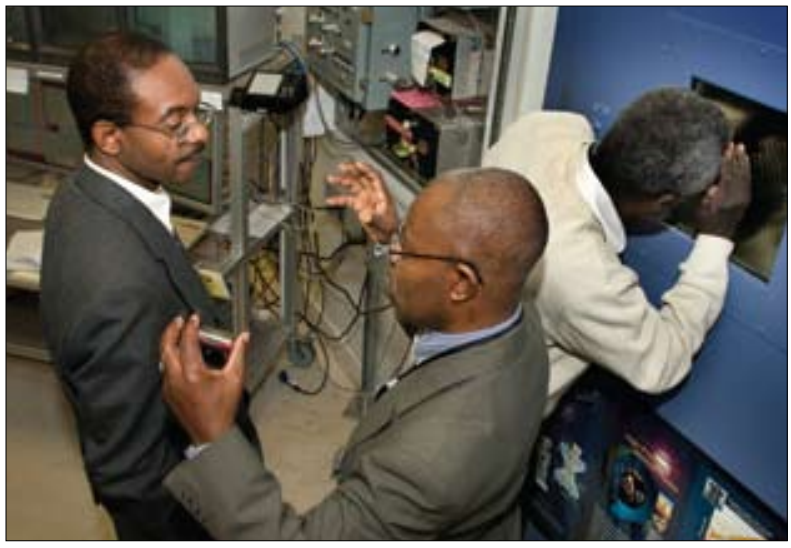

Scouring the experiment floor for clues, about 50 children of NSLS Uss and staff members take on the role of scientific detectives as part of the national Take our Sons and Daughters to Work Day

Brookhaven Scientists Receive Hall of Fame Award for Microbeam Radiation Therapy

Brookhaven scientists F. Avraham Dilmanian and James F. Hainfeld, together with Gerard M. Morris, a guest researcher at Brookhaven from Morvus Technology Ltd., Wales, win The Long Island Technology Ha novation for the individual. The patent is for microbeam radiation therapy, which, as first implemented, uses the NSLS to produce array 5 of parallel, very thin $x$-ray beams to irradiate and destroy malignan Iumors, while keeping normal adjacent lissues fiee from ham.

Al Boerner, Mike Buckley Receive

Team Sitewide Safety Stewardship Award

NSLS employees Al Boerner and Mike Buckley receive a team 2007 Sitewide Safety Stewardship Award for their efforts to ensure tha practices.

RapiData Celebrates 10 Years of Teaching Crystallography Skills

One of the most widely recognized courses at the NSLS - RapiDatadesigned to introduce participants to the best and latest equipments and techniques for macromolecular x-ray crystallography.

April

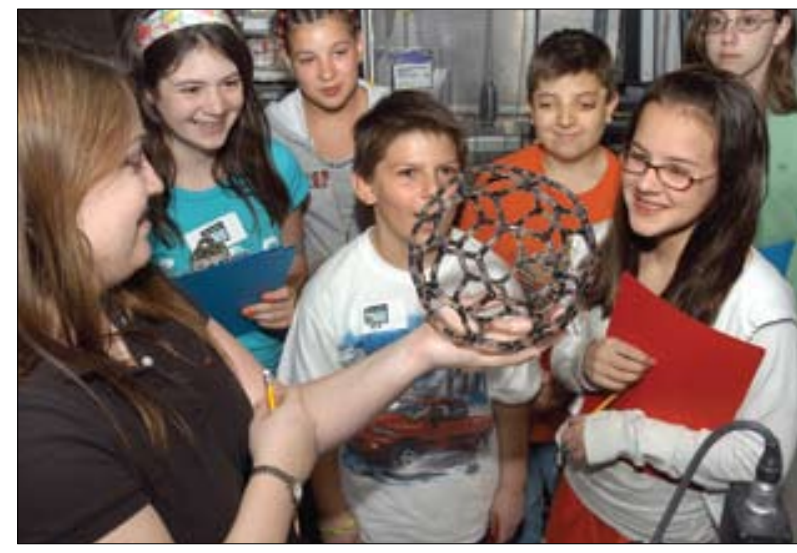

The HBCU User Consortium professors explore the NSLS experimental floor
Participants in the NSLS Take our Sons and Daughters to 
2008 NSLS-CFN Joint Users' Meeting

About 400 people attend the third joint meeting of the NSLS and Center for Functional Nanomaterials user communities, which focused on defining the role of synchrotron science and research at the nanoscale for Brouk haven and he nathon at large. Penary speakers Director for Science Programs Pat Dehmer Associate Laboratory Dector for Light Sources Steve Dierker, CFN Director Emilio Mendez, and NSLS Chair Chi-Chang Kao.

\section{UEC Community Service Awards go to Jingzhu Hu,} Randy Smith

The NSLS Users Executive Committee presents two Community Service Awards: one to Stony Brook University's Jingzhu Hu and the for service, inotion, and dedication to users of the NSIS. gV.

Eli Sloutskin Receives 2008 Julian Baumert Award

Harvard University physicist Eli Sloutskin receives the 2008 Julian Baumert Ph.D. Thesis Award for his work on liquid surfaces and the searcher who has recently conducted a thesis project that included measurements at the NSLS.

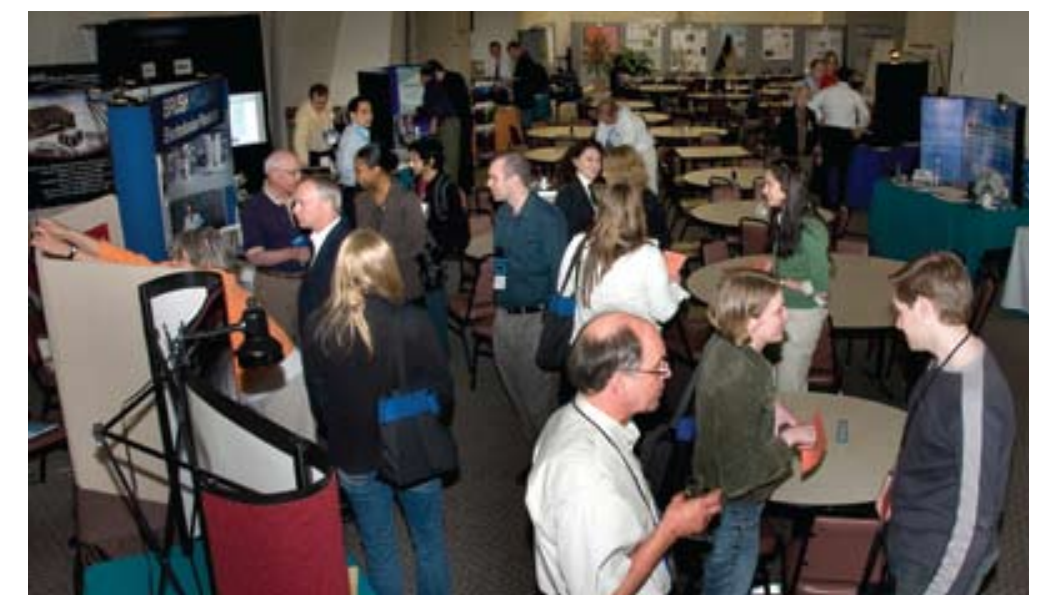

Participants in the 2008 Joint NSLS/CFN Users' Meeting mingle at the poster and vendor session.
Gabriella Carini Wins IEEE Young Engineer Award NSLS researcher Gabriella Carini wins the 2008 Institute of Electrica and Electronics Engineers (IEEE) Long Istand Section's Outstanding

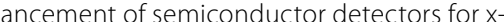

BioCD-2008: Synchrotron Radiation Circular Dichroism Spectroscopy of Proteins and other Biomolecules

A weeklong workshop focusing on circular dichroism (CD) spectrosdents to the NSLS CD is particularly useful for studying the structure of proteins, DNA, RNA and other biopolymers in solution, and this was a major focus of the workshop.

\section{Annual Crystallization Course}

\section{Draws More Than 40 Participants}

Forty-five researchers from across the country and the world gathe liztion from deascuss and learn about membrane protein crystal"Membrane Protens" workhop. Caried out by about 20 crystiIzation experts and volunters, the sixth annual course includes 10 hands-on tutorials for participants to choose from.

"The hands-on aspect to this course is what makes it such a success We want to provide a basic background for beginners in the field, but then give them the opportunity to develop skills in the lab."

- Vivian Stojanoff, NSLS physicist \& crystallization workshop organizer

NSLS Hosts 2nd Annual Historically Black Colleges

xpanded in both attendance and duration, the 2nd annual NSLS

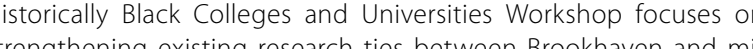
hority-serving schools as well as establishing new relationships The workshop attracted 17 participants from nine institutions to learn (a)

\section{NSLS Summer Sunday Draws}

Record Number of Visitors

More than 800 community members attend the NSLS Summer Sunfacility The NSLS was the fist of five frellties to be show oared the lab-wide program, during which the public is invited to explore some of Brookhaven's most exciting science.

\section{NSLS Users Rack Up Numerous Awards}

Six NSLS users win a number of prestigious honors. They include Program R\&D Award: Cold Spring Harbor researcher Leemor Joshe National Center for Scientific Research (CNRS) scientist Ricardo (Ric) Lobo, recipient of the Ludwig-Genzzl-Prize; Carnegie Institution of Thein member of the Royal Society of London: adjunct Stond arook professor David Sayre who won the 2008 Ewald Prize; and Bar-lln University doctoral student Lilach Tamam, who received one of two best poster awards at the intemational conference on Surface $x$-ray

\section{NSLS Synchrotron Catalysis Consortium}

Funding for the Synchrotron Catalysis Consortium - an organization of the unique investigation toots as sis besearch by taking advantage through the US. Department of Energy's Office of Basic Energy S ences. The $\$ 1$ million award lasts for three years.
July

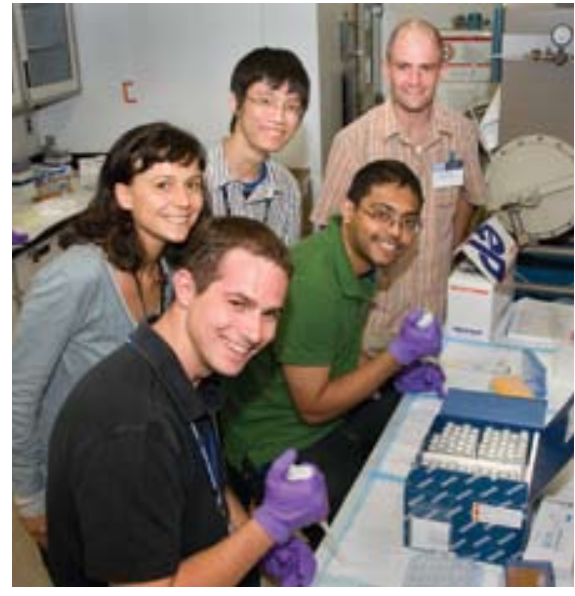

Participants in the 2008 "Crystallization:
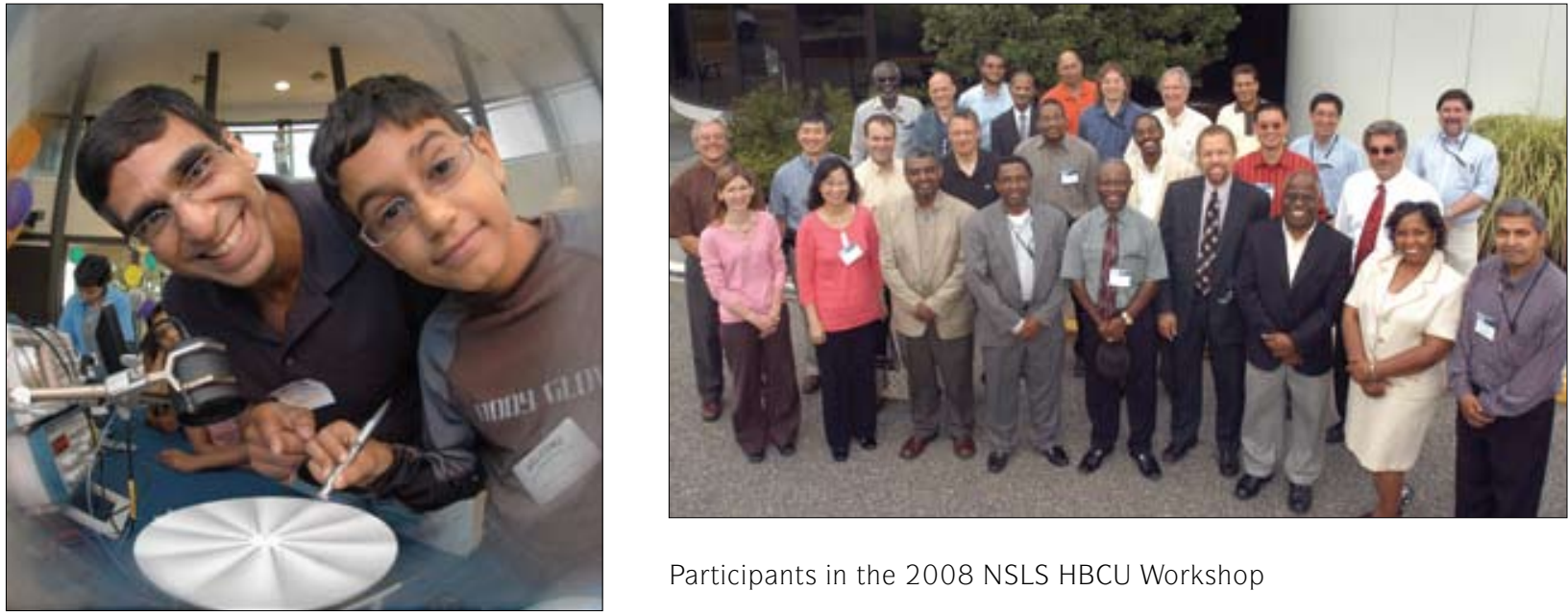

Participants in the 2008 NSLS HBCU Workshop 
"This grant will allow us to explore threedimensional integration techniques for smart two-dimensional detectors. That translates into higher detector sensitivity, superior image quality, and lower acquisition times."

\section{- Pete Siddons, Head of the NSLS Detector Group}

NSLS Summer Student Projects Range from Crystallography to Detector Development

Eleven college students perform summer research projects at the NSLS, working with scientists and engineers from the department in
research fields ranging from medical sciences to electrat and me chanical engineering. In addition to their research projects, students had the opportunity to attend scientific lectures, tour Brookhavent's research facilities, and participate in numerous social activities.

\section{DOE Awards NSLS \$2.2 Million}

\section{for Advanced X-ray Detector Development}

The NSLS receives a \$2.2 million, three-year, renewable grant from the Department of Energy's Office of Basic Energy Sciences to develop the next gentrationof advanced $x$ Tay delectors for synchrotion the possibility fof applying three dimensional integration techniaves for "smart" two-dimensional detectors.
Employees Enjoy Food, Recognition

at Light Sources Directorate Awards Barbeque

The annual Light Sources Directorate Awards picnic, hosted by NSLS tor for light Sources includes a barbeque, clambake, and awards to honor NSLS and NSLS-ll employees for another year of smooth and productive operation

International Collaborations, Funding Help Open the Secrets of Radiation-Protective Drugs

Gulgun Cakmak, a graduate student from the Middle East Technical University, uses the NSLS to study the molecular effect of a popular. To conduct her research she received support fram numerous sauts. es, including: a $\$ 9,000$ scholarship from the Scientific and Technica Research Council of Turkey; a $\$ 2,000$ grant from the U.S. Department of Energy's Cooperative Research Program for SESAME, which stand the Middle East: and \$2,500 from the

Nobel Prize in Chemistry Linked

to NSLS Protein Work

Two American scientists and a Japanese researcher win the 2008 protein that has become a ubiquitous tool in bioscience Their work centered on a protein, found in a type of jellyfish, that glows green under ultraviolet light. Known as green fluorescent protein (GFP), this sides of living cells or whole animals and watching mobectese act in real time The structure of GFP was first reported in the journ Science in 1996, partially as the result of $x$-ray studies at the NSLS.

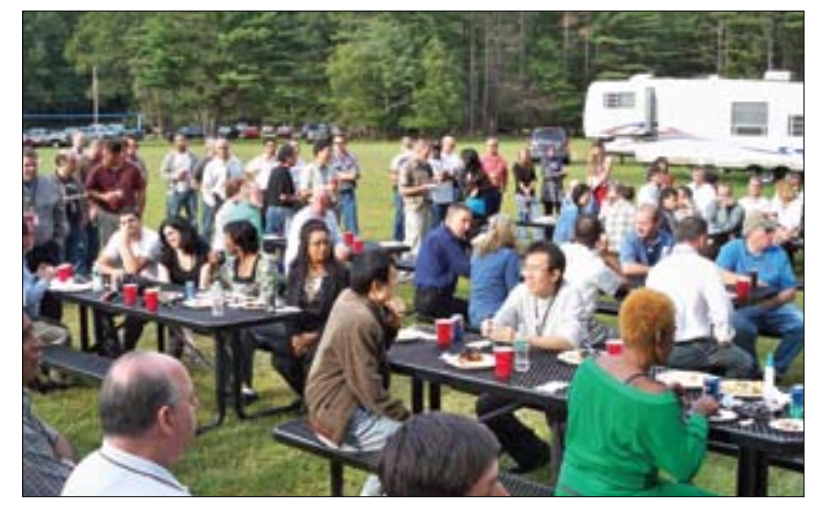

Light Sources Directorate employees celebrate another

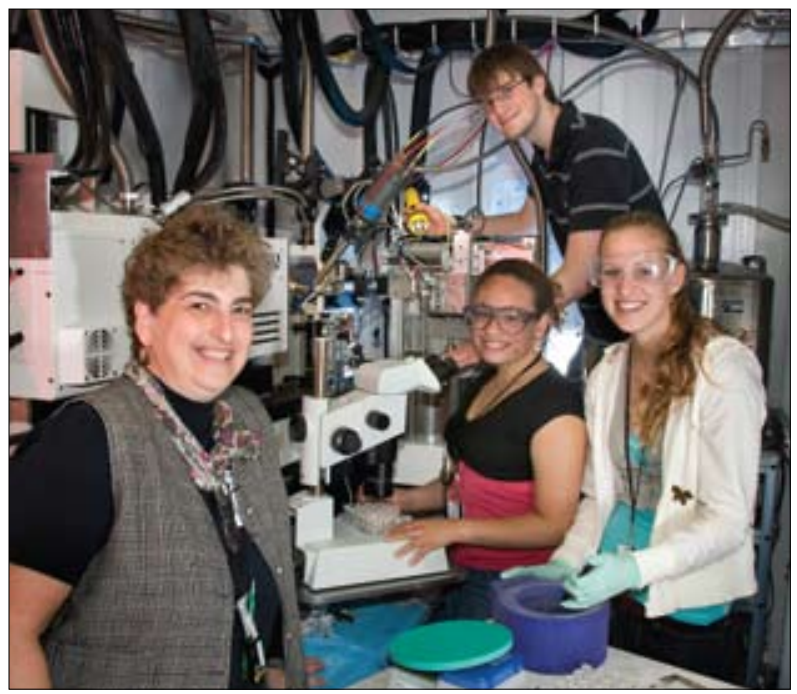

Three of the 11 college students who worked at the NSLS in
summer 2008 pictured with NSLS physicist Vivian Stojanoff.

NSLS Beamline Used as Test Bed for NASA Detector Using powerful x-rays produced by the NSLS as a calibration tool, a team of researchers from NASA's Goddard Space Flight Center tests

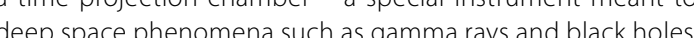

\section{Site Preparation Work Begins
For NSLS-II Ring Building}

Site preparation work for construction of NSLS-II begins. The project. expected to be completed over the next six years, will include the
construction of conventional facilities, installation of the accelerator and experimental equipment and the startup, testing, and commissioning of all systems.

High-Pressure Workshop Highlights Advances in Field, Beamline Scientists' Dedication

An NSLS-held workshop on "Advances in High-Pressure Science UsIng Synchrotron X-Rays" is attended by more than 50 scientists, postcoctoral fellows, and st is a

442nd Brookhaven Lecture: Elaine DiMasi

NSLS physicist Elaine DiMasi gives the 442nd Brookhaven Lecture Which Came First, the Eggshell or the Egg? - Answering Riddles organisms form sturdy materials such as bones, mollusk shells, and other structures.

November

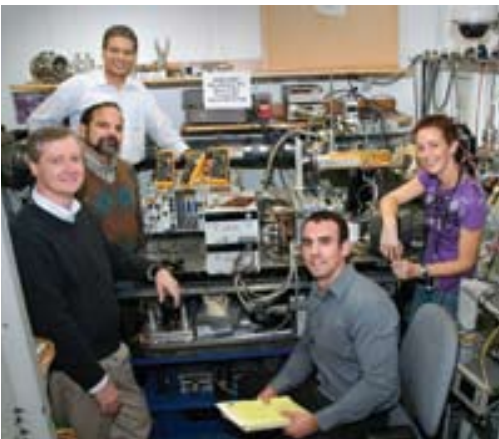

Counter clockwise researchers Syed Khalid (NSLS), C.J. Martoff (Temple University), Kevin Dion (Temple University), and Joe Hill (NASA).

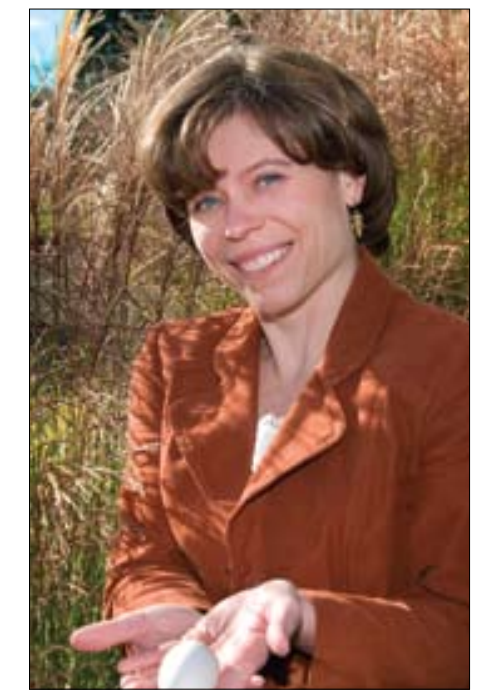

Elaine DiMasi
"Naturally Obsessed" Documentary

Wows NSLS, BNL Crowd

Brookhaven employees and community members are treated to tw pert at the NSIS Recorded over a thee-yer span the do cuned eatures Columbia University student crystallographers mentored by NSLS user Larry Shapiro as they study a protein known as AMP-actvated protein Knase (AMPS), which conld reveal a new pay

Chi-Chang Kao Named Founding Directo of New Photon Science Institute

Chi-Chang Kao, a physicist and Chair of the National Synchrotron Ligh Sciences Institute (UPSI) an interdisciplinary resers soint Pho meant to exploit the properties of advanced light sources to address challenging problems in science and technology. Kao, who will continue to serve as Chair of the NSLS, will be responsible for developing the scientific programs w
construction of the building.

Introduction to XAFS: Experiment,

Theory, Data Analysis

The short course in $x$-ray absorption fine-structure spectroscopy ners, included beamline experiments, lectures by experts in the field, tutorials, and data analysis sessions. 


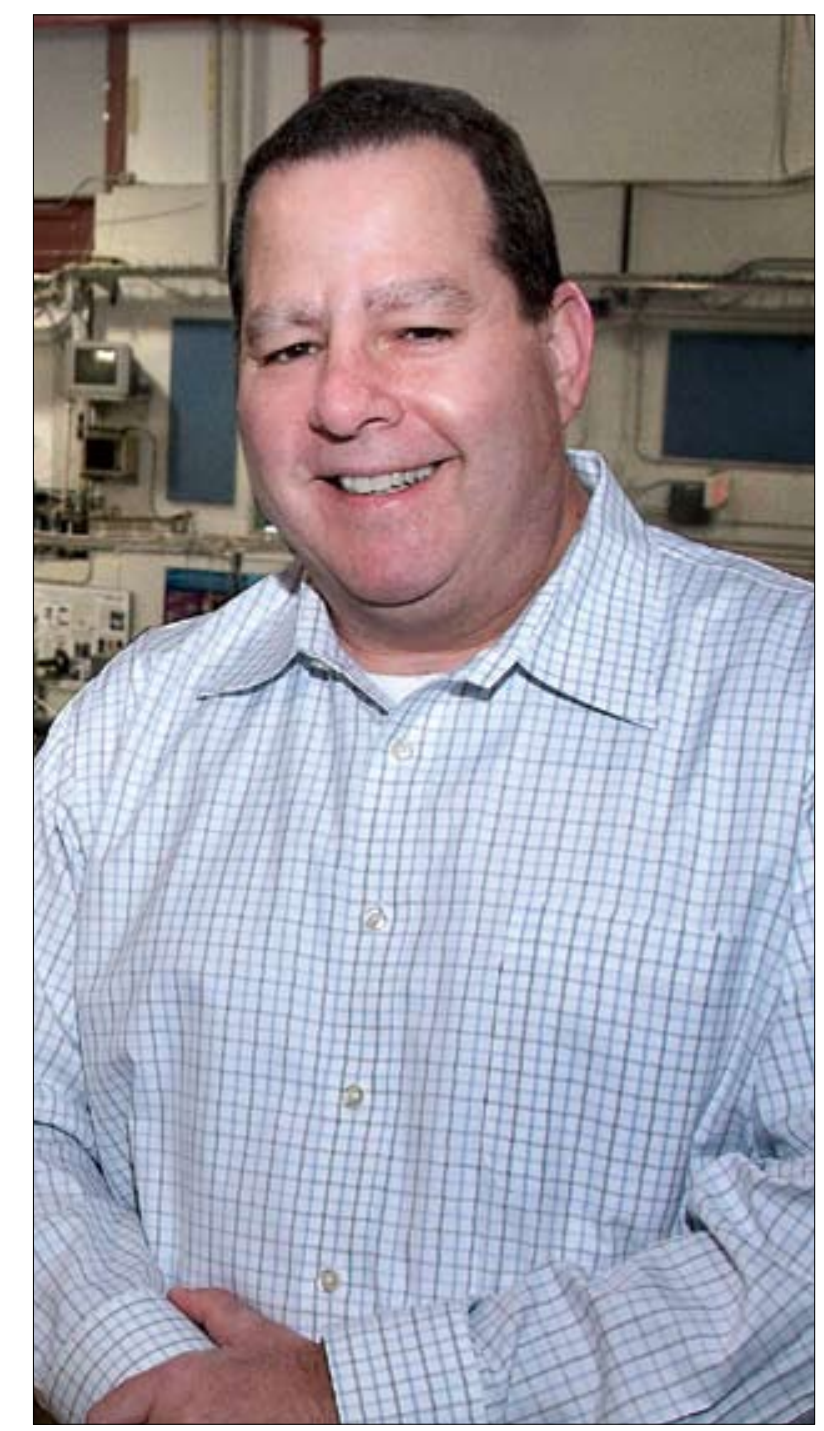

Everyone was busy in 2008 and there was considerable Environment, Safety. activity through-

- The NSLS maintained independent registration with the Environmental Management System (ISO 14001) and the Occupational Health and Safety Assessment Series (OHSAS) - an important goal for the Laboratory.

- An audit of the management of nanoscience risks was completed by a Department of Energy (DOE) Environmental, Safety, Security, and Health team. The NSLS scores were excellent and the department program was recognized as the best at the Laboratory.

- Personnel protective equipment requirements for work with cryogens were defined through a detailed risk assessment and regulatory analysis that has become the basis for these requirements throughout the Laboratory.

- A detailed oxygen-deficiency hazard analysis was completed for work with cryogens within the macromolecular crystallography hutches, yielding recommendations for important control improvements and allowing for proper risk classification of these facilities.

- Training in "Human Performance" principles was initiated and completed for more than 90 percent of the staff. Incorporation of these principles to work operations has begun and an implementation team has been created.

\section{Andrew Ackerman}

- Inspection of electrical equipment for compliance with Nationally Recognized Testing Laboratory requirements was advanced for facility and user equipment. The department is on schedule for completing the remaining required inspections and a robust process to capture equipment entry as part of the user experiment program is established.

- The management safety observation program was much improved with excellent involvement from the department management.

The NSLS wet chemistry laboratories were cleared of excess or legacy equipment and a program for completing detailed experiment safety review documents was established.

Several performance measures are tracked to follow the effectiveness of the ESH\&Q programs. In 2008

A detailed ESH Improvement Plan was generated with 39 targets assigned to individuals and tracked within the electronic NSLS Family Assessment Tracking System. Progress on all was good.

- Training compliance was excellent and emphasis on Human Performance training was met with staff support and cooperation.

Numerous internal and external audits resulted in few findings and the department response was timely and organized.

Waste generation continues to be low and well managed.
- Personnel exposure to chemical and physical hazards was well controlled and well below allowable limits.

- Radiation exposure remains very low with a collective dose of approximately $70 \mathrm{mRem}$ for the year measured through use of some 2,300 personnel dosimeters.

- A greater number of routine workplace inspections were completed than last year, with each inspection resulting in some findings, efficient stoff response, an correction.

- Injuries were all minor, with no "days away, restricted transferred" (DART) cases, only one "recordable" case, and seven first-aid cases.

- And three events - two that involved equipment failure and resulted in smoke conditions, and one that involved poor transfer of liquid helium with a first-aid injury were analyzed for cause and lessons to be learned.

There is more to report, but the summaries above provide a good overall picture of the department's activity and performance in ESH\&Q. The NSLS programs are acknowledged throughout the Laboratory and by the DOE as excellent, and there is much reason for pride in staff and user attention to keeping the facility a safe place to work. Good performance indicators and well-managed programs are important, but what is most important is that we completed an enormous amount of science last year without significant injury or environmental insult:
"The NSLS safety programs are acknowledged throughout

the Laboratory and by the DOE as excellent, and there is much reason for pride in staff and user attention to keeping the facility a safe place to work." 


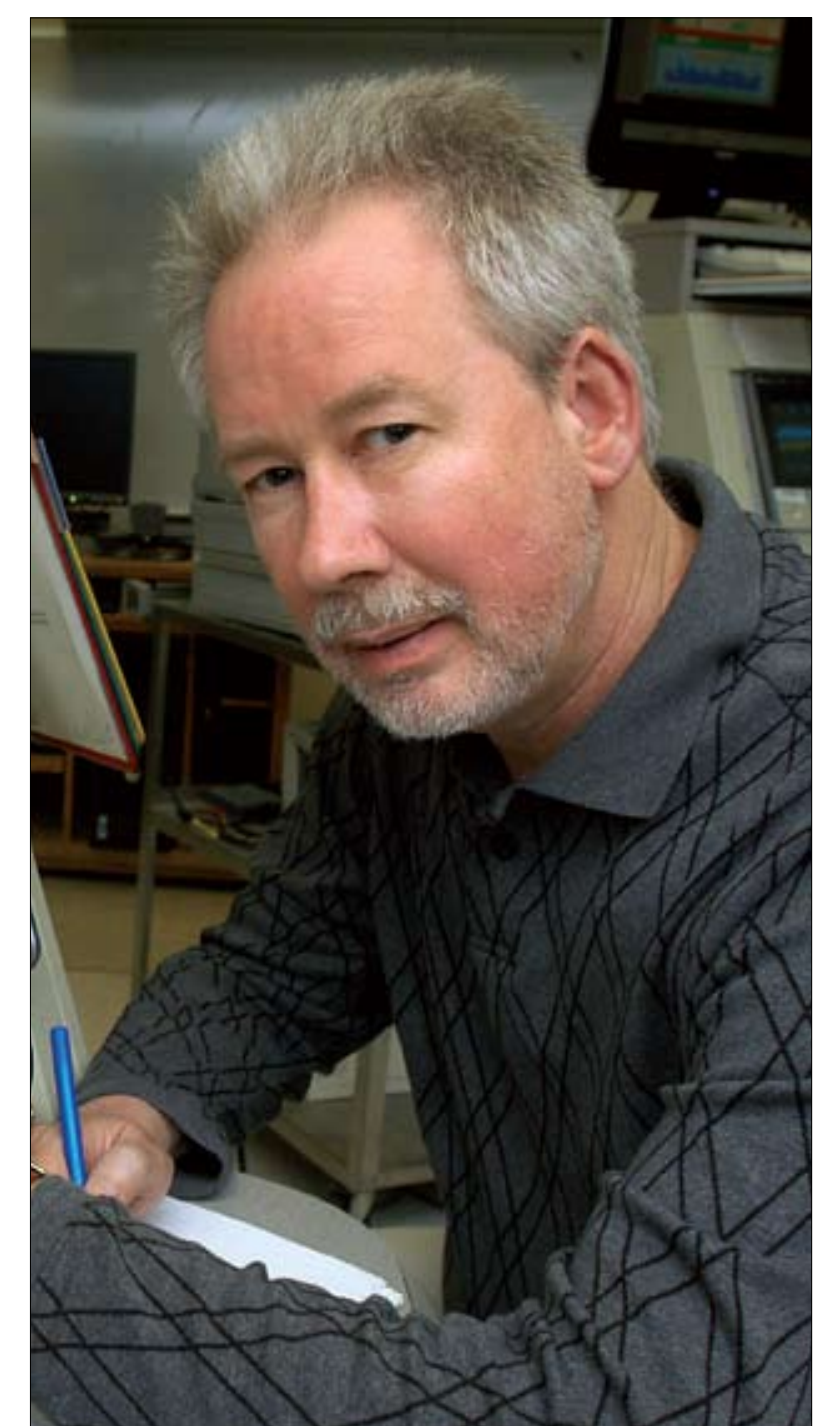

\section{James B. Murphy}

In calendar year 2008 (CY08), our users enjoyed continued robust NLLS operation of our two storage rings. The Vacuum Ultraviolet Ring (VUV) remained strong at 97.5 percent reliability and the $X$-Ray Ring reliability came in at 93.2 percent. Both statistics handily beat our Department of Energy (DOE) requirement of greater than 90 percent reliability. In addtion, our users also benefited from our excellent availability in both rings (VUV 110.5 percent, X-Ray 105.7 percent). Availability is a resul of unscheduled hours coming fiom early

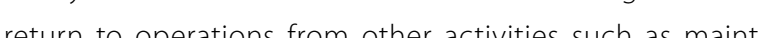
nance

The budgetary continuing resolution enacted by the federa government impacted the NSLS funding profile, which resulted in an additional shutdown period starting in August and ending in late September. The NSLS staff took advantage of this shutdown period to install the $X 9$ mini-gap undulator (MGU) and replace two kicker drivers responsible for bumping the electron beam into the Booster and out to the X-Ray transport line. To provide additional beam time to the user community, we extended operations past the Thanksgiving holiday and started the winter shutdown in both rings on December 8.

\section{Injection System}

Many of the activities in the operations group have been centered on improvements of the reliability of the injection system. In response to an issue raised in the 2006 Machine Operations Reliability Evaluation (MORE) review, a considerable effort was directed toward redesign and replacement of four pulsed magnet drivers in the Booster Kicker magnets are required to offset the orbit of the electrons as they are iniected into and extracted from the accelersors. Pulsed magnet drivers magnet divers provide the kickermagnets with a current on a de a meres (A) in pulses lasting several tens of microseconds to generate fields of a few kilogauss that deflect the electron bunches into the Booster synchrotron and then out of the Booster into the extraction transport lines at the precise moment in time Four drivers were dentified in the MORE review as a vulnerability for reliable operations due to their age and the difficulty to repair them. Our operations team designed and built the first kicker driver, which is actually two drivers in one cabinet, and installed it in the Booster Ring during the August-September shutdown period. One half of the driver is responsible for kicking the electron beam into the Booster from the Linac and the other half kicks the beam out of the booster and into the X-Ray transport line. The careful design, fabrication, and testing proved worthy, giving us a very swift and smooth $X$ Ray start-up in September. The remaining two kicker drivers both responsible for kicking the beam from the Booster into the VUV transport line, were installed during the 2008 winter shutdown. Since the Booster provides electron beams to both rings, we all benefit from these important upgrades to our equipment.

Since timing of the kicker magnet pulses is so critical to successful storage ring injection, a kicker timing monitor system was developed and put into operation just prior to the spring 2008 shutdown. Because errors both in timing and pulse shape can cause a failure to inject electrons, the new LabView-based system allows for monitoring of the kicker pulses themselves as well as their relation to each other The new system also gives us the abilit to store ock. The new system a so gives us the ablity to store al which will prove extremely valuable for troubleshooting injection timing. The display and control of this new too has become part of the center operator console for use by our staff of machine operators.
"In 2008, our users enjoyed continued robust operation of our two storage rings. The Vacuum Ultraviolet Ring remained strong at 97.5 percent reliability and the X-Ray Ring reliability came in at 93.2 percent. Both statistics handily beat our Department of Energy requirement of greater than 90 percent reliability."
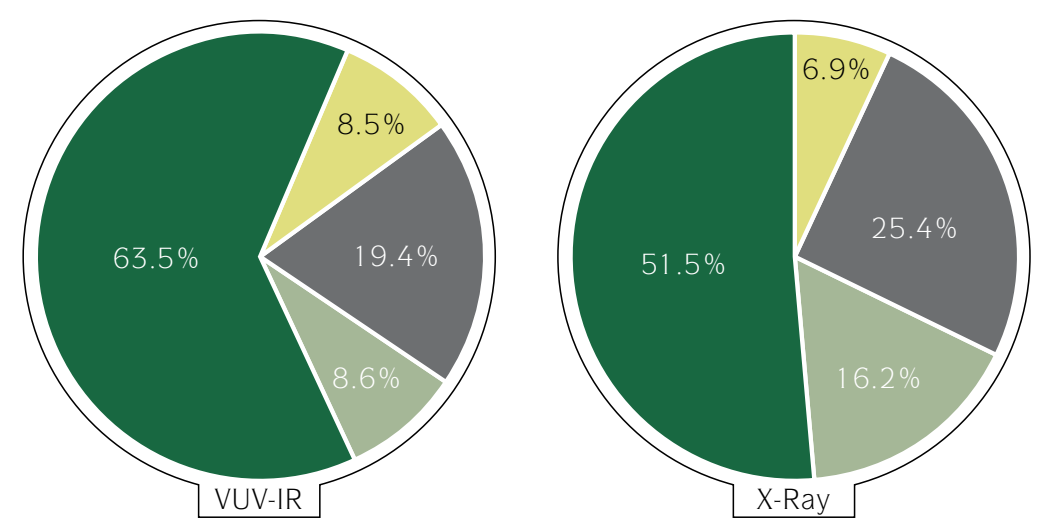

08 machine activities

Scheduled Operations

$\square$ Maintenance

$\square$ Other - Studies, Com/Con, Holiday, Interlock 
As a hedge against future klystron failures, we took proactive steps to develop a procedure that allows us to fill the two storage rings with only two of the three klystrons in operation. The injection energy from the Linac to the Booster was lowered from 120 mega-electron volts (MeV) to $80 \mathrm{MeV}$. Magnet settings in the Linac-to-Booster transport line were scaled down proportionally to the beam energy, the Linac timing was moved 15 milliseconds ( $m s$ ) earlier and the low energy part of the Booster ramps, trims and injection kickers were modified We were able to obtain a current of $15 \mathrm{mAin}$ the Booster at the top energy and extracted it efficiently to the transport line. The successful development of this procedure will minimize the downtime due to a failed klystron in the future. This effort goes in concert with another effort being undertaken in 2009 to install new radiofrequency (RF) windows in the waveguide between each klystron and the corresponding Linac tank With these windows in place, the Linac can still operate while the failed klystron is replaced and conditioned.

Our efforts to maintain a stock of spare Linac klystrons continued in 2008. At the end of the year, a new vendor capable of rebuilding our klystron tubes was identified. The new vendor has promised a much quicker turn-around than we have ever experienced in the past. Thanks to this very quick turn-around, we look forward to the receipt and testing of the rebuilt klystron tube in the first quarter of 2009 .

We used the Methodical Accelerator Design (MAD) tools to optimize the extraction parameters, and achieved a more than 10 percent reduction on the extraction loss and about 50 percent reduction on the shot-to-shot fluctuation in established that a significant amount of Booster beam is lost in a 2-meter region around the extraction area, where we have limited steering ability. To address this, we designed, built, and tested a compact C-frame trim magnet that provides about 1 milliradian (mrad) kick in both the horizontal and vertica directions that last for about $10 \mathrm{~ms}$ during the X-Ray extraction. This has been installed at the very beginning of the Booster-to-X-Ray down and has been undergoing commissioning.

\section{VUV Ring}

A series of VUV Ring feasibility studies to provide beamline
U4B users with fast-switching, elliptically polarized radiation has been performed. Polarization was controlled by moving the vertical orbit at the U4B source point (dynamic orbit bump), thus effectively moving the beamline detector in and out of the bend plane. Control of the bump was performed by extending the algorithm used in the VUV Ring digital orbit feedback. Achieving the required levels of polarization requires rather substantial (about $1 \mathrm{~mm}$ ) orbit variation at the U4B source point. At the same time, much sticter tost af the ring. Meeting these reau turns out to be the resuts and user feng g control systems problem. intial results and user feedback were very encouraging; up to 5 hertz switching rates appear possible without significant hardware modifications. These studies will continue as the beamline is being equipped with additional photon beam position diagnostics.

\section{X-Ray Ring}

Another important project planned and carried out by our operations staff in 2008 was the replacement of an aging ube-based pre-amplifier with a solid-sate 3-kilowatt am- plifier that drives the final 125-kilowatt amplifier in one of our four RF systems. The tube-based amplifier was burdened with multiple bias power supplies as well as a $100-$ watt preamplifier of its own. The difficulty and expens required to maintain the tube amplifier was eliminated with the installation of the solid-state amplifier. The new amplifier reduces our equipment count and its modular design allows for a speedy swap-out of defective modules. All of these factors will contribute to improved machine reliability The new found physicat space will be a updated $125-k$ lowat phase supply, w an a May 2009 installation

The NSLS operations staff played critical roles in the succes of the new X9 MGU. A well-designed and implemented bakeout controller helped ensure that the temperature of the permanent magnets did not exceed a maximum level. This controller performed flawlessly during both the lab pre-installation bake-out as well as the in-situ bake-out following ring installation in August. Other vital systems contributing to the success of the X9 MGU include an active interlock system and a motor control system based on updated computer boards that will serve as a model for future motor control systems.
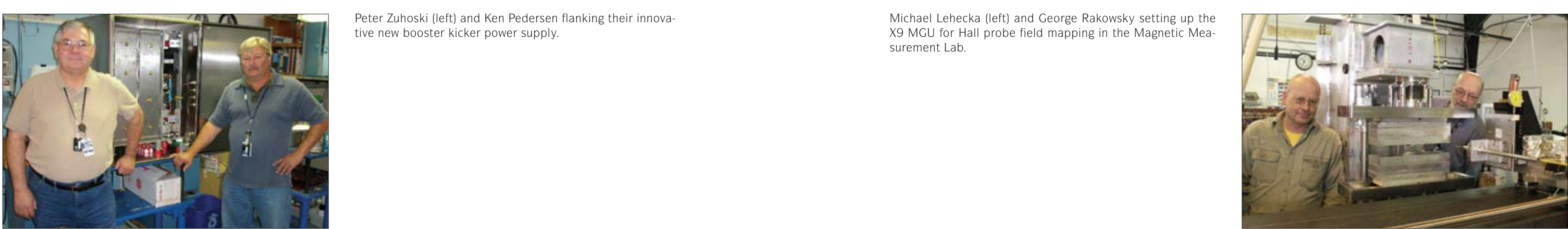


\section{Overall Improvements}

NSLS diagnostics routinely used in operations do not have capabilities to measure a single-turn electron beam orbit that could greatly help in optimization injection process into both the $X$-Ray and VUV Rings, In CY08, we started installation and commissioning of a new diagnostic system, a so-called Libera Brilliance receiver, allowing real-time observations of turn-by-turn beam dynamics. Each ring has so far been equipped with one test system, and initial results have been very encouraging. The new system has already allowed us to carry out beam-based measurements of the temporal profiles of the fast-injection kickers in the VUV Ring. Commissioning and studies are continuing and additionat systems are being considered.

\section{Magnetic Measurement Lab (MML)}

In 2008, a new in-vacuum MGU was completed and installed at $X 9$ to serve the new Center for Functional Nanomaterials beamline. This MGU is similar to the X29
MGU in that it just fits between a pair of $\mathrm{RF}$ cavities. However, it has a longer period length $(14.5 \mathrm{~mm}$ vs. $12.5 \mathrm{~mm})$, achieves a higher peak field (1.28 tesla (T) vs. $0.96 \mathrm{~T}$ ), and provides a wider tuning range (2:1 vs. 1.4:1), which gives full spectral coverage from $2.2 \mathrm{keV}$ to over $20 \mathrm{keV}$ without gaps, using both odd and even harmonics up to the 7th. A redesigned support structure accommodates the 75 percent higher magnetic load A new model-based magnet soring algorith was developed and implemented to determine an optimal magnet sequence th minimized the effect of magnetization errors on trajectory straightness. As a result, the MGU produced a straight trajectory with phase error less than 2.2 degrees root mean square with no post-assembly shimming.

Installation of X9 MGU had been planned for the December 2007 shutown. Hower, the NdFeB magnets (the X X $25 \mathrm{MGU}$ ) failed to withstand a key "pre-bake" test at elevated temperature. This prompted us to conduct a series of destructive thermal tests on a short prototype model, which determined that the safe limit for these magnets in-situ is only 90 degrees Celsius, but that ultra-high vacuum can be achieved at this temperature, albeit with a much longer duration bake. Consequently, an elaborately instrumented and temperature-limited bakeout scheme was implemented, first in the MML and again in the ring, to protect the magnets from permanent demagnetization. The MGU was re-measured after the first bake and verified that no magnetic changes had occurred, although mechanical "creep" had introduced some gap taper and systematic phas thermat cycling of structure before he mGu was de remed structure before the MGU was deemed ready for installation. A special short shutdown in August was dedicated to installation and final bakeout in the X-Ray Ring.

R\&D efforts in the area of cryogenic permanent magnet undulators optimally sorting and as installing the MGU in the superconduting undulator Vertical Test Facility and mapping it at room temperature and preparing a Cryogenic Safety Review for measurements at 77 degrees Kelvin.

\section{Source Development Laboratory}

The Source Development Laboratory (SDL) is a linear accelerator and laser-based R\&D facility dedicated to the exploration of new radiation sources and high brightness electron beams. In 2008, the scientific program emphasized three key themes:

- High-gain laser-seeded free electron laser (FEL amplifiers

High-intensity terahertz (THz) radiation

- Ultrafast electron diffraction (UED)

The high-gain laser-seeded FEL amplifier program is funded by the Joint Technology Office (JTO) and the Office of Naval Research (ONR). The scientific resuls from the THz source development and characterization program were published in Physical Review Letters and Physical Review $A$. The hardware for the ultrafast electron diffraction source is being assembled and should be operational in the coming year.
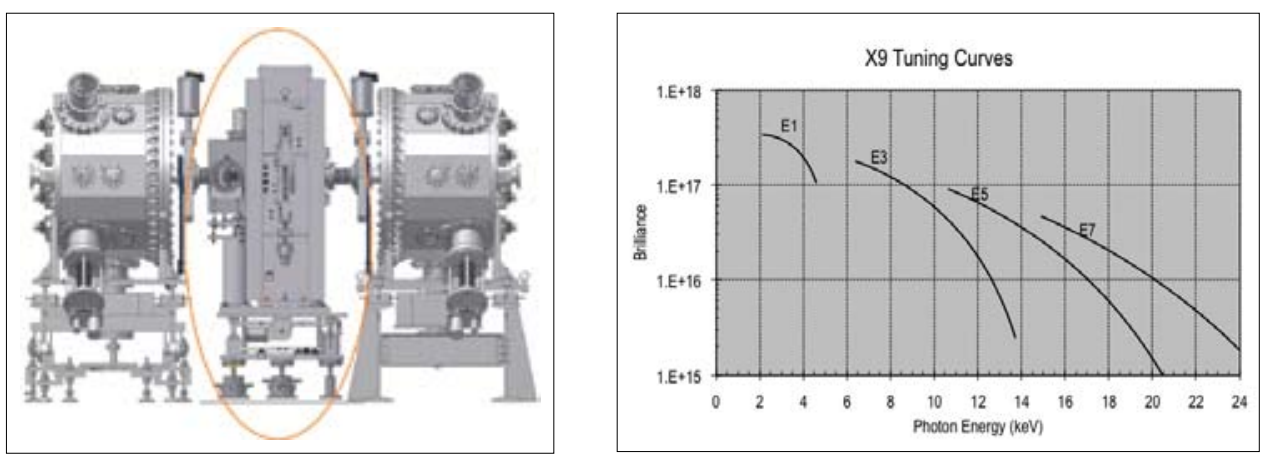

Left, the X9 MGU beween RF accelerating curves for X9 MGL Odd harmonics shown: is indicated, showing full coverage from 2.2 o over $20 \mathrm{keV}$.

The X9 mini-gap und monitor

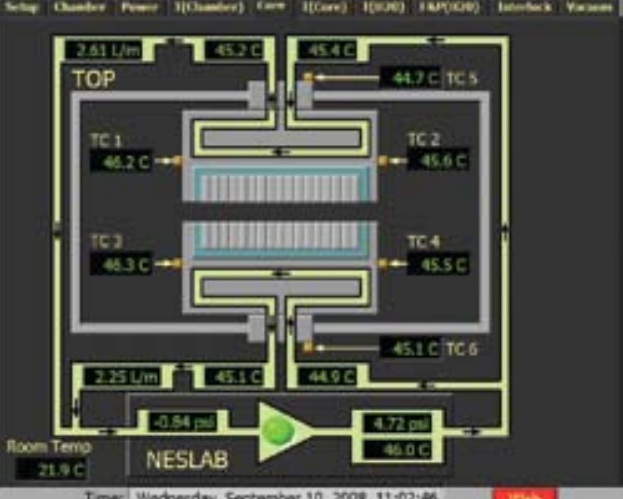




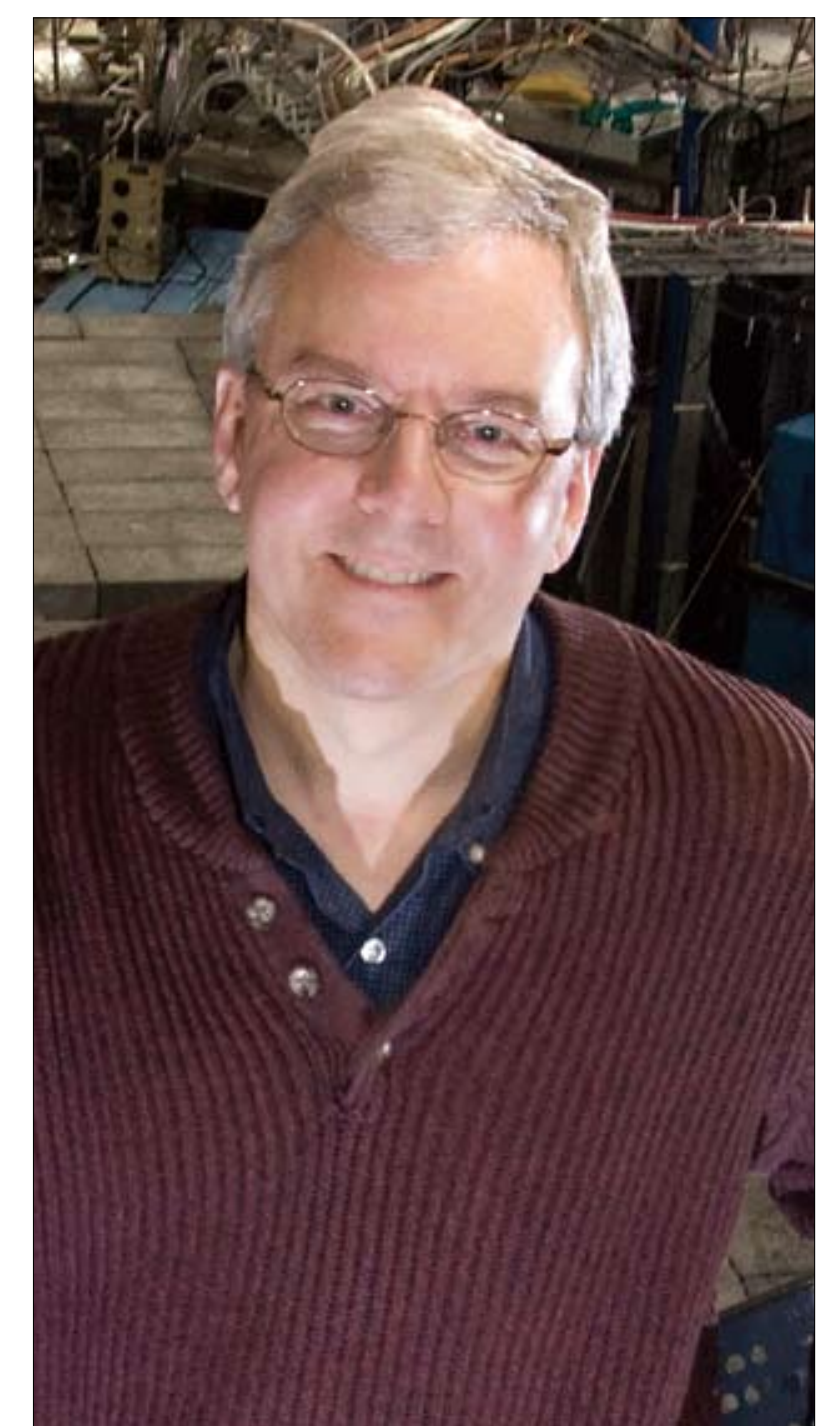

Steven Hulbert

Experimental Systems Division Head
The major activities, projects, and accomplishments of the Experimental Systems Division in 2008 are summarized below.

\section{Beamline $R \& D$}

During 2008, members of the Beamline R\&D Section, led by Lonny Berman, were heavily engaged in NSLS beamline and endstation construction and upgrade projects, as well as NSLS-II project beamline design preparation and R\&D.

At the NSLS, construction of the new $X 9$ beamline and endstation for small angle $\mathrm{x}$-ray scattering (SAXS)/wide angle $x$-ray scattering (WAXS) moved closer to completion. The undulator and front end for this beamline were installed in 2008, as were major components of the beamline and the endstation, and the beamline is on track for commissioning and startup of operation during 2009. Construction of the new X13A endstation for soft $x$-ray scattering made further advances through the construction of its vacuum chamber and rotary feedthrough, sample transfer system, and superconducting magnet, and will proceed through he end of 2009. Projects that began in 2007 and were compled 2008 included an upgrade of the X7B monochromator based on bent Laue diffracting silicon crystals optimized for high $x$-ray energies and an upgrade of the X18A beamline based on replacement of its monochromator and mirror with new-

"Design and R\&D efforts on behalf of the NSLS-II project beamlines commanded a significant fraction of time on the part of Beamline R\&D Section members as well as members of other NSLS sections - as much as 50 percent in some cases."

er ones optimized for tunability and operation to high $\mathrm{x}$-ray energies. Both of these projects were intended to uphold new experimental programs at these beamlines; namely, high $x$-ray energy powder diffraction and pair distribution function measurements at X7B and combined diffraction/ extended $x$-ray absorption fine structure (EXAFS), including time-resolved, at X18A. These new programs are currently serving users. Finally, groundwork was laid for a new X17A beamline and endstation, which will employ a single double-focusing bent Laue diffracting silicon crystal delivering a fixed high energy $x$-ray beam to an endstation instrument that will be devoted to pair distribution function measurements. The project is expected to be completed in 2010.

Design and R\&D efforts on behalf of NSLS-II project beamlines commanded a significant fraction of time on the part of Beamline R\&D Section members as well as members of other NSLS sections - as much as 50 percent in some cases. NSLS staff members led the preparation of the preliminary designs for four out of the six NSLS-I project beamlines: the coherent hard $x$-ray beamline, the coherent soft $x$-ray beamline, the hard $x$-ray nanoprobe beamline, and the powder diffraction beamline. These designs were subjects of the CD-2 review of NSLS-II, which occurred in November 2007 Efforts by these NSLS staff members, working together with NSLS-II project beamline staff, continued on behalf of these designs through the remainder of the year, leading up to the CD-3 review in September 2008. In addition, NSLS staff members helped organize workshops held on behalf of the project beamlines and conducted associated R\&D for the beamlines' optics and diagnostics.

Two infrared projects were undertaken at diagnostic \& instrumentation beamline U4IR in 2008. The NSLS, in collaboration with the City College of New York, completed the installation of a $10 \mathrm{~T}$ split-coil superconducting magnet for use with far- and mid-infrared synchrotron radiation. The system will be redeployed at beamline U121R once the optics have been restored to their original conditions and the magnet cryostat's windows have been upgraded from quartz to polypropylene to expand the spectral range. The second project was optimization of the optical interface of the National Institutes of Health-funded infrared focal plane array (FPA) microspetrometer system for use at a large-horizontal-collection infrared beamline. The system will be moved from U4IR to a permanent location at infrared beamline U10 in 2009.

Turning to $x$-ray focusing optics R\&D, diamond offers severa distinct advantages as an optic material for producing hard $x$-ray $(E>4 \mathrm{keV}$ ) focusing lenses, including its relatively larg decrement in refractive index, relatively low absorption, and high thermal conductivity. Current trends in beamline

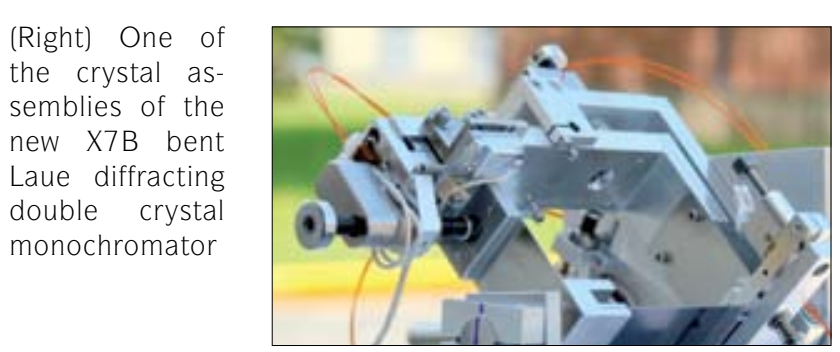

(Right) View of a kinoform lens fabricated from diamond polycrystalline material. The prototype lens was functional, but fu-
ture lenses will need to have dee erches in more useful larger-sized apertures (taken from A. Isakovic et al.,

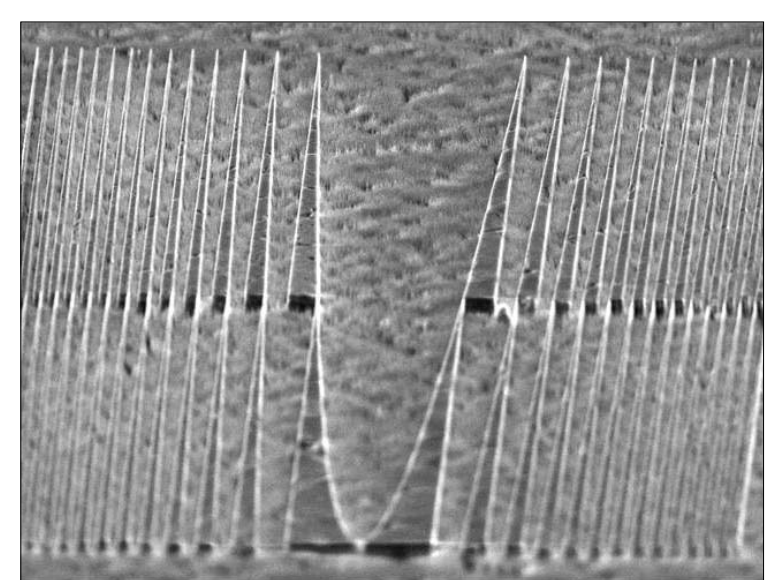

(


design are to preserve the coherence of the source, and a practical way to do this is to minimize the number of optical elements in a beamline, and to use only optical elements that are perfect enough to preserve the source coherence. $A$ good choice for fabricating such a phase-preserving single optic that can withstand the direct beam from a synchrotron is a kinoform fabricated from diamond. A prototype was made by the Beamline R\&D Section. While this lens displayed focusing behavior, there is much that remains to be done. For example, the prototype optic was fabricated from the polycrystalline material, and it is expected that the performance of the optic will be dramatically improved by using single-crystal material. Additional improvements will come from larger apertures to collect more light as the fabrication technique is improved.

A relatively new focus of the Beamline R\&D Section is to track the performance of NSLS beamlines. Toward this effort, 2008 activities centered on taking performance measurements for all of the $x$-ray spectroscopy beamlines and building a new instrument that can measure various aspects of the beam resolution function. A summary of the $x$-ray spectral flux findings for the $x$-ray spectroscopy beamlines reveals that those beamlines whose performance falls farthest below expectation tend to be those that use mirrors (with one exception). Several of these mirrors are of old vin- tage and have poor reflectivity, and these findings indicate that replacement of these may be a useful upgrade pathway for improved performance of these beamlines.

The newest member of the Beamline R\&D Section arrived during the latter part of 2008 and is leading a program to coordinate and grow industrial research at the NSLS. Work started with General Electric to develop and use a hightemperature furnace for powder diffraction to study ceramic materials, and continues with IBM on developing a remoteaccess capability for beamline X20B.

\section{Detectors}

The mission of the Detector Group, headed by Peter Siddons, is threefold: to develop and implement new detectors for synchrotron applications, to support these systems for beamline use at the NSLS, and to support those systems provided to other labs as necessary

During 2008, the Detector Group successfully tested prototypes of the $x$-ray imaging detector designed by NSLS for the Linac Coherent Light Source (LCLS) project at the SLAC National Accelerator Laboratory. The $64 \times 64$ pixel prototype shows that the requirements of the LCLS pumpprobe experiment can be met. These successful tests also demonstrate that this detector will be extremely valuable for normal synchrotron applications, such as protein crystallography (PX) The prototype has been used to record PX diffraction spots in fine-slicing mode. With the full-scale version of this detector, a 1,000-frame dataset could be collected in less than 10 seconds (assuming sufficient $x$-ray intensity). Current PX detectors require a time on the order of seconds to read a single frame.

A new opportunity for the Detector Group has been provided by a Department of Energy (DOE) grant to study the aplication of a new circuit fabrication technology to x-lay aplication of a new circu nology curently being explored by he semiconductor industry to extend the circuit density of systems by expanding in the third dimension, i.e. upwards. This circuit technology is achieved by bonding complementary metal-oxide semiconductor (CMOS) integrated circuits one atop the other, with micronscale interconnections between layers. One could imagine putting the floating-point processor directly above the CPU in a microprocessor, thus greatly reducing the number of long wires required in a planar geometry to connect these two units. Similarly, detectors can be built using the appropriate technology for each type of circuit. For example, low-noise analog circuits have a sweet spot around $0.3 \mu \mathrm{m}$ whereas digital circuits can be effective down to tens of nanometers. 3D integration could allow both technologies to coexist in the same device, and be bonded directly to the thick x-ray-sensitive detector This could open the doors for developing detectors with more "intelligence" in each pixe for example, energy-resolving imaging detectors or detectors with time-correlation calculations performed in real time. Under this three-year DOE grant, awarded in August 2008, the possibilities of using 3D circuit integration for synchrotron $x$-ray detector applications will be explored.

\section{Mechanical Systems}

The Mechanical Systems Section, led by Payman Mortazavi, provides mechanical engineering, design, and technical support to all NSLS divisions, both for operations and for project upgrades, large and small. The largest undertaking for the Mechanical Section this year was completion of the X9 project, described below, which involved significant mechanical section engineering, design, and technical efforts. The Mechanical Section also continued preventative maintenance and emergency repair efforts on all accelerator and storage ring systems and components with the goal of better than or equal to 95 percent reliability delivered to NSLS users. As part of this effort, numerous components subject to wear and degradation were replaced (hoses, fittings, valves, and connectors), rebuilt (e.g. the X17

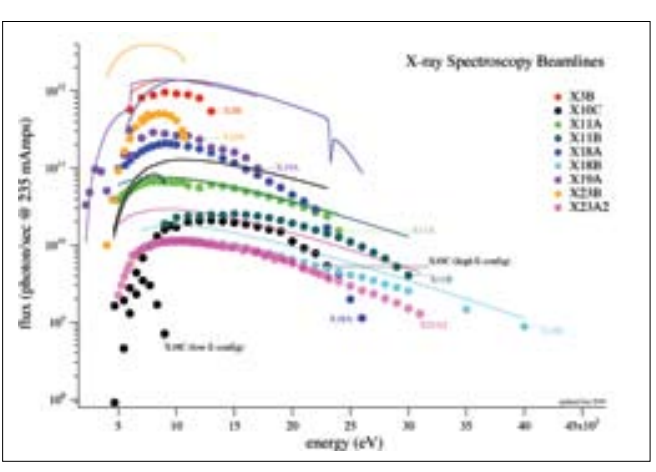

Measured spectral flux at various $x$-ray spectroscopy beamlines (dotted
simulations (solid lines)

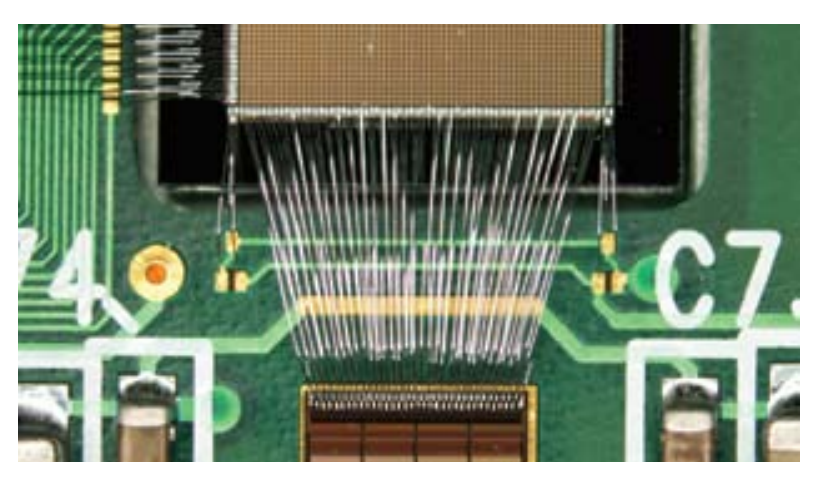

the $64 \times 64$ sensor with its wire-bonds connecting it to the custom chip for readout.
Image and histograms corresponding to a reflection of a sample of thaumatin taken at X6A at $12.2 \mathrm{keV}$ with a beam size at the sample of
$200 \times 200 \mathrm{~mm}^{2}$ The rotation speed was $0.5^{\circ} / \mathrm{s}$ and data integration time $32 \mathrm{~ms}$. The pixel size is $90 \times 90 \mathrm{~mm}^{2}$.

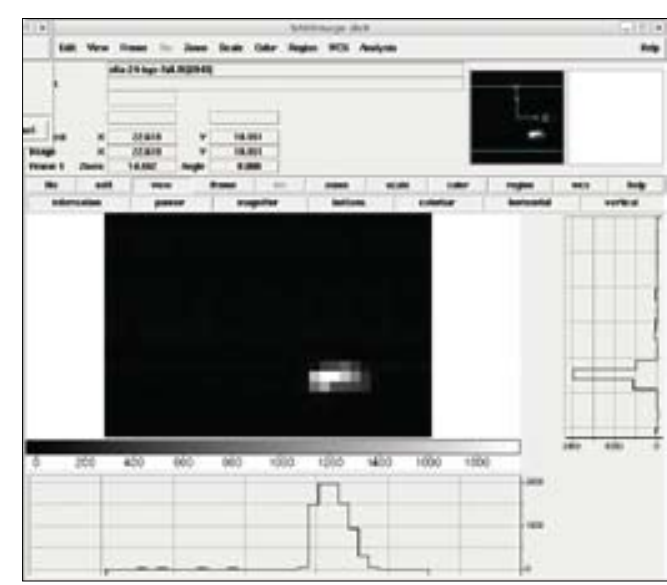

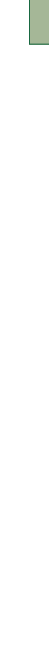


cryogenic refrigerator/liquefier), and calibrated (e.g. gauges and instruments) during 2008 .

The major NSLS projects for which the Mechanical Systems Section provided significant support during 2008 include:

Accelerator

Injection System: Good progress was madeon a project to identify spare and missing transfer line magnet coils. The scope was first expanded to include the identification of redundant magnets and magnet coil protections and later again to include the booster, $X$-Ray, and VUV Ring magnets.

Booster Ring: Three ion pumps in the NSLS Booster Ring were replaced to improve vacuum. Replacement of two of these parts was planned, owing to their age and condition, while the third was replaced following discovery that it was leaking.

X9 undulator: Engineering, detailed design, and construction of the $X 9$ mini-gap undulator (MGU) began in-house in 2007 and continued throughout 2008. The project included installation of upstream and downstream pick-up electrodes for straight-section beam-position monitoring. The X9 MGU project culminated in early September 2008 when installation of the X9 MGU into the X-Ray Ring was completed.
RF cavities near X9: Two new all-copper radio frequency (RF) cavities XRF1 and XRF2 that "bookend" the new X9 undulator in the X9 insertion device straight section of the X-Ray Ring were installed during past shutdowns.

X9 front end: Design, fabrication, and installation of the new $X 9$ front end required a total of three shutdown pertods, all of 2008 , to accomplish. The first was to remove all of the old $\mathrm{X} 9$ bending magnet components and take the nec essary measurements for design, and the second and third were to install and precisely align the new front-end components. The XY front end components were engineered and designed to handle the undulator power including a specially designed differential ion pump that provides windowless vacuum isolation between the front end and the rest of the $\mathrm{X} 9$ beamline.

Utilities

Installation was completed of the Automated Process and Control Software (APACS), industry-standard software tha collects inputs from numerous temperatures, pressures, valve position e a termined remotely. The assessment of the need for additional sensors to provide a more complete set of control inputs and enhance the capabilities of the system will continue.
Beamlines

In addition to the mechanical engineering, design, and technical development and support for the beamline acefforts were undertaren by the Mechntical section:

Engineering, fabrication, and installation support for a new beamline at X9 occurred throughout 2008, including a new experimental end station enclosure. Most of the fabrication work was completed by Central Fabrication Services, but many smaller items were made by Mechanical Section technicians, wh much of the installation work and all of the survey and alignment work.

Implementation of new external exhaust capabilities at X18, X19, X21, and X22 were undertaken. Extensive new design and modifications were needed to supply highefficiency particulate air (HEPA)-filtered external exhaust capabilities to the participating research teams at X18A, X18B, and X19A for nanoscience work. Additionally, external $x$ hat and $x 228$. The add capabihy for $x 21$ wil vent a new gas cabinet and a class IV excimer laser that will be added within the X21 Experimental End Station Enclosure (EESE) to pulsed laser deposition growth of thin films for in-situ x-ray diffraction studies. These new exhaust system connections should be completed early in 2009

The engineering and design work for the addition of a new beamline at X17A was another large undertaking. The design work for this effort started late in 2008. A single-bounce sagittal bent Laue monochromator (5) Si reflection, Zhong optical design) will take photon from the X17A shutter and diffract, focus, and deflect them into the new X17A beamline. Adding the X17A beamline to the existing $X 17 B, C$ beamline suite will $r$ quire expansion of the small and large $\times 17$ transport Closures on the outboard side. A new X17 E EESE wi be engineered, designed, and specified for procurement. The beamline design layout work for this proj ect is ongoing and sketches/statements of work for the new X17A EESE and X17 transport enclosure modifications will be written and sent out for quotes in 2009 A novel monochromator design is being undertaken, which will utilize two-axis bending to simultaneously dertaken to determine the limits of two-axis bending for this new device.

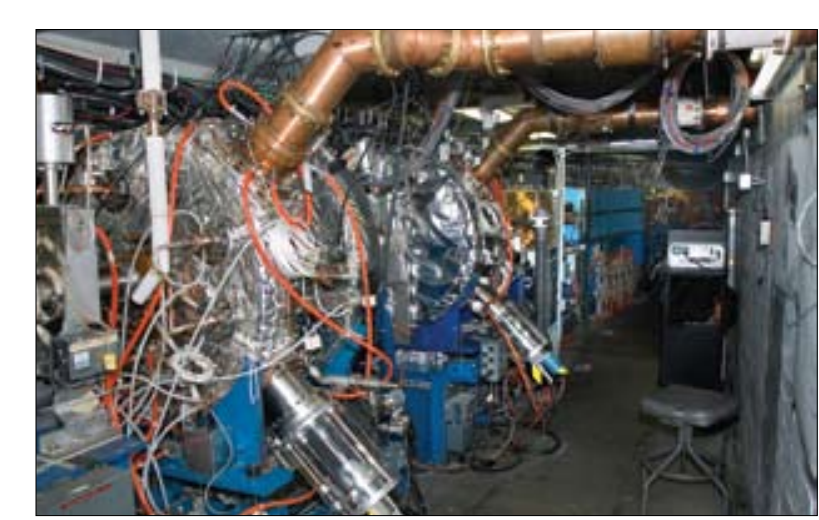

XRF1 and XRF2 cavities

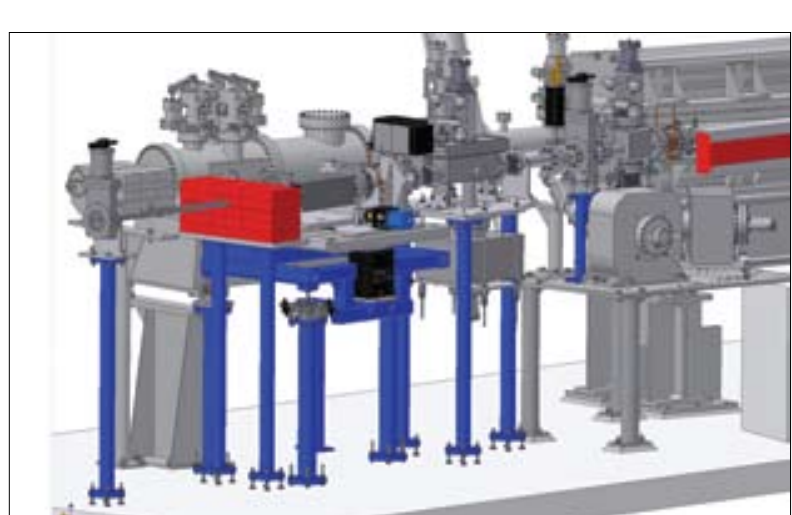

$x 9$ front end configuration

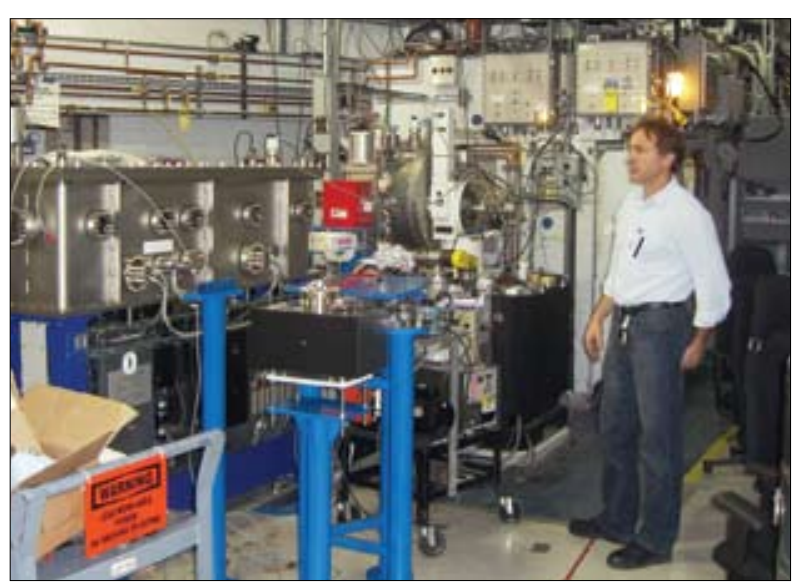




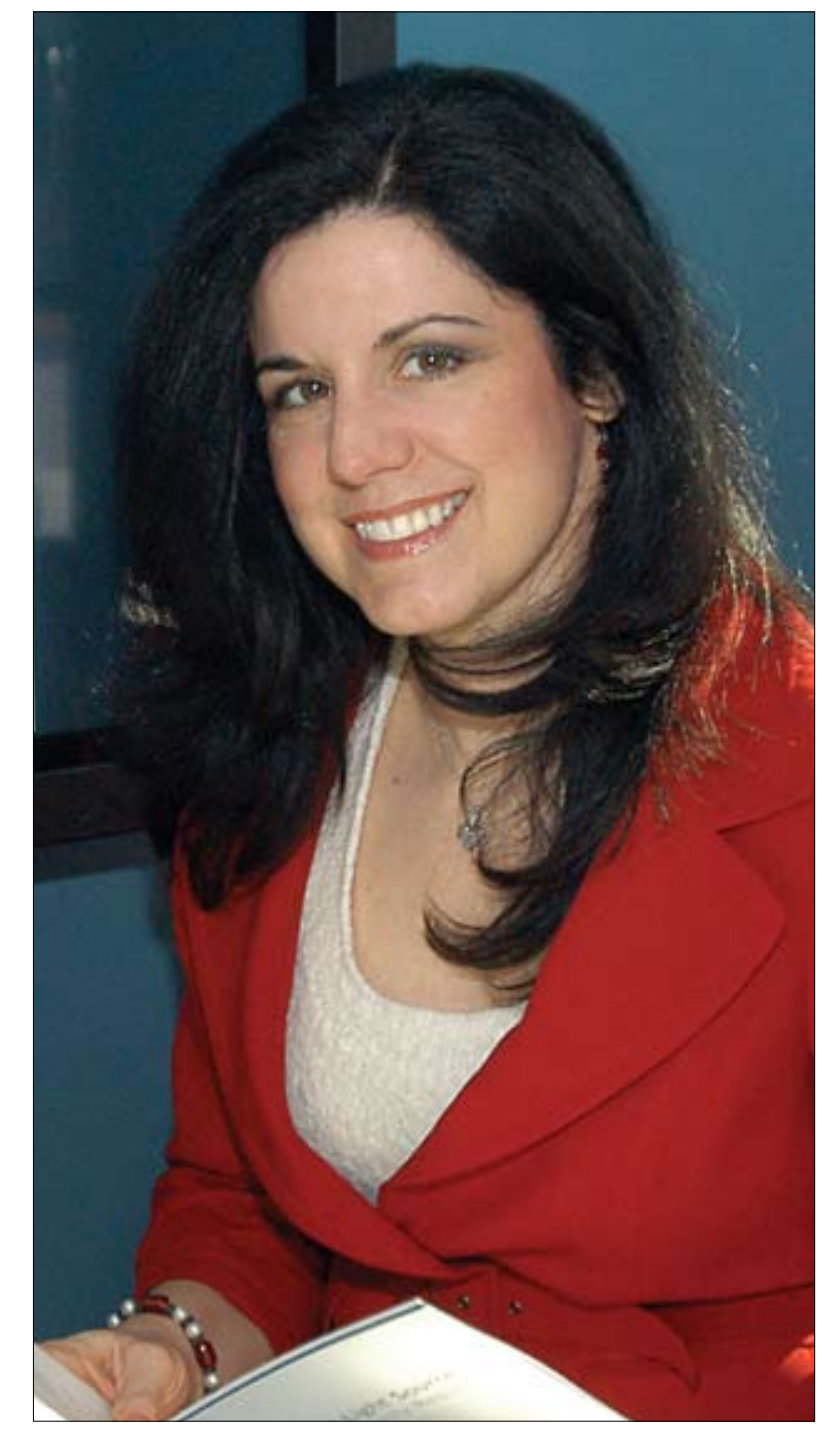

Kathleen Nasta

Kathleen Nasta
The NSLS is a facility open to researchers, called "users," that operates around the clock throughout the year except during pre-announced maintenance and studies periods in 2008, 51

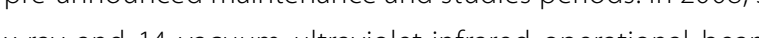
lines were available for a wide range of experiments utilizing a variety of techniques. There are two types of beamlines at the NSLS: Facility Beamlines (FBS), of which there are 18; and Participating Research Beamlines (PRTS), currently totaling 47. FBs are operated by the NSLS staff and reserve a minimum of 50 percent of their beam time for users from various institutions outside the NSLS, called general users. Some FBS atso host Contributing Users (CUs) who ent hence endstion capabost Con bues bilities and provide generalzed suppont to general users. PRT beamlines are operated by user groups with related interests from one or more institutions. PRT beamlines reserve 25 percent of their beam time for general users, although they can grant additional time at their own discretion. Membership in a PRT or CU program is open to all members of the scientific community who can contribute significantly to the program of the beamline. For example, this can include funding, contribution of equipment, scientific program, design and engineering, or operations staffing. The following pages provide details on the NSLS operational beamlines, including their unique characteristics.

Users at the NSLS primarily are awarded beam time by submitting a "General User" proposal through our peer reviewed, web-based proposal system. The proposat is rated based on various scientic criteria, and can rated based on valious scientic criterla, and car years). In fiscal year 2008, more than 1,000 requests for beam time were submitted, nearly half of those requests on new proposals. Beam time is given without charge, as long as the research results are published in open literature. Work that is proprietary in nature is charged on a full-cost recovery basis according to U.S. Department of Energy (DOE) guidelines.

During the calendar year 2008, hundreds of visitors attended the many workshops, short courses, seminars, reviews, and tours offered at the NSLS In addition to the annual Joint NSLS/ (In May and the second triennial review of the NSLS by the U.S. Department of Energy, 14 other workshops were held, as well as 6 beamline reviews, 133 seminars, and 70 tours of the facility.

In fiscal year 2008, about 400 different institutions sent close to 2,200 users to the NSLS to conduct their research. Of this number, about 600 were new users. The majority (710\%) of users comes from academic institutions, and a steady 7 percent of users were from industry.

The users who visited in 2008 were characterized by their felds of research in different ways. The greatest number works in the life sciences field, with materials sciences studies following closely. Considering the number of days spent on experiments - based on running times gathered from aterials sciences studies make up the greatest portion of beam time used.
About half of our users are U.S. citizens, and nearly 30 percent are women. Nearly one-third of our users are from within New York State, ar nearby in the northeastern states.

In 2008, nearly 40 percent of the researchers working at the NSLS were students in undergraduate or graduate studies. Almost 22 percent of the users were post-doctoral researchers, with faculty members, professional staff, or research scientists making up the balance.

Just about equal to last year's record-breaking number, NSLS users and staff published 964 articles in FY 2008 . Of these, nearly 21 percent were published in premier journals. A publcation is considered premier if the journal has an impact factor of 6 or greater (from Journal Citation Report 2005, Thomson Institute for Scientific Information). The table shown on page 60 summarizes publications during the past year. The first column in the table lists the number of publications reported to the NSLS during the 2008 fiscal year (October 1, 2007 through September 30, 2008) and published between 2005 and 2008 . Although some of these publications were published earlie than FY 2008, they were not reported to the NSLS until this fiscal year. Thus, they have not been counted in prior years' reports. The second column in the table lists the number of papers published in the 2008 calendar year and reported to the NSLS as of February 27, 2009 . These numbers are slightly tower than the fiscat year values because they contain only years to account for user and staff publications.

"Visits to the NSLS were brisk business in 2008! In addition to our annual Users' Meeting and the triennial review by the U.S. Department of Energy, the NSLS hosted 14 workshops, 6 beamline reviews, 133 seminars, and 70 tours." 
X-Ray and VUV-IR Parameters

\begin{tabular}{|c|c|c|}
\hline & X-Ray & VUV-IR \\
\hline Energy & $2.800 \mathrm{GeV}$ & $0.808 \mathrm{GeV}$ \\
\hline Maximum Current & $300 \mathrm{~mA}$ & $1.0 \mathrm{~A}$ \\
\hline $\begin{array}{l}\text { Photon Critical Wavelength } \\
\text { (Energy) for Dipole }\end{array}$ & $1.75 \AA(7.1 \mathrm{keV})$ & $19.9 \AA(622 \mathrm{eV})$ \\
\hline $\begin{array}{l}\text { Photon Critical Wavelength } \\
\text { (Energy) for X17 wiggler at }\end{array}$ & $0.57 \AA(22 \mathrm{keV})$ & \\
\hline Horizontal Emittance & $62 \mathrm{~nm}$-rad & $160 \mathrm{~nm}$-rad \\
\hline Vertical Emittance & $0.34 \mathrm{~nm}$-rad & $\geq 0.35 \mathrm{~nm}$-rad (4 nm-rad in normal ops.) \\
\hline Electron Orbital Period & 567.2 nanoseconds & 170.2 nanoseconds \\
\hline Number of RF Buckets & 30 & 9 \\
\hline Typical Bunch Mode & 25 & 7 \\
\hline Natural RMS Energy Spread & $9.2 \times 10^{-4}$ & $5.0 \times 10^{-4}\left(\mathrm{I}_{\mathrm{b}}<20 \mathrm{~mA}\right)$ \\
\hline RMS Bunch Length & $44 \mathrm{~mm}$ & $5 \mathrm{~cm}\left(\mathrm{l}_{b}<20 \mathrm{~mA}\right)$ \\
\hline
\end{tabular}

\section{Publications}

\begin{tabular}{l|c|c|}
\hline & Reported in FY08* & Published in CY08** \\
\hline Journals, peer-reviewed, premier & 202 & 163 \\
Journals, other peer-reviewed & 603 & 509 \\
Journals, non peer-reviewed & 25 & 16 \\
Books/Chapters in Books & 17 & 9 \\
Published Conference Proceedings & 69 & 32 \\
Reports: Technical, Formal, Informal & 4 & 4 \\
Theses/Dissertations & 43 & 26 \\
Patents & 1 & 6 \\
\hline Total Publications & 964 & 765 \\
\hline NSLS VUV-IR User Publications & 104 & 76 \\
NSLS X-Ray User Publications & 729 & 600 \\
NSLS Staff Publications & 131 & 89 \\
\hline Total Publications & 964 & 765
\end{tabular}

Total Publications

964

nd published between 2005 - 2008

** Publications published in 2008 as reported to the NSLS by Feb. 27, 2009.
Users by Field of Research

Fiscal Year 2008

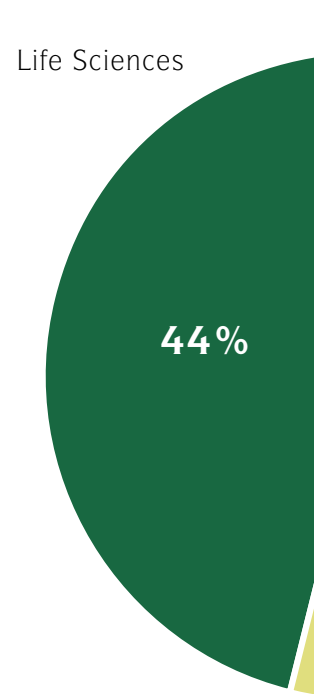

Geosciences and Ecology

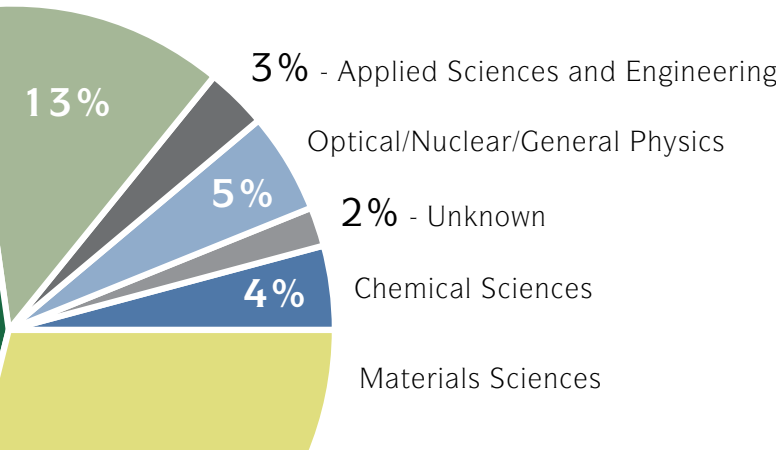

Users by Affiliation Fiscal Year 2008

ther Labs and Affiliations

Federal Agencies (non-DOE) - $2 \%$ DOE Employees (non-BNL) - 2\%

Geographical User Distribution Fiscal Year 2008

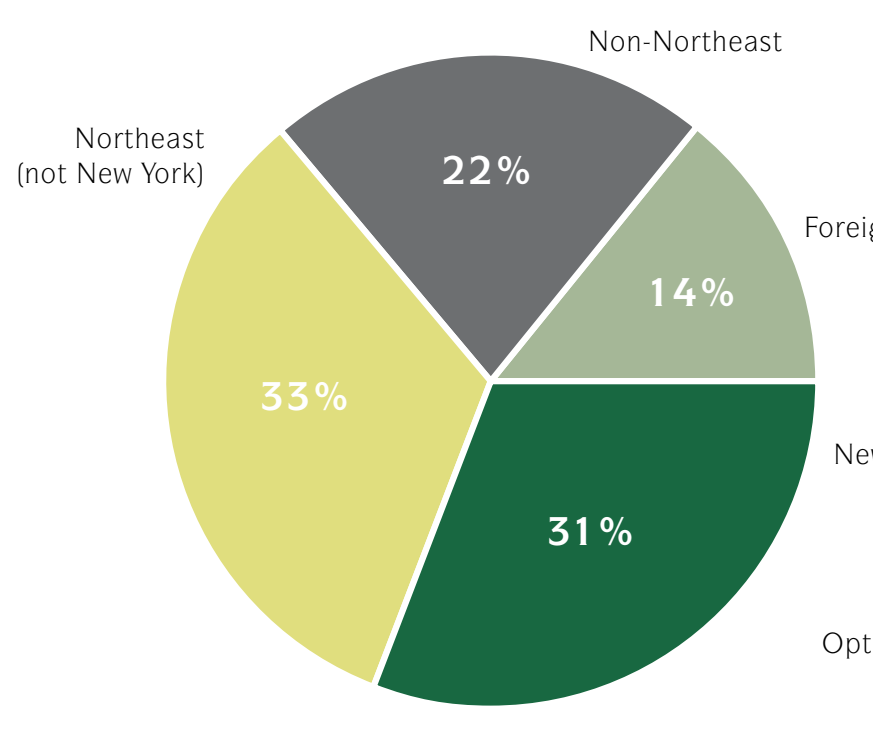

BNL Employees
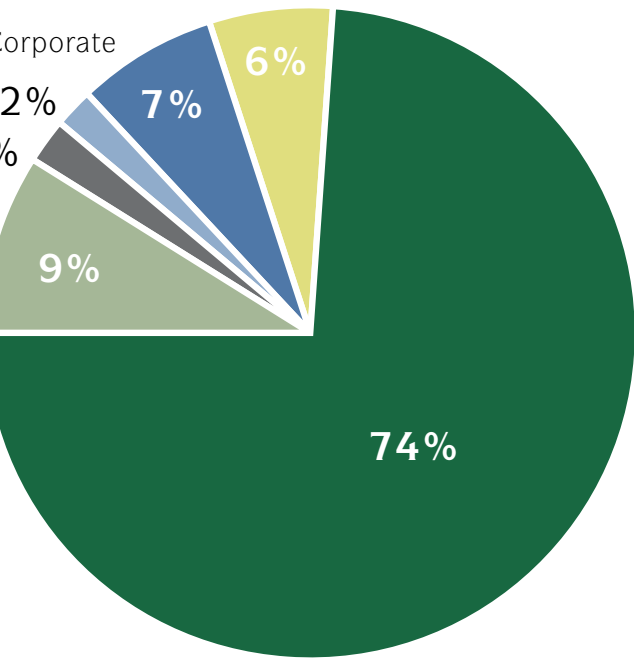

Beamtime Used* Fiscal Year 2008

Applied Sciences and Engineering

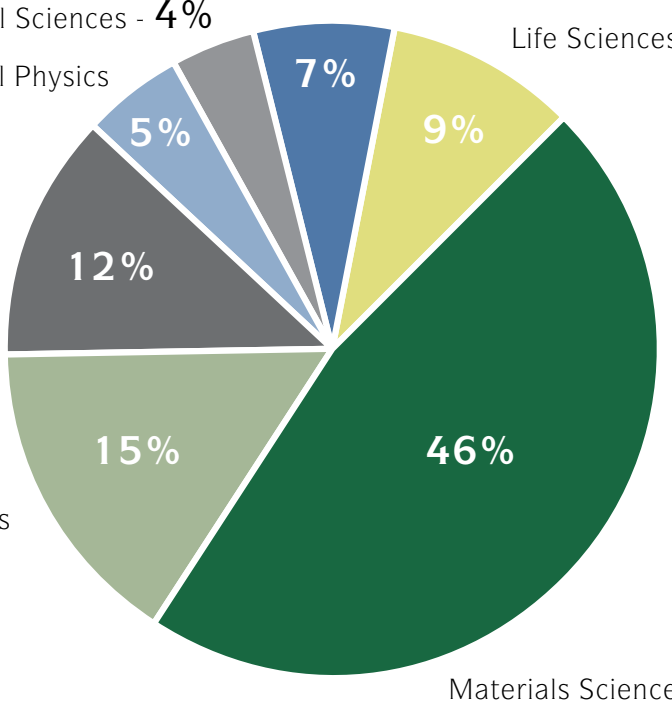




\begin{tabular}{|c|c|c|c|c|c|}
\hline Beamline & Source & Type of Research & Energy Range & Type & Organization \\
\hline \multicolumn{6}{|c|}{ VUV-IR Beamlines } \\
\hline UIA & Bend & $\begin{array}{l}\text { XAS } \\
\text { EXAFS } \\
\text { NEXAFS }\end{array}$ & $270-900 \mathrm{eV}$ & PRT & $\begin{array}{l}\text { ExxonMobil Research and } \\
\text { Engineering Co. }\end{array}$ \\
\hline U2A & Bend & $\begin{array}{l}\text { IRMS } \\
\text { High pressure research } \\
\text { RR spectroscopy }\end{array}$ & $30-10000 \mathrm{~cm}^{-1}$ & $F B$ & $\begin{array}{l}\text { COMPRES } \\
\text { Carnegie Institution of Washington } \\
\text { BNLLNSLS }\end{array}$ \\
\hline U2B & Bend & IRMS & $500-4000 \mathrm{~cm}^{-1}$ & PRT & Case Western Reserve University \\
\hline U3C & Bend & Metrology & $50-1000 \mathrm{eV}$ & PRT & $\begin{array}{l}\text { Lawrence Livermore National Laboratory } \\
\text { Los Alamos National Laboratory } \\
\text { National Security Technologies } \\
\text { Sandia National Laboratory }\end{array}$ \\
\hline UAB & Bend & $\begin{array}{l}\text { X-ray reflectivity } \\
\text { X-ay scattering, magnetic } \\
\text { X-ray scattering, resonant } \\
\text { MCD } \\
\text { XAS } \\
\text { X-ray fluorescence spectroscopy }\end{array}$ & $20-1200 \mathrm{eV}$ & FB & $\begin{array}{l}\text { Montana State University } \\
\text { BNL-NSLS }\end{array}$ \\
\hline USUA & $\begin{array}{l}\text { Insertion } \\
\text { Device }\end{array}$ & $\begin{array}{l}\text { ARPES } \\
\text { UPS, spin-resolved }\end{array}$ & $15-150 \mathrm{eV}$ & $F B$ & $\begin{array}{l}\text { BNL-NSLS } \\
\text { BNL-CFN }\end{array}$ \\
\hline U7A & Bend & $\begin{array}{l}\text { NEXAFS } \\
\text { XPS }\end{array}$ & $180-1200 \mathrm{eV}$ & PRT & $\begin{array}{l}\text { BNL-Chemistry } \\
\text { Dow Chemical Company } \\
\text { National Institute of Standards \& } \\
\text { Technology }\end{array}$ \\
\hline U9B & Bend & $\begin{array}{l}\text { Time-resolved spectroscopy } \\
\text { UV-CD } \\
\text { UV florescence spectroscopy }\end{array}$ & $0.8-8 \mathrm{eV}$ & PRT & BNL-Biology \\
\hline U1OB & Bend & IRMS & $500-4000 \mathrm{~cm}^{-1}$ & FB & BNL-NSLS \\
\hline U11 & Bend & $U V-C D$ & 3-10 ev & PRT & BNL-Biology \\
\hline U12A & Bend & $\begin{array}{l}\text { XAS } \\
\text { XPS }\end{array}$ & $100-800 \mathrm{eV}$ & PRT & Oak Ridge National Laboratory \\
\hline U121R & Bend & $\begin{array}{l}\text { IR spectroscopy } \\
\text { Magnetospectroscopy } \\
\text { THz / millimeter wave spectroscopy } \\
\text { Time-resolved spectroscopy }\end{array}$ & $8-600 \mathrm{~cm}^{-1}$ & $F B$ & BNL-NSLS \\
\hline U13UB & $\begin{array}{l}\text { Insertion } \\
\text { Device }\end{array}$ & $\begin{array}{l}\text { UPS } \\
\text { ARPES }\end{array}$ & $3-30 \mathrm{eV}$ & PRT & $\begin{array}{l}\text { Boston College } \\
\text { Boston University } \\
\text { BNL-Physics } \\
\text { Columbia University }\end{array}$ \\
\hline
\end{tabular}

\section{Beamline Guide Abbreviations}

$\begin{aligned} \text { ARPES } & \text { Photoelectron Spectroscopy, Angle-Resolved } & \text { SAXS } & \text { Small Angle X-Ray Scattering } \\ \text { DAFS } & \text { X-Ray Diffraction Anomalous Fine Structure } & \text { STXM } & \text { Scanning Transmission X-Ray Microscopy } \\ \text { DEI } & \text { Diffraction-Enhanced Imaging } & \text { UPS } & \text { UV Photoelectron Spectroscopy } \\ \text { EXAFS } & X \text {-Ray Absorption Spectroscopy, Extended Fine Structure } & \text { UV-CD } & \text { Ultraviolet Circular Dichroism }\end{aligned}$

$\begin{aligned} \text { HARMST } & \text { High Aspect Ratio Microsystems Technology } & \text { WAXD } & \text { Wide-Angle X-Ray Diffraction } \\ \text { IRMS } & \text { Infrared Microspectroscopy } & \text { WAXS } & \text { Wide-Angle X-Ray Scattering } \\ \text { MAD } & \text { Mulit-Wavelength Anomolous Dispersion } & \text { XAS } & \text { X-Ray Absorption Spectroscopy } \\ \text { MCD } & \text { Magnetic Circular Dichroism } & \text { XPS } & \text { X-Ray Photoelectron Spectroscopy } \\ \text { NEXAFS } & \text { Near Edge X-Ray Absorption Spectroscopy } & \text { XRD } & \text { X-Ray Diffraction } \\ \text { PEEM } & \text { Photo Emission Electron Microscopy } & \text { XSW } & \text { X-Ray Diffraction, Standing Waves }\end{aligned}$




\begin{tabular}{|c|c|c|c|c|c|}
\hline Beamline & Source & Type of Research & Energy Range & Type & Organization \\
\hline \multicolumn{6}{|c|}{ X-Ray Beamlines } \\
\hline XIAT & $\begin{array}{l}\text { Insertion } \\
\text { Device }\end{array}$ & $\begin{array}{l}\text { STXM } \\
\text { NEXAFS }\end{array}$ & $0.25-0.50 \mathrm{keV}$ & PRT & $\begin{array}{l}\text { BNL-Environmental Sciences } \\
\text { ExxonMobil Research and } \\
\text { Engineering Co. } \\
\text { Stony Brook University } \\
\text { SUNY @ Plattsburgh } \\
\text { University of Texas @ Houston }\end{array}$ \\
\hline X1A2 & $\begin{array}{l}\text { Insertion } \\
\text { Device }\end{array}$ & STXM & $0.25-1 \mathrm{keV}$ & PRT & Stony Brook University \\
\hline $\mathrm{X} 1 \mathrm{~B}$ & $\begin{array}{l}\text { Insertion } \\
\text { Device }\end{array}$ & $\begin{array}{l}\text { XAS } \\
\text { X-ray fluorescence spectroscopy } \\
\text { XPS }\end{array}$ & $0.2-1.6 \mathrm{keV}$ & PRT & $\begin{array}{l}\text { Boston University } \\
\text { Thomas Jefferson National Accelerator } \\
\text { Facility } \\
\text { University of Illinois }\end{array}$ \\
\hline$X 2 B$ & Bend & $X$-ray microtomography & $8-35 \mathrm{keV}$ & PRT & $\begin{array}{l}\text { ExxonMobil Research and } \\
\text { Engineering Co. }\end{array}$ \\
\hline X3A & Bend & $\begin{array}{l}\text { MAD } \\
\text { Macromolecular crystallography }\end{array}$ & $4.6-15.1 \mathrm{keV}$ & PRT & $\begin{array}{l}\text { Case Western Reserve University } \\
\text { Rockefeller University } \\
\text { Sloan-Kettering Institute for Cancer } \\
\text { Research }\end{array}$ \\
\hline Х3B & Bend & $\begin{array}{l}\text { XAS } \\
\text { EXAFS }\end{array}$ & $5-13.7 \mathrm{keV}$ & PRT & Case Western Reserve University \\
\hline X4A & Bend & $\begin{array}{l}\text { MAD } \\
\text { Macromolecular crystallography }\end{array}$ & $3.5-20 \mathrm{keV}$ & PRT & $\begin{array}{l}\text { Albert Einstein College of Medicine } \\
\text { City University of New York (CUNYY) } \\
\text { Columbia University } \\
\text { Cormell University } \\
\text { Mount Sinai School of Medicine } \\
\text { New York Structural Biology Center } \\
\text { New York University } \\
\text { sUNY @ Buffalo } \\
\text { Sloan-Kettering Institute for Cancer } \\
\text { Research } \\
\text { Wadsworth Center }\end{array}$ \\
\hline$x 4 C$ & Bend & $\begin{array}{l}\text { MAD } \\
\text { Macromolecular crystallography }\end{array}$ & $7-20 \mathrm{keV}$ & PRT & 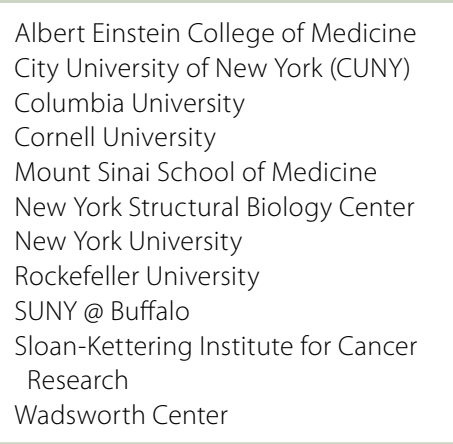 \\
\hline X6A & Bend & $\begin{array}{l}\text { MAD } \\
\text { Macromolecular crystallography }\end{array}$ & $6.0-23 \mathrm{keV}$ & $F B$ & BNL-NSLS \\
\hline X6B & Bend & $\begin{array}{l}\text { XRD, surface } \\
\text { WAXD } \\
\text { X-ray reflectivity }\end{array}$ & $6.5-19 \mathrm{keV}$ & $F B$ & $\begin{array}{l}\text { BNL-CFN } \\
\text { BNLNSLS }\end{array}$ \\
\hline$x 7 B$ & Bend & $\begin{array}{l}\text { XRD, single crystal } \\
\text { XRD, time resolved } \\
\text { WAXD } \\
\text { WAXS }\end{array}$ & $25-50 \mathrm{keV}$ & PRT & $\begin{array}{l}\text { BNL-Chemistry } \\
\text { General Electric }\end{array}$ \\
\hline X8A & Bend & Metrology & $1.0-5.9 \mathrm{keV}$ & PRT & $\begin{array}{l}\text { Lawrence Livermore National } \\
\text { Laboratory } \\
\text { Los Alamos National Laboratory } \\
\text { National Security Technologies } \\
\text { Sandia National Laboratory }\end{array}$ \\
\hline
\end{tabular}

\begin{tabular}{|c|c|c|c|c|c|}
\hline Beamline & Source & Type of Research & Energy Range & Type & Organization \\
\hline$x_{88}$ & Bend & $\begin{array}{l}\text { MAD } \\
\text { Macromolecular crystallography }\end{array}$ & 5-19 keV & PRT & $\begin{array}{l}\text { Biogen Incorporated } \\
\text { Biotechnology Research Institute } \\
\text { Hoffmann-La Roche } \\
\text { National Institutes of Health }\end{array}$ \\
\hline x9 & Bend & $\begin{array}{l}\text { SAXS } \\
\text { WAXS }\end{array}$ & $10-20 \mathrm{keV}$ & & \\
\hline X10A & Bend & $\begin{array}{l}\text { XRD, powder } \\
\text { WAXD } \\
\text { SAXS } \\
\text { WAXS }\end{array}$ & 8-11 keV & PRT & $\begin{array}{l}\text { ExxonMobil Research and } \\
\text { Engineering Co. }\end{array}$ \\
\hline X10B & Bend & $\begin{array}{l}\text { XRD, powder } \\
\text { XRD, surface } \\
\text { WAXD } \\
\text { X-ray reflectivity } \\
\text { X-ray cattering, surface } \\
\text { WAXS }\end{array}$ & $14 \mathrm{keV}$ & PRT & $\begin{array}{l}\text { ExxonMobil Research and } \\
\text { Engineering Co. }\end{array}$ \\
\hline $\mathrm{x} 10 \mathrm{C}$ & Bend & $\begin{array}{l}\text { XAS } \\
\text { EXAFS } \\
\text { NEXAFS }\end{array}$ & 4-24 keV & PRT & $\begin{array}{l}\text { ExxonMobil Research and } \\
\text { Engineering Co. }\end{array}$ \\
\hline X11A & Bend & $\begin{array}{l}\text { DAFS } \\
\text { XAS } \\
\text { EXAFS } \\
\text { NEXAFS }\end{array}$ & $4.5-35 \mathrm{keV}$ & PRT & $\begin{array}{l}\text { BNL-Material Sciences } \\
\text { BNL-Environmental Sciences } \\
\text { Canadian Light Source } \\
\text { ETH LLbs - Zuerich } \\
\text { Natural Resources Canada } \\
\text { Naval Research Laboratory (NRL) } \\
\text { Naval Surface Warfare Center } \\
\text { New Jersey Institute of Technology } \\
\text { North Carolina State University } \\
\text { Sarah Lawrence College } \\
\text { Stony Brook University }\end{array}$ \\
\hline X11B & Bend & $\begin{array}{l}\text { XAS } \\
\text { EXAFS } \\
\text { NEXAFS }\end{array}$ & $5.0-23 \mathrm{keV}$ & PRT & $\begin{array}{l}\text { BNL-Environmental Sciences } \\
\text { BNL-Material Sciences } \\
\text { Canadian Light Source } \\
\text { ETH Labs - Zuerich } \\
\text { Natural Resources Canada } \\
\text { Naval Research Laboratory } \\
\text { Naval Surface Warfare Center } \\
\text { New Jersey Institute of Technology } \\
\text { North Carolina State University } \\
\text { Sarah Lawrence College } \\
\text { Stony Brook University }\end{array}$ \\
\hline X12B & Bend & $\begin{array}{l}\text { MAD } \\
\text { Macromolecular crystallography }\end{array}$ & $5-20 \mathrm{keV}$ & PRT & BNL-Biology \\
\hline $\mathrm{x} 12 \mathrm{C}$ & Bend & $\begin{array}{l}\text { MAD } \\
\text { Macromolecular crystallography }\end{array}$ & $5.5-20 \mathrm{keV}$ & PRT & BNL-Biology \\
\hline X13A & $\begin{array}{l}\text { Insertion } \\
\text { Device }\end{array}$ & $\begin{array}{l}\text { X-ray scattering, magnetic } \\
\text { x-ray scattering, resonant } \\
\text { MCD }\end{array}$ & $0.2-1.6 \mathrm{keV}$ & FB & BNL-NSLS \\
\hline X13B & $\begin{array}{l}\text { Insertion } \\
\text { Device }\end{array}$ & Microdiffraction Imaging & 4-16 keV & FB & $\begin{array}{l}\text { Columbia University } \\
\text { BNL-NSLS }\end{array}$ \\
\hline X14A & Bend & $\begin{array}{l}\text { MAD } \\
\text { XRD, powder } \\
\text { XRD, single crystal } \\
\text { XRD, time resolved } \\
\text { WAXD } \\
\text { X-ray reflectivity }\end{array}$ & $5-26 \mathrm{keV}$ & PRT & $\begin{array}{l}\text { New York State College of Ceramics } \\
\text { Oak Ridge National Laboratory } \\
\text { Tennenssee Technological University } \\
\text { University of Tennessee }\end{array}$ \\
\hline X15A & Bend & $\begin{array}{l}\text { XSW } \\
\text { DEI }\end{array}$ & $\begin{array}{l}3-25 \mathrm{keV} X \mathrm{XS} \\
10-60 \mathrm{keV} \text { DEI }\end{array}$ & FB & BNL-NSLS \\
\hline
\end{tabular}




\begin{tabular}{|c|c|c|c|c|c|}
\hline Beamline & Source & Type of Research & Energy Range & Type & Organization \\
\hline X15B & Bend & $\begin{array}{l}\text { XAS } \\
\text { EXAFS } \\
\text { NEXAFS }\end{array}$ & $0.8-15 \mathrm{keV}$ & PRT & $\begin{array}{l}\text { BNL-Environmental Sciences } \\
\text { Lucent Technologies, Inc. } \\
\text { Stony Brook University } \\
\text { Temple University } \\
\text { University of Texas @ Austin }\end{array}$ \\
\hline X16C & Bend & XRD, powder & $6.5-25 \mathrm{keV}$ & PRT & Stony Brook University \\
\hline X1781 & $\begin{array}{l}\text { Insertion } \\
\text { Device }\end{array}$ & XRD, powder & $\begin{array}{l}55-80 \mathrm{keV} \text { mono } \\
20-150 \mathrm{keV} \text { white }\end{array}$ & FB & $\begin{array}{l}\text { BNL-NSLS } \\
\text { Rutgers University }\end{array}$ \\
\hline X17B2 & $\begin{array}{l}\text { Insertion } \\
\text { Device }\end{array}$ & $\begin{array}{l}\text { XRD, powder } \\
\text { XRD, time resolved } \\
\text { High pressure research }\end{array}$ & $20-130 \mathrm{keV}$ & $F B$ & $\begin{array}{l}\text { COMPRES } \\
\text { BNL-NSLS } \\
\text { Stony Brook University }\end{array}$ \\
\hline X17B3 & $\begin{array}{l}\text { Insertion } \\
\text { Device }\end{array}$ & $\begin{array}{l}\text { XRD, powder } \\
\text { XRD, single crystal } \\
\text { High pressure research }\end{array}$ & $5-80 \mathrm{keV}$ & $F B$ & $\begin{array}{l}\text { COMPRES } \\
\text { BNL-NSLS } \\
\text { Princeton University } \\
\text { Stony Brook University }\end{array}$ \\
\hline X17C & $\begin{array}{l}\text { Insertion } \\
\text { Device }\end{array}$ & $\begin{array}{l}\text { XRD, powder } \\
\text { XRD, single crystal } \\
\text { High pressure research }\end{array}$ & $5-80 \mathrm{keV}$ & $F B$ & $\begin{array}{l}\text { COMPRES } \\
\text { BNL-NSLS } \\
\text { Princeton University } \\
\text { Stony Brook University }\end{array}$ \\
\hline X18A & Bend & $\begin{array}{l}\text { XRD, powder } \\
\text { XRD, single crystal } \\
\text { XRD, surface } \\
\text { WAXD } \\
\text { XAray reflectivity } \\
\text { X-ray scattering, surface } \\
\text { WAXS } \\
\text { XAS }\end{array}$ & $5-25 \mathrm{keV}$ & PRT & $\begin{array}{l}\text { BNL-Chemistry } \\
\text { BNL-Electrochemistry } \\
\text { BNL-NSLS } \\
\text { Oak Ridge National Laboratory } \\
\text { UOP LCC } \\
\text { University of Delaware } \\
\text { University of Massachusetts } \\
\text { Yeshiva University }\end{array}$ \\
\hline x18B & Bend & $\begin{array}{l}\text { XAS } \\
\text { EXAFS } \\
\text { NEXAFS }\end{array}$ & $4.8-40 \mathrm{keV}$ & $F B$ & $\begin{array}{l}\text { BNL-Chemistry } \\
\text { BNLElectrochemistry } \\
\text { BBLL-NSLS } \\
\text { ORNL } \\
\text { UOP LLC } \\
\text { University of Delaware } \\
\text { Yeshiva University }\end{array}$ \\
\hline X19A & Bend & $\begin{array}{l}\text { X-ray scattering, resonant } \\
\text { XAS } \\
\text { EXAFS } \\
\text { NEXAFS }\end{array}$ & $2.1-17 \mathrm{keV}$ & FB & $\begin{array}{l}\text { BNL-Chemistry } \\
\text { BNLElectrochemistry } \\
\text { BNL-NSLS } \\
\text { ORNL } \\
\text { UOP LLC } \\
\text { University of Delaware } \\
\text { Yeshiva University }\end{array}$ \\
\hline$\times 19 \mathrm{C}$ & Bend & $\begin{array}{l}\text { XRD, surface } \\
\text { X-ray topography } \\
\text { X-ray reflectivity } \\
\text { X-ray scattering, liquid } \\
\text { X-ray scattering, surface }\end{array}$ & $6-17 \mathrm{keV}$ & PRT & $\begin{array}{l}\text { Fairfield Crystal Technology, LLC } \\
\text { Kansas State University } \\
\text { Stony Brook University } \\
\text { sUNY @ Albany } \\
\text { University of Illinois @ Chicago }\end{array}$ \\
\hline X20A & Bend & $\begin{array}{l}\text { XRD, single crystal } \\
\text { WAXD } \\
\text { Microdiffraction Imaging } \\
\text { X-ray reflectivity } \\
\text { X-ray scattering, surface }\end{array}$ & $4.5-13 \mathrm{keV}$ & PRT & IBM Research Division \\
\hline$\times 20 \mathrm{C}$ & Bend & $\begin{array}{l}\text { XRD, single crystal } \\
\text { XRD, surface } \\
\text { XRD, time resolved } \\
\text { X-ray reflectivity } \\
\text { X-ray scattering, surface }\end{array}$ & $4-11 \mathrm{keV}$ & PRT & IBM Research Division \\
\hline
\end{tabular}

\begin{tabular}{|c|c|c|c|c|c|}
\hline Beamline & Source & Type of Research & Energy Range & Type & Organization \\
\hline x21 & $\begin{array}{l}\text { Insertion } \\
\text { Device }\end{array}$ & $\begin{array}{l}\text { XRD, single crystal } \\
\text { XRD , sufface } \\
\text { WAXD } \\
\text { X-ray cattering, magnetic } \\
\text { X-ras scattering, resonant } \\
\text { X-ray scattering, surface } \\
\text { WAXS }\end{array}$ & 5-15 keV & FB & $\begin{array}{l}\text { Boston University } \\
\text { BNL-NSLL } \\
\text { University of Vermont }\end{array}$ \\
\hline х22B & Bend & X-ray scattering, liquid & $8 \mathrm{keV}$ & PRT & $\begin{array}{l}\text { BNL-CMPMSD } \\
\text { BNL-CFN }\end{array}$ \\
\hline x22C & Bend & $\begin{array}{l}\text { XRD, single crystal } \\
\text { XRD, surface } \\
\text { X-ray reflectivity } \\
\text { X-ray scattering, magnetic } \\
\text { X-ray scattering, surface }\end{array}$ & $3-12 \mathrm{keV}$ & PRT & $\begin{array}{l}\text { BNL-CMPMSD } \\
\text { Massachusetts Institute of Technology } \\
\text { Rutgers University }\end{array}$ \\
\hline X23A2 & Bend & $\begin{array}{l}\text { DAFS } \\
\text { XAS } \\
\text { EXAFS } \\
\text { NEXAFS }\end{array}$ & $4.7-30 \mathrm{keV}$ & PRT & $\begin{array}{l}\text { National Institute of Standards } \\
\text { \& Technology }\end{array}$ \\
\hline х23в & Bend & $\begin{array}{l}\text { XRD, powder } \\
\text { XAS } \\
\text { EAAFS } \\
\text { NEXAFS }\end{array}$ & $4-10.5 \mathrm{keV}$ & PRT & $\begin{array}{l}\text { Hunter College } \\
\text { National Institute of Standards } \\
\& \text { Technology } \\
\text { Naval Research Laboratory } \\
\text { Naval Surface Warfare Center } \\
\text { New Jersel Institute of Technology } \\
\text { Northeastern University } \\
\text { Sarah Lawrence College }\end{array}$ \\
\hline X24A & Bend & $\begin{array}{l}\text { XSW } \\
\text { Auger spectroscopy } \\
\text { EXAFS } \\
\text { X-ray fluorescence spectroscopy } \\
\text { XPS }\end{array}$ & $1.8-6 \mathrm{keV}$ & PRT & $\begin{array}{l}\text { National Institute of Standards } \\
\text { \& Technology }\end{array}$ \\
\hline $\mathrm{x} 24 \mathrm{C}$ & Bend & $\begin{array}{l}\text { X-ayy reflectivity } \\
\text { UV absorption spectroscopy } \\
\text { XAS }\end{array}$ & $0.006-1.8 \mathrm{keV}$ & PRT & $\begin{array}{l}\text { Naval Research Laboratory } \\
\text { SFA, Inc. } \\
\text { Universities Space Research } \\
\text { Association }\end{array}$ \\
\hline x25 & $\begin{array}{l}\text { Insertion } \\
\text { Device }\end{array}$ & $\begin{array}{l}\text { MAD } \\
\text { Macromolecular crystallography }\end{array}$ & $5-20 \mathrm{keV}$ & FB & $\begin{array}{l}\text { BNL-Biology } \\
\text { BNL-NSLS }\end{array}$ \\
\hline X26A & Bend & $\begin{array}{l}\text { Microdiffraction Imaging } \\
\text { X-ray microprobe }\end{array}$ & 3-30 keV & PRT & $\begin{array}{l}\text { BNL-Environmental Sciences } \\
\text { University of Chicago } \\
\text { University of Kentucky }\end{array}$ \\
\hline x26C & Bend & $\begin{array}{l}\text { MAD } \\
\text { Macromolecular crystallography }\end{array}$ & $5-20 \mathrm{keV}$ & PRT & $\begin{array}{l}\text { BNL-Biology } \\
\text { Cold Spring Harbor Laboratory } \\
\text { Stony Brook University }\end{array}$ \\
\hline X27A & Bend & X-ray microprobe & $4.5-32 \mathrm{keV}$ & FB & $\begin{array}{l}\text { BNL-Environmental Sciences } \\
\text { BNL-NSLS } \\
\text { Stony Brook University }\end{array}$ \\
\hline x27B & Bend & HARMST & $8-40 \mathrm{keV}$ & PRT & BNL-Nonproliferation \& National Security \\
\hline x27C & Bend & $\begin{array}{l}\text { XRD, time resolved } \\
\text { WAXD } \\
\text { SAXS } \\
\text { WAXS }\end{array}$ & $9 \mathrm{keV}$ & PRT & $\begin{array}{l}\text { Air Force Research Laboratory } \\
\text { National Institutes of Health } \\
\text { Naval Surface Warfare Center } \\
\text { Stony Brook University }\end{array}$ \\
\hline x28C & Bend & -ray Footprinting & $\begin{array}{l}\text { Focused White } \\
\text { Beam }\end{array}$ & PRT & Case Western Reserve University \\
\hline X29A & $\begin{array}{l}\text { Insertion } \\
\text { Device }\end{array}$ & $\begin{array}{l}\text { MAD } \\
\text { Macromolecular crystallography }\end{array}$ & 6-15 keV & PRT & $\begin{array}{l}\text { BNL-Biology } \\
\text { Case Western Reserve University }\end{array}$ \\
\hline
\end{tabular}




\section{Users' Executive Committee}

The NSLS regularly consults with the Users' Executive Committee UEssions he committee provides a forum for ongoing, organized disvarious research disciplines and the management and adminisistration at the NSLS and Brookhaven National Laboratory. The purpose is to communicate current and future needs, concerns, and trends, and
disseminate information about future plans for the NSLS and BNL.

Chair John Parise, Stony Brook University

Vice Chair Bruce Ravel, National Institute of Standards and Technology

Past Chair Daniel Fischer, National Institute of Standard
and Technology

General Member Peter Abbamonte, University of Illinois at

Urbana-Champaign
Ceneral Member Jean Jordan-Sweet, IB

General Member George Flynn, SUNY at Plattsburgh

General Member Don Weidner, Stony Brook University

General Member Peter Stephens, Stony Brook University

Ex-Officio Chi-Chang Kao, NSLS Chair, BNL

Ex-Officio Kathleen Nasta, Manager, NSLI Information

Outreach \& User Administration, BNL

\section{Scientific Advisory Committee}

The NSLS Scientific Advisory Committee (SAC) advises the NSLS Chair S tific productivity of the NSLS.

Mario Amzel, Johns Hopkins University
Simon Bare, UOP, LLC

Joel Brock, Cornell Un

Tony Heinz, Columbia University

Robert Hettel, Stanford Synchrotron Radiation Laboratory

Stanford Linear Accelerator Center
Eric Isaacs, Argonne National Labortot

ELeemor Joshua-Tor, Cold Sppring Harbor Laboratory

James Kaduk, INEOS Technologies

Edward Kramer, University of California, Santa Barbara

Diam Thomlinson Canadian Light Sof Michiga

Daniel Fischer (UEC Chair), National Institute of Standard and Technology
Special Interest Group Representatives

Special Interest Group (Sp|G) Representatives are listed below; these

Bio. Crystallography Annie Heroux, BNL/Biology $\&$ Diffraction

High Pressure Michael Vaughan, Stony Brook University Imaging Dawit Solomon, Cornell University

Industrial Users Gary Mitchell, The Dow Chemical Company Infrared Users Jiufeng Tu, City University of New York

Magnetism Cecilia Sanchez-Hanke, BNL/NSLS NSLS-II Daniel Fischer, National Institute of

Students \& Post Docs Andreana Leskovian, Stony Brook University Time Resolved John Sutherland, BNL/Biology

Topography

Dudley, Stony Brook University

Photoemission \& Jeff Keister SEA Inc

Surface Science
XAFS Faisal Alamgir, Georgia Institutue of Technology X-ray Scattering \& Helmut Strey, Stony Brook University
Crystallography

Proposal Review Panels

As part of the peer-review process of GU proposals, the Proposal Rebeview and rate the proposals with hity and usually serve a two-year term. Each PRP has an appointed Chair, who is part of the Proposal Oversight Panel (POP), established to review any proposals that might need special attention due to use appointed members, listed below after the PRP membership.

* = Chair of PRP

Imaging and Microprobes: Biological and Medica

Leroy Chapman, University of Sask
Paul Dumas, Soleil Synchrotro

Kathleen Gough, University of Manitoba

Carolyn Larabell, Lawrence Berkeley Nationa I Laboratory

Irit Sagi, Weizmann Institute of Science

Stefan Vogt, Argonne National Laboratory
Imaging and Microprobes: Chemical and Materials Sciences Harald Ade* North Carolina State University David Black, Topographix Ismail No, Un Costy or Wisconsing

Nobumichi Tamura, Lawrence Berkeley National Laboratory

maging and Microprobes: Environmental and Geosciences Don Baker, McGill Universty
David Black, Topographix

George Flynn, SUNY at Plattsburg

Matthew Ginder-Vogel, University of Delaware Keith Jones*, BNL

Mark Rivers, University of Chicago

R/UV/Soft X-ray Spectroscopy: Chemical Sciences/Soft Matter/<smiles>[AsH2][AsH2]</smiles>

Daniel Fischer", National Institute of Standards \& Technology Jan Genzer, North Carlina State Universily

Gary Mitchell, The Dow Chemical Company

IR/UV/Soft X-ray Spectroscopy: Magnetism/Strongly Correlated

X-

Di-ling Huang, Synchin

Jever

David Mullins Oak Ridge Notionatsatchewa

Boris Sinkovic, University of Connecticut

Jifeng Tu, City Un
Tonica Valla, BNL

Methods and Instrumentation

Leroy Chapman, University of Saskatchew

Jeffrey Keister, SFA, linc.

Ralf Hendrik, Menk Sincrotrone Trieste

Macromolecular Crystallography Alex Bohm*, Tufts University Ashley Deacon, Stanford Synchrotton

Nicolas Nassar Stony Brook University

Brenda Schulman, St. Jude Children's Research Hospita

Hao Wu, Cornell University

Powder/Single Crystal Crystallography Thomas Duffy*, Princeton University
Andrew Fitch, European Synchrotron Radiation Facility Stefan khlenberg, University of Innsbruck

anes M Ma, University of Guelph

Wendy Panero, Ohio State University

X-Ray Scattering: Magnetism/Strongly Correlated Electrons/Surface Kenneth Finkelstein*, Cornell Inniversity

Peter Hatton, University of Durho
Karl Ludwig, Boston Univen

Christopher Marrows University ofteeds

George Srajer, Argonne National Laboratory

Trevor Tyson, New Jersey Institute of Technology

-Ray Scattering: Soft Matter and Biophysics Masafumi Fukuto, B.

Randall Headrick, University of Vermont

Benjaminin Hsiao", Stony Brook Universt

Thomas Russell. University

Detleff-Matthias Smilgies, Cornell University

Lei Zhu, University of Connecticut

X-Ray Spectroscopy: Biological, Environmental and Geosciences Martine Duff, Westinghouse Savannaun River Co. Graham George, University of Saskatchewan Douglas Hunter, Westinghouse Savannah River Matthew Newville, University of Chicago

$X$-Ray Spectroscopy: Chemical and Material Sciences simon Bare, UOP

Scott Calvin, Sarah Lawrence College

Steve Heald, Argonne National Laboratory Bruce Ravel, National Institute of Standards \& Technology

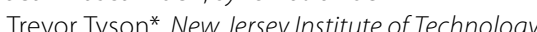

Proposal Oversight Panel Members

Antonio Lanzirotti, University of Chicago

Jonathan Hanson, BNL

eter Stephens, Stony Brook University

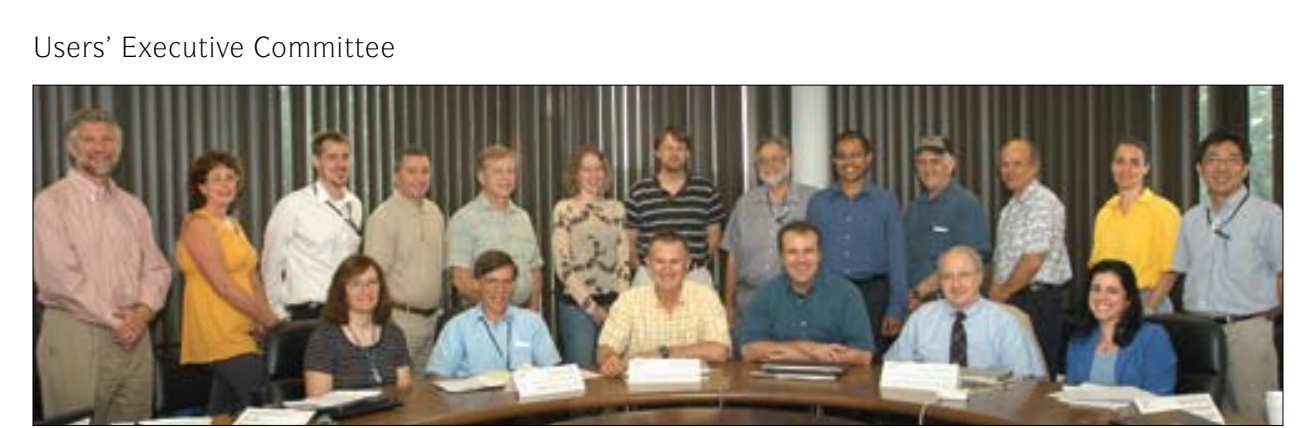

Scientific Advisory Committee

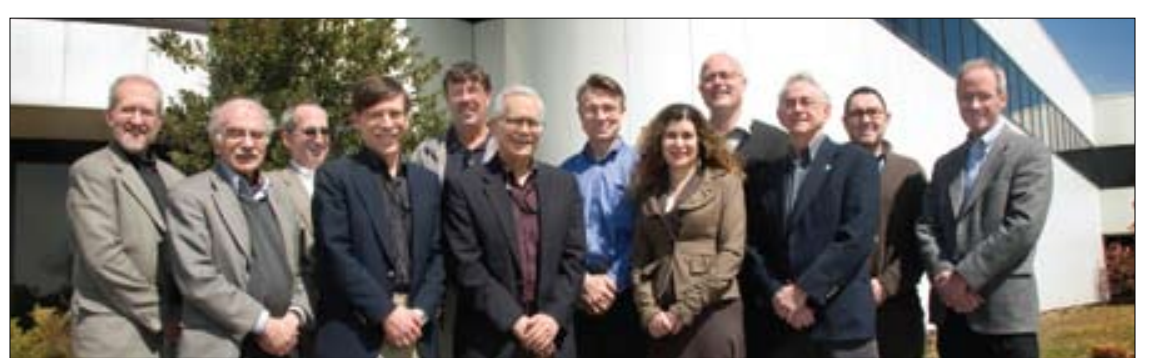


